\title{
Interfacial Properties of a Hydrophobic Dye in the Tetrachalorethylene-Water-Glass Systems
}

by

D. M. Tuck

Westinghouse Savannah River Company

Savannah River Site

Aiken, South Carolina 29808

C. Rulison

This paper was prepared in connection with work done under the above contract number with the U. S.

Department of Energy. By acceptance of this paper, the publisher and/or recipient acknowledges the U. S. Government's right to retain a nonexclusive, royalty-free license in and to any copyright covering this paper, along with the right to reproduce and to authorize others to reproduce all or part of the copyrighted paper. 


\section{DISCLAIMER}

This report was prepared as an account of work sponsored by an agency of the United States Government. Neither the United States Government nor any agency thereof, nor any of their employees, makes any warranty, express or implied, or assumes any legal liability or responsibility for the accuracy, completeness, or usefulness of any information, apparatus, product, or process disclosed, or represents that its use would not infringe privately owned rights. Reference herein to any specific commercial product, process, or service by trade name, trademark, manufacturer, or otherwise does not necessarily constitute or imply its endorsement, recommendation, or favoring by the United States Government or any agency thereof. The views and opinions of authors expressed herein do not necessarily state or reflect those of the United States Government or any agency thereof.

This report has been reproduced directly from the best available copy.

Available to DOE and DOE contractors from the Office of Scientific and Technical Information, P. O. Box 62, Oak Ridge, TN 37831; prices available from (423) 576-8401.

Available to the public from the National Technical Information Service, U. S. Department of Commerce, 5285. Port Royal Road, Springfield, VA 22161. 


\section{DISCLAIMER}

\section{Portions of this document may be illegible in electronic image products. Images are produced from the best available original document.}


WSRC-TR-97-0038

\section{Interfacial Effects of a Hydrophobic Dye in the Tetrachloroethylene-Water-Glass System (U)}

David M. Tuck

Christopher Rulison

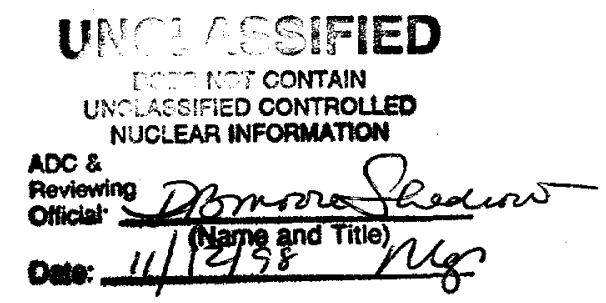

Westinghouse Savannah River Company Savannah River Site

Aiken, SC 29808 
WSRC-TR-97-0038

November 4, 1998

Rev. 0

\section{Interfacial Effects of a Hydrophobic Dye in the Tetrachloroethylene-Water-Glass System (U)}

David M. Tuck

Christopher Rulison

(Krüss USA Charlotte, NC)

Westinghouse Savannah River Company

Savannah River Site

Aiken, SC 29808 


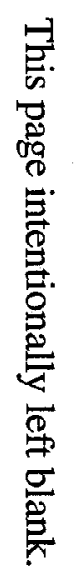




\section{Contents}

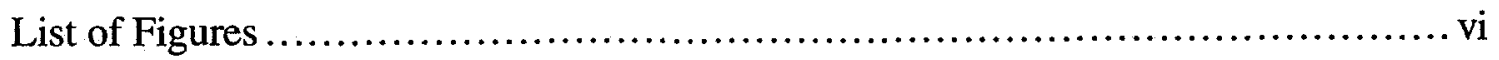

List of Tables .....................................................................

Executive Summary ............................................................ vii

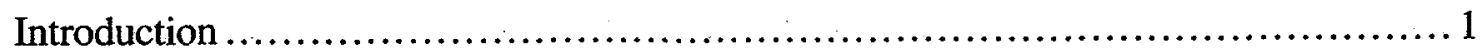

Experimental Methods ......................................................... 4

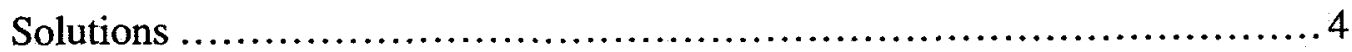

Interfacial Tension......................................................... 4

Screening Tests Using PCE Lens Thickness ......................... 4

Du Noüy Ring Method .......................................... 5

M-Area DNAPL-Water Interfacial Tension ........................ 6

Contact Angle ................................................................... 6

Results and Discussion ........................................................ 7

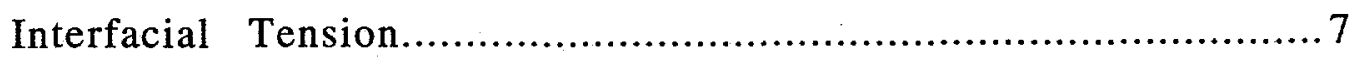

PCE Lens Thickness Screening Test..........................................

Du Noüy Ring Measurements ..................................... 7

Drop Volume Measurements......................................... 7

Contact Angle Measurements .............................................. 8

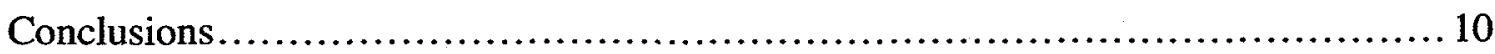

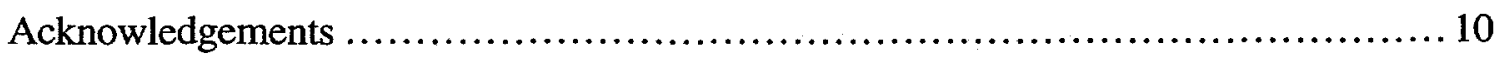

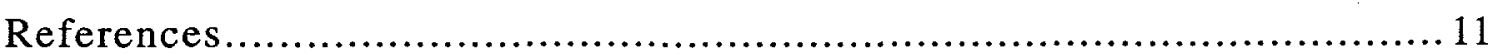

Appendix A. Krüss USA Report, November 27, 1995

Appendix B. Wilhelmy Plate Interfacial Tension Measurements of M-Area DNAPL Appendix C. Recalculated Drop Volume Interfacial Tension Values 


\section{List of Figures}

Figure 1 ..... Contact angle illustration $\quad 14$

Figure $2 \ldots .$. Distribution of wetting and nonwetting phases in a conical capillary $\quad 14$

Figure $3 \ldots .$. Chemical structures of commonly used organic dyes 15

Figure 4..... General profiles of floating NAPL lenses 16

Figure 5.... Dyed-PCE-water interfacial tension by drop volume technique 17

Figure 6..... Lowest measured dyed-PCE-water interfacial tension 18

Figure 7.... Contact angle between dyed-PCE, water, and glass 19

\section{List of Tables}

Table 1..... Tetrachloroethylene (PCE) solutions and Sudan IV dye concentrations

Table 3..... Mean interfacial tension between undyed PCE and water

Table 4..... Mean interfacial tension between dyed PCE of concentraton C4 and water 21

Table 5..... Mean interfacial tension between dyed PCE of concentraton C3 and water 22

Table 6..... Mean interfacial tension between dyed PCE of concentraton C2 and water 22

Table 7..... Mean interfacial tension between dyed PCE of concentraton C1 and water 23

Table 8..... Contact angle in the Sudan IV-dyed-PCE-water-glass system. 23 


\section{EXECUTIVE SUMMARY}

Interfacial effects play an important role in governing multiphase fluid behavior in porous media. Strongly hydrophobic organic dyes, used in many experimental studies to facilitate visual observation of the phase distributions, have generally been implicitly assumed to have no influence on the interfacial properties of the various phases in porous media. Sudan IV is the most commonly used dye for non-aqueous phase liquids (NAPLs) in laboratory experiments. It has also been used in at least one field experiment. The effects of this dye on the tetrachloroethylene (PCE)-water-glass system were investigated to test the assumption that the dye does not effect the interfacial properties and therefore PCE mobility. The results indicate that the dye does indeed change the interfacial relationships.

The effect of the dye on the interfacial relationships is a complex function of the dye concentration, the solid phase composition, and the dynamic rate of new interface formation. The dye caused a slight $(<10 \%)$ increase in interfacial tension at low concentrations $(<0.1 \mathrm{~g} / \mathrm{L})$ and high rates of new interface formation. The dye reduced interfacial tension between PCE and water at low rates of new interface formation for all dye concentrations tested $(0.00508$ to 5.08 $\mathrm{g} / \mathrm{L}$ ). At the highest dye concentration, the PCE-water interfacial tension was significantly reduced regardless of the rate of new interface formation. The apparent interfacial tension increase at low dye concentrations is suspected to be an artifact of a low measured IFT value for the undyed PCE caused by leaching of rubber o-rings by the PCE prior to testing in the final drop-volume configuration.

In addition to reducing interfacial tension, the dye was found to significantly alter the wetting relationship between PCE and water on a glass surface at and above the range of reported dye concentrations cited in the literature $(1.1$ to $1.7 \mathrm{~g} / \mathrm{L})$. The wetting relationship was rendered neutral from a water-wet initial condition at the highest dye concentration. The contact angle, measured through the aqueous phase, changed from $58^{\circ}$ for undyed PCE to $93^{\circ}$ at a dye concentration of $5.08 \mathrm{~g} / \mathrm{L}$. Complete reversal of the wettability is likley given the short equilibration time used in this study (approximately five minutes) together with literature indications that hundreds to thousands of hours may be required to reach equilibrium during contact angle measurements. Observations suggesting changing wetting relationships were also noted between PCE, water, and the platinum-iridium surface used in the standard du Nouiy ring method for measuring interfacial tension.

Observations of the dyed-PCE-water interface behavior during du Noüy ring interfacial tension measurements were similar to observations noted previously during measurements of the interfacial tension between the Savannah River Site (SRS) M-Area Settling Basin DNAPL (M-Area DNAPL) and water. This observation suggests that the M-Area DNAPL may contain surface active components. If this proves to be the case, it would have significant implications for how the M-Area DNAPL is distributed and moves in the SRS subsurface. 


\section{INTRODUCTION}

Interfacial effects play an important role in governing multiphase fluid behavior in porous media $[1,2]$. For instance, several dimensionless numbers have been developed to express important force ratios applicable to multiphase flow in porous media [3-7]. The two original numbers used to define these ratrios are the capillary number, $\mathbf{N}_{\mathrm{ca}}$, and the Bond number, $\mathrm{N}_{\mathrm{B}}$. The capillary number expresses the ratio of the viscous drag force of a flowing, continuous phase to capillary force acting on a discontinuous phase. The viscous force acts to mobilize the discontinuous phase while the capillary force acts to resist mobilization. In the case of a residual NAPL in a water saturated porous medium, the capillary number is given as

$$
\mathrm{N}_{\mathrm{ca}}=\frac{\mu_{\mathrm{w}} v_{\mathrm{w}}}{\gamma_{\mathrm{nw}}}
$$

where $\mu_{\mathrm{w}}$ is dynamic viscosity of water $(\mathrm{g} / \mathrm{cm}-\mathrm{sec}), v_{\mathrm{w}}$, is average pore velocity $(\mathrm{cm} / \mathrm{sec})$, and $\gamma_{\text {nw }}$ is NAPL-water interfacial tension (dynes/cm, $\mathrm{g} / \mathrm{sec}^{2}$ ). The Bond number expresses the ratio of gravity to capillary forces. The Bond number is expressed as

$$
\mathrm{N}_{\mathrm{B}}=\frac{\left(\rho_{\mathrm{n}}-\rho_{\mathrm{w}}\right) \mathrm{gR}^{2}}{\gamma_{\mathrm{nw}}}
$$

where $\rho_{\mathrm{n}}$ and $\rho_{\mathrm{w}}$ are the NAPL and water densities $\left(\mathrm{g} / \mathrm{cm}^{3}\right), \mathrm{g}$ is the acceleration of gravity $\left(\mathrm{cm} / \mathrm{sec}^{2}\right)$, and $R$ is a characteristic length $(\mathrm{cm})$, generally taken to be the mean grain diameter $(\mathrm{cm})$. In analogy with the capillary number, the gravity forces act to mobilize the discontinuous phase (assuming that a difference in density exists) while the capillary forces resist mobilization.

Both viscous drag forces and gravity forces effect residual NAPL ganglia in porous media during enhanced recovery processes using surfactants or cosolvents. Thus both forces should, ideally, be considered when evaluating NAPL mobilization potential. Addition of the two force ratios cannot be done directly, however, because of the difference in their magnitudes [3, 8]. Morrow et al. (1988) found it necessary to multiply the bond number by 0.001412 in order to sum the two numbers. Pennell et al. (1996) suggest that the reason for the difference in magnitude between the Bond and capillary numbers is due to a difference in the characteristic length scale over which they are defined. Pennell et al. derived an expression for what they call the total trapping number $\left(\mathrm{N}_{\mathrm{T}}\right)$ to avoid the empirical nature of the sum as carried out by Morrow et al. The total trapping number is, effectively, a sum of the capillary and Bond numbers, where both are based on the same length scale, the intrinsic permeability of the porous medium. The total trapping number is given by [6]:

$$
\begin{aligned}
\mathrm{N}_{\mathrm{T}} & =\sqrt{\mathrm{N}_{\mathrm{Ca}}^{2}+2 \mathrm{~N}_{\mathrm{Ca}} \mathrm{N}_{\mathrm{B}} \sin \alpha+\mathrm{N}_{\mathrm{B}}^{2}} \\
& =\frac{2 \mathrm{kk}_{\mathrm{rw}} \beta}{\mathrm{r}_{\mathrm{n}} \mathrm{d}_{\mathrm{b}}}
\end{aligned}
$$

where $\alpha$ is the angle the flow makes with the positive, horizontal $\mathrm{x}$-axis, $\mathrm{k}$ is the intrinsic permeability of the porous medium $\left(\mathrm{cm}^{2}\right), \mathrm{k}_{\mathrm{rw}}$ is the relative permeability to the continuous aqueous phase (dimensionless), $r_{n}$ is a measure of the average pore throat for the medium $(\mathrm{cm}), \mathrm{d}_{\mathrm{b}}$ is a characteristic ganglion length $(\mathrm{cm})$, and $\beta$ is a dimensionless number given by

$$
\beta=1-\frac{r_{n}}{r_{b}}
$$

where the ratio, $r_{n} / r_{b}$, is a characteristic average ratio of pore throat to pore body radii. For horizontal flow $\left(\alpha=0^{\circ}\right), \mathrm{N}_{\mathrm{T}}$ reduces to: 


$$
\mathrm{N}_{\mathrm{T}}=\sqrt{\mathrm{N}_{\mathrm{Ca}}^{2}+\mathrm{N}_{\mathrm{B}}^{2}}
$$

For vertical flow $\left(\alpha=90^{\circ}\right), \mathrm{N}_{\mathrm{T}}$ reduces to:

$$
\mathrm{N}_{\mathrm{T}}=\left|\mathrm{N}_{\mathrm{Ca}}+\mathrm{N}_{\mathrm{B}}\right|
$$

The capillary and Bond numbers in this formulation are defined as follows:

$$
\begin{aligned}
& \mathrm{N}_{\mathrm{Ca}}=\frac{\mathrm{q}_{\mathrm{w}} \mu_{\mathrm{w}}}{\gamma_{\mathrm{nw}} \cos \theta} \\
& \mathrm{N}_{\mathrm{B}}=\frac{\left(\rho_{\mathrm{n}}-\rho_{\mathrm{w}}\right) \mathrm{gkk}_{\mathrm{rw}}}{\gamma_{\mathrm{nw}}}
\end{aligned}
$$

where $\mathrm{q}_{\mathrm{w}}$ is the Darcy flow velocity of the aqueous phase $(\mathrm{cm} / \mathrm{sec})$ and $\theta$ is the contact angle between the NAPL-water interface and the solid surfaces of the porous media materials. The total trapping number is thus, in effective, a ratio of a sum of the mobilizing forces (viscous and bouyancy) to the resistive force (capillary). The importance of the force ratios expressed in equations (1) to (6) make knowledge of the fluid-fluid interfacial tension essential when conducting or interpreting experiments on multiphase fluid flow in porous media. Dawson and Roberts [7] derived similar equations to those of Pennell et al. (1996).

Another important consideration in multiphase fluid flow in porous media is the wetting relationship between the fluids and the solid materials. This relationship is generally measured via the contact angle, defined as the angle made between the fluid-fluid interface and the solid surface of the mineral grains. Contact angles are illustrated in Figure 1 for a two different situations, a nonwetting NAPL drop and a wetting NAPL drop. The contact angle represents a mechanical balance between interfacial tensions at each of the three interfaces. It is defined by the Young equation as follows $[9,10]$ :

$$
\cos \theta=\frac{\gamma_{\mathrm{ns}}-\gamma_{\mathrm{ws}}}{\gamma_{\mathrm{nw}}}
$$

where $\gamma_{\mathrm{ns}}$ is the NAPL-solid interfacial tension (dynes/cm, i.e., $\mathrm{g} / \mathrm{sec}^{2}$ ) and $\gamma_{w s}$ is the water-solid interfacial tension (dynes/cm, i.e., $\mathrm{g} / \mathrm{sec}^{2}$ ). The wetting relationship controls the distribution of the fluid phases in the porous medium. The wetting phase will tend to occupy the pendular region around grain-grain contact points and the smaller pores in the porous medium. This is illustrated in Figure 2. The pressure drop across the fluid-fluid interface is also controlled, in part, by the wetting relationship.

Application of the force ratios expressed in equations (1), (2), (3), (5) and (6) implicitly assumes a uniformly-wet porous medium, i.e., the porous medium is composed of a single solid phase. Generally water is assumed to be the wetting phase, and thus the NAPL exists as residual blobs or ganglia or as "pools" trapped on fine-grained materials which act as barriers to vertical movement. This is the most common assumption made regarding multiphase flow in porous media involving water as one of the fluid phases. Components in either fluid phase that adsorb onto the solid surface can alter the wetting relationship by changing the solid-fluid interfacial tensions, $\gamma_{n s}$ and $\gamma_{\text {ws. }}$. Water-soluble surfactants are commonly used in solutions to change wetting properties. Jaffé and co-workers [11-15] examined the influence of a nonylphenyl phosphate ester surfactant on PCE mobilization in porous media. This surfactant was found to reverse the wetting relationship between PCE and water on a glass surface [11]. Other researchers have also documented changing wetting relationships with surfactant adsorption onto the solid surface $[16,17]$. Thus surface active 
components in the aqueous phase can significantly alter the expected distribution of a NAPL in the subsurface. The same is potentially true of surface active components in a NAPL or DNAPL phase. In fact, several researchers have found that NAPL wetting tends to increase with contact time against the solid [18]. This must occur due to sorption of NAPL components at the solid-solution interfaces.

Strongly hydrophobic organic dyes have been used in many experimental studies of multiphase flow to facilitate visual observation of the separate phase distributions [6, 19-23]. Sudan IV is the most commonly used dye for nonaqueous phase liquids (NAPLs) in laboratory experiments $[20,21,23]$, and has been used in at least one field experiment [22]. Typical dye concentrations used in these experiments ranged between 1.1 and $1.7 \mathrm{~g} / \mathrm{L}$. Of these studies, the only one to mention examining or testing the effect of the dye on the fluid phase behavior was that of Pennell et al. (1996). They reported that an "oil-red-O" dye concentration of $0.0001 \mathrm{M}$ (approximately $0.04 \mathrm{~g} / \mathrm{L}$ ) had "no observable effect" on PCE mobility in the quartz sand media they used.

The objective of this study was to examine the effects of Sudan IV on the interfacial properties of the tetrachloroethylene (PCE)-water-glass system. Interfacial tension was measured as a function of the Sudan IV concentration in PCE. The contact angle made by the PCE-water interface against a flat glass slide was also measured as a function of Sudan IV concentration. 


\section{Experimental Methods}

\section{Solutions}

Sudan IV is an organic dye commonly used for staining NAPLs during multiphase fluid flow studies in porous media [20-23]. The dye was used as received from Eastman Kodak, Inc. The dye structure is illustrated in Figure 3 along with that of a related dye, oil-red$O$, which has also been used in multiphase fluid flow studies in porous media [6]. The dye content of the Eastman Kodak sample was $81 \%$. The remaining $19 \%$ is inorganic salts, most likely either $\mathrm{NaCl}$ or $\mathrm{KCl}$ (Aldrich Chemical Company, Inc. 1997, personal communication).The PCE used to prepare all solutions was "Tetrachloroethylene 99\%". It was used as received from Mallinckrodt Inc. (Paris, KY). Dyed PCE solutions were prepared by dissolving $0.508 \mathrm{~g}$ of the dye, as received, into $100 \mathrm{~mL}$ of PCE. Serial dilutions of this stock solution were then prepared. Symbols for the various solutions, and the dye concentrations are presented in Table 1. All solutions were allowed to equilibrate for several days prior to measuring the interfacial properties. The density of all PCEsaturated aqueous phases was 0.9962 $\mathrm{g} / \mathrm{mL}$ with a standard deviation of 0.0025 $\mathrm{g} / \mathrm{mL}(\mathrm{n}=13)$.

\section{Interfacial Tension Screening Tests Using PCE Lens Thickness}

The effect of the Sudan IV dye on PCEwater interfacial tension was investigated by measuring the maximum thickness of a floating lens of dyed and undyed PCE which could be supported on an air-water interface. The dye concentration was approximately $1.5 \mathrm{~g} / \mathrm{L}$. The following equation provides a theoretical estimate of the maximum thickness of a floating PCE lens [24]

$$
t^{2}=-\frac{2 S_{p / w} \rho_{w}}{g \rho_{p} \Delta \rho}
$$

where $\rho_{w}$ is the density of water, $\rho_{p}$ is the density of PCE, $\Delta \rho$ is the density difference between PCE and water, and $\mathrm{S}_{\mathrm{p} / \mathrm{w}}$ is the spreading coefficient of PCE on an air-water interface. $S_{\mathrm{p} / \mathrm{w}}$ is given by the following equation

$$
S_{p / w}=\gamma_{w a}-\left\{\gamma_{p a}+\gamma_{p w}\right\}
$$

where $\gamma$ is the interfacial tension between the subscripted phases, and the subscripts are a for air, $w$ for water, and $p$ for PCE. Equation (10) is only applicable if the liquid of the floating lens is nonspreading, i.e., if the spreading coefficient of liquid A (in our case PCE, p) on liquid $B$ (in this case water, w), $\mathrm{S}_{\mathrm{A} / \mathrm{B}}$, is negative. PCE is, in fact, nonspreading on an air-water interface. Surface activity effects of the dye will reduce the surface and interfacial tensions in the quantity in brackets. We assumed the dye effect on the PCE density and PCE-air surface tension was negligible, and therefore that any changes in lens thickness are only a result of changes in the PCE-water interfacial tension. The first assumption is confirmed by the data in Table 1. Surface activity of the dye in the PCE phase would thus result in a smaller lens thickness.

The effect of the dye was tested by carefully adding small additions of PCE (dyed or undyed) to the surface of deionized water in a $50 \mathrm{~mL}$ beaker until a drop was released from the floating PCE lens. Lens thickness was measured after each addition of PCE. The lens thickness just prior to release of a drop to the bottom of the beaker was taken to be the equilibrium lens thickness which the water-air interface could support. The thickness of the lens was measured using a mm scale. Figure 4 is a schematic illustration of the lens thickness measurement set-up. The capillary fringe, $f_{c}$, of water along the inside edge of the beaker was opaque, optically blocking vision of the full floating lens. The capillary fringe was approximately 
$3.0 \mathrm{~mm}$ thick. PCE lens thicknesses were measured from the base of the capillary fringe to the bottom of the floating lens. The estimated maximum lens thickness, $t_{\max }$, was obtained by assuming an additional thickness of PCE above the base of the fringe equal to half the capillary fringe thickness, i.e., the estimated maximum thickness was taken to be the sum of the measured thickness in $\mathrm{mm}$ plus $1.5 \mathrm{~mm}$. These tests were only used for screening purposes to detect whether the dye changed the surface properties of the PCE-water system. The measurement technique was crude and the lens thickness theory not entirely appropriate since it was formulated for a lens of lower density fluid floating on a higher density fluid, i.e., opposite to the situation here. Therefore interfacial tensions were not calculated from the data. The results were only used as a rapid screening test of whether, in fact the dye had any influence on the PCE-water interfacial tension.

\section{Interfacial Tension by Du Noüy Ring Method}

The du Noüy ring technique [25] was applied to measure the interfacial tension between Sudan IV-dyed PCE and water. This work was done using a Krüss Processor Tensiometer K12. The interfacial tension, $\gamma_{n w}$, is is given by the following equation [26]

$$
\gamma_{\mathrm{nw}}=\frac{\mathrm{F}_{\max }-\mathrm{F}_{\mathrm{V}}}{\mathrm{L} \cdot \cos \theta}
$$

where $F_{\max }$ is the maximum force measured as the tensiometer varies the height of the ring above the interface, $F_{v}$ is the weight of the volume of liquid directly under the ring, and $\mathrm{L}$ is the wetted length of the ring. The contact angle is normally assumed to be zero [26]. The du Noüy ring method also requires corrections for the effect of curvature of the deformed interface inside of the wire ring $[24,26]$.

\section{Drop Volume Technique}

The effect of Sudan IV dye on the PCEwater interfacial tension was also measured using a dynamic drop volume technique. Difficulty was experienced during attempts to measure the "equilibrium" interfacial tension using the standard du Noüy ring and Wilhelmy plate methods [24]. The difficulty occurred because the interface between the dyed PCE and water behaved in an unusual fashion; it would break in an irregular manner while lifting or pushing the platinum ring through the interface. Visual observation indicated that PCE was wetting at least part of the ring, thus violating the complete wetting assumption required for successful application of the ring technique. Dynamic measurements were made instead using the drop volume technique with varying rates of drop formation.

Dynamic interfacial tension between water and the dyed-PCE solutions was measured using a Krüss Drop Volume Tensiometer (model DVT10). The interfacial tension was measured as a function of the PCE flow rate from a precision syringe pump into the water phase through a specially designed alumina tip. The PCE drops were counted by an optical system which is part of the tensiometer. The drop volumes were determined by the pump rate and the length of time between successive drops. The interfacial tension is computed from the drop volume using the following equation [27]:

$$
\gamma_{n w}=\frac{V_{D} \Delta \rho g}{\pi d}
$$

where $\gamma_{\mathrm{nw}}$ is the NAPL-water interfacial tension, $V_{D}$ is the volume of the drop, $\Delta \rho$ is the density difference between the two fluids, $\mathrm{g}$ is the gravitational acceleration, and $d$ is the diameter of the tip from which the drop is suspended. More details on the measurement system are contained in Appendix A. 


\section{M-Area DNAPL-Water Interfacial Tension}

A sample of the M-Area DNAPL and an associated colloidal emulsion was obtained from well MSB-3D in June 1994. A subsample was placed in a 40 $\mathrm{mL}$ vial. After settling for approximately 20 days, this subsample segregated into three "phases": a high density, light brown, transluscent phase (hereafter referred to as the "pure" M-Area DNAPL), an intermediate density, milky white emulsion, and a well-equilibrated aqueous phase. The composition of the "pure" M-Area DNAPL is estimated to be approximately $95 \% \mathrm{PCE}$ and 5\% TCE (trichloroethylene) [28]. The Wilhelmy plate method $[24 ; 26]$ was used to measure the interfacial tension between the "pure" M-Area DNAPL phase (i.e., without any colloidal phase present) and the well-equilibrated aqueous phase collected with the sample. A glass pipette was inserted below the emulsion to collect the sample of "pure" M-Area DNAPL. A fresh, clean glass pipette was used to collect a sample of the wellequilibrated aqueous phase for the interfacial tension analysis. Additional measurements were made between the "pure" M-Area DNAPL and a sample of clean tap water. The interfacial tension was also measured using the du Noüy ring method for this later pair of liquids.

\section{Contact Angle}

The wetting relationships between Sudan IV-dyed PCE and water on a glass surface were examined by measuring contact angle as a function of the dye concentration. Contact angles were measured using a Krüss Goniometer (model G10). For each concentration, a drop of the dyed PCE was placed on a glass slide which had been submerged in water pre-equilibrated with undyed PCE. The drop was allowed to equilibrate on the glass surface for approximately five minutes. The contact angle was then measured through the PCE phase (see Figure 5 of Appendix A). 


\section{Results and Discussion}

\section{Interfacial Tension \\ PCE Lens Thickness Screening Test}

The PCE lens thickness measurements are presented in Table 2. A t-test was conducted to determine whether the difference observed in the two sample means was significant [29]. The calculated t-statistic from the experimental data is 3.52. Critical values of the $t-$ distribution with five degrees of freedom are 3.365 for $\mathrm{p}=0.02$ and 4.032 for $\mathrm{p}=$ 0.01 . The means are therefore statistically significantly different at a confidence level of $98 \%$. Thus the dye appeared to have a significant effect on the PCE-water interfacial tension. Further testing was therefore needed to characterize the magnitude of the effect on the interfacial tension as a function of dye concentration. This test is not sufficiently sensitive to quantify the interfacial tension reduction as a function of the dye concentration.

\section{Du Noüy Ring Interfacial Tension Measurements}

Difficulties were encountered when the du Noüy ring method was applied to dyed PCE. Slow changes in the measured interfacial tension were observed. In addition, the interface between the dyed PCE and water behaved in an unusual fashion; it would break in an irregular manner while lifting or pushing the platinum ring through the interface. These same behaviors occurred whether the ring was pushed down from the aqueous phase into the PCE phase or was pulled up through the interface. Visual observations suggested that the wetting relationship between $\mathrm{PCE}$, water, and the platinum ring was not constant, but was changing with time. This type of behavior on platinum has been noted by other researchers [30]. The change in wetting violates the assumptions of the measurement technique, rendering any results suspect. Hence the results are not reported here.

In June 1994, interfacial tension was measured between SRS tap water and a sample of the M-Area DNAPL obtained from well MSB-3D. Similar interfacial behavior was noted during those measurements, including one-directional changes in interfacial tension and irregular breaking of the interface during du Noüy ring measurements. The best results achieved during those measurements were attained using the Wilhelmy plate method with the wellequilibrated well water [24]. The mean interfacial tension was $9.592 \mathrm{mN} / \mathrm{m}$ with a standard deviation of $0.006 \mathrm{mN} / \mathrm{m}$ $(n=10$, see Appendix B).

\section{Drop Volume Interfacial Tension Measurements}

Water was initially pumped upward into a continuous PCE phase to measure the interfacial tension. Continually decreasing values of interfacial tension were obtained at the same flow rate. This suggested that the PCE was leaching components from the rubber o-ring used to seal the apparatus. Cracks were observed in the o-ring when the system was disassembled, confirming this assessment. Similar results were attained when an o-ring made of a more solventresistant material (Kalrez) was used in the device under the same configuration of pumping water up into the PCE phase, although the magnitude of change was significantly lower. Consequently, the system was switched to pumping PCE down into a continuous water phase. The PCE tended to wet a tungsten-carbide tip that was used initially in this configuration. The PCE tendency to partially wet a metal surface was consistent with the results observed on the platinum ring. This situation violates the assumptions of the equation applied to calculate interfacial tension. An alumina tip alleviated the PCE wetting problem. 
Water remained the wetting solution in all the remaining tests.

The mean interfacial tension results between Sudan IV-dyed PCE and water are given as a function of the PCE flow rate in Tables 3 to 7 for the different dye concentrations. PCE flow rate is roughly proportional to the rate of new interface formation. Interfacial tensions, corrected for the PCE and aqueous solution density, were calculated from the raw drop volume data in Appendix A along with the fluid density data in Table 1 using equation (13). These calculations are presented in Appendix C. In all cases the interfacial tension decreases as the PCE flow rate decreases. The results are illustrated in Figure 5 as a function of flow rate. The undyed PCE-water interfacial tension leveled off at approximately 45.89 dynes $/ \mathrm{cm}(\mathrm{mN} / \mathrm{m})$ at the lowest two flow rates applied for that system, $0.5 \mathrm{~mL} / \mathrm{hr}$ and $0.25 \mathrm{~mL} / \mathrm{hr}$. This value is thought to be low due to incorporation of rubber components leached during the initial attempts to measure IFT when the undyed PCE was in contact with a rubber o-ring.

The IFT of the lowest dye concentration solution, $\mathrm{C} 4=0.00508 \mathrm{~g} / \mathrm{L}$, also appeared to level off, but at a lower value of approximately 40.3 dynes $/ \mathrm{cm}(\mathrm{mN} / \mathrm{m})$ and at lower PCE flow rates, $0.1 \mathrm{~mL} / \mathrm{hr}$ and $0.05 \mathrm{~mL} / \mathrm{hr}$. The interfacial tensions of all the remaining solutions of higher dye concentration appeared to still be decreasing with decreasing flow rate even at the lowest applied flow rate of 0.05 $\mathrm{mL} / \mathrm{hr}$. At the lower dye concentrations, less than or equal to $0.5 \mathrm{~g} / \mathrm{L}$, the dye appeared to increase the interfacial tension at the higher flow rates. This apparent IFT increase is thought to be due to contamination of the undyed PCE by leaching rubber components as discussed above. At the highest dye concentration, $5.08 \mathrm{~g} / \mathrm{L}$, all interfacial tension results were significantly less than the results for the undyed-PCE-water system. Figure 6 contains plots of the lowest measured interfacial tension as a function of the dye concentration and the interfacial tension measured at a PCE flow rate of 0.25 $\mathrm{mL} / \mathrm{hr}$ (the lowest flow rate used with the undyed PCE). The lowest interfacial tension results suggest that Sudan IV reduces the PCE-water interfacial tension even at the lowest dye concentration tested. These results are consistent with literature observations that dynamic methods of interfacial tension measurement tend to yield high interfacial tension values for solutions $[24,31]$.

\section{Contact Angle Measurements}

Contact angle results for the Sudan IV dyed PCE with respect to water are given in Table 8. At the lower three dye concentrations, the dye appeared to increase the hydrophobic/non-polar nature of the PCE phase. The contact angles measured through the PCE phase increased, indicating that the aqueous phase was relatively more wetting on the glass surface than was the case for undyed PCE. At the highest concentration, however, the wetting relationship was rendered neutral; contact angle decreased to $87^{\circ} \pm 3^{\circ}$. Two additional solutions were prepared to examine the contact angle behavior at concentrations between 5.08 and 0.508 $\mathrm{g} / \mathrm{L}$. Dilutions of the C1 PCE solution were prepared to yield dye concentrations of approximately $1.27 \mathrm{~g} / \mathrm{L}$ in solution $\mathrm{C} 1.2$ and $1.69 \mathrm{~g} / \mathrm{L}$ in solution $\mathrm{C} 1.6$. The contact angles for these solutions also indicated that significant changes occurred in the wetting behavior. The contact angles were $70^{\circ} \pm 3^{\circ}$ in $\mathrm{C} 1.2$ and $75^{\circ} \pm 3^{\circ}$ in $\mathrm{C} 1.6$. The contact angle measured through the aqueous phase is plotted as a function of dye concentration in Figure 7. The wetting relationship clearly changes as the dye concentration increases.

NAPL wetting has been shown to increase with time of exposure to the solid surface for complex NAPLs characteristic of natural or refined oil [18, $32]$, presumably due to adsorption and/or deposition of organic matter onto the solid surface. As a result, Anderson 
[33], has suggested that equilibrium contact angle measurements involving NAPLs containing surface active agents may require aging for hundreds to thousands of hours. It is therefore likely that, given longer equilibration time, the dyed PCE could become the wetting phase, even at lower dye concentrations, based on these previous literature results together with the fact that only a very short equilibration time (approximately 5 minutes) was used during this study. Recent experimental evidence supports this prediction [34].

Reversal of the wetting relationship has major implications for DNAPL mobility in the saturated subsurface. First, the wettability relationship controls the fluid phase distribution in the subsurface as illustrated in Figure 2 [10]. Therefore, as the wetting relationship changes, so the fluid phase distribution will change. Second, the mechanism of DNAPL migration into fresh, uncontaminated areas will change as the wettability relationship changes. DNAPL moves pore-to-pore via piston-type displacement governed by the capillary and Bond number force ratios when it is nonwetting with respect to the aqueous phase. As the DNAPL becomes the wetting phase, however, it may begin to migrate via thin-film flow $[34,35]$. The ultimate result of changing the wetting relationship is that the concept of a permanent capillary barrier to DNAPL migration may not fully represent reality in the subsurface. The surface chemical reactions of complex DNAPLs need to be investigated with respect to different sedimentary minerals in order to assess the importance of this topic to understanding DNAPL behavior in the subsurface. Currently little or no such information is available. 


\section{CONCLUSIONS}

Sudan IV dye has significant influences on interfacial properties of the PCEwater-glass system. At concentrations greater than approximately $0.05 \mathrm{~g} / \mathrm{L}$ it begins to reduce the interfacial tension between water and the dyed PCE. This will therefore result in a decreased capillary force resisting mobility of the PCE phase. In addition, at concentrations greater than $1 \mathrm{~g} / \mathrm{L}$ the dye can significantly alter the wetting relationship between the fluid phases. The wetting relationship may change significantly even at lower dye concentrations. This prediction has been confirmed experimentally, and is further supported by slow changes in wetting relations noted in the literature $[18,32]$. These results indicate the importance of testing the effects of dyes prior to using them in experimental systems. The interfacial effects of the dye also suggest that previous experimental results obtained using Sudan IV-dyed DNAPLs should be used with caution or perhaps be re-interpreted.

The similarity noted between behavior of the dyed-PCE-water interface and the MArea DNAPL-water interface during du Noüy ring method interfacial tension measurements suggests that the dye makes PCE behave in a fashion similar to that observed with the M-Area DNAPL. The possibility of altered wetting relationships caused by components of the DNAPL would have significant implications for how the M-Area DNAPL is distributed and moving in the SRS subsurface. This possibility should be examined experimentally. Specifically, experimental work is required to 1) identify what types of DNAPL components possess surface active characteristics, 2) examine the surface chemistry of model DNAPL surface active components at both the DNAPLwater interface and at the DNAPL-mineral surfaces, and 3) evaluate the mobility of surface-active DNAPLs in the subsurface, particularly with respect to the major mechanism of movement.

\section{Acknowledgements}

The information contained in this report was developed during the course of work under Contract No. DE-AC09-

96SR18500 with the U.S. Department of Energy. Funding was provided by the Office of Science \& Technology under TTP No. SR-1410-10. 


\section{REFERENCES}

1. Neustadter, E.L. "Surfactants in enhanced oil recovery" in Surfactants, T.F. Tadros, Editor. p. 277-285. Academic Press, Inc., New York. (1984).

2. Tuck, D.M., et al. "Enhancing recovery of immobile residual non-wetting hydrocarbons from the unsaturated zone using surfactant solutions". NWWA/API Conference on Petroleum Hydrocarbons and Organic Chemicals in Ground Water: Prevention, Detection, and Restoration. Houston, TX: National Water Well Association. pp. 457-478. (1988).

3. Morrow, J.C. and B. Songkran. "Effects of viscous and bouyancy forces on monwetting phase trapping in porous media" in Surface Phenomena in Enhanced Oil Recovery, D.O. Shah, Editor. p. 387-411. Plenum Press, New York. (1981).

4. Chatzis, I. and N.R. Morrow. "Correlation of capillary number relationships for sandstone". Society of Petroleum Engineers Journal 24, p. 555-562 (1984).

5. Wardlaw, N.C. "Fluid topology, pore size and aspect ratio during imbibition". Transport in Porous Media 3, p. 17-34 (1988).

6. Pennell, K.D., G.A. Pope, and L.M. Abriola. "Influence of viscous and bouyancy forces on the mobilization of residual tetrachloroethylene during surfactant flushing". Environmental Science \& Technology 30, p. 1328-1335 (1996).

7. Dawson, H.E. and P.V. Roberts. "Influence of viscous, gravitational, and capillary forces on DNAPL saturation". Ground Water 35, p. 261-269 (1997).

8. Morrow, N.R., I. Chatzis, and J.J. Taber. "Entrapment and mobilization of residual oil in bead packs". SPE Reservoir Engineering 3, p. 927-934 (1988).

9. Young, T. "An essay on the cohesion of fluids". Philosophical Transactions of the Royal Society (London) 95, p. 65-87 (1805).

10. Dullien, F.A.L. Porous Media: Fluid Transport and Pore Structure. 2nd ed. pp. 574. Academic Press, Inc., San Diego. (1992).

11. Hohmann, J.D. Toward Mobilizing tetrachloroethylene (PCE) in contaminated aquifers: laboratory contact angle studies. Junior Thesis, Princeton University. (1987).

12. Jaffé, P.R., et al. Investigation of Residual Solvent Recovery in Soils Using Surfactants, prepared for the N.J. Department of Environmental Protection. 89WR-1. Princeton University, Water Resources Program, Princeton, NJ., (1989).

13. Jaffé, P.R., D.M. Tuck, and J. Zou. Solvent Recovery in Soils Using Surfactants; Part II, prepared for the N.J. Department of Environmental Protection. 91-WR-1. Princeton University, Water Resources Program, Princeton, NJ., (1991).

14. Tuck, D.M. Immiscible displacement of residual tetrachloroethylene from saturated and unsaturated porous media. Ph. D. Thesis, Princeton University. (1992). 
15. Tuck, D.M. and P.R. Jaffé. "Enhanced displacement of tetrachloroethylene from unsaturated sediments by surfactant solutions". 207th American Chemical Society National Meeting. San Diego, CA: American Chemical Society Division of Environmental Chemistry (preprints of Papers Series). pp. 632. (1994).

16. Gau, C.-S. and G. Zografi. "Relationships between adsorption and wetting of surfactant solutions". Journal of Colloid and Interface Science 140, p. 1-9 (1990).

17. Varadaraj, R., et al. "Relationships between dynamic contact angle and dynamic surface tension properties for linear and branched ethoxylate, ethoxysulfate, and sulfate surfactants". Journal of Colloid and Interface Science 147, p. 403-406 (1991).

18. Cohen, R.M. and J.W. Mercer. DNAPL Site Evaluation. pp. 339. C.K. Smoley, Boca Raton, FL. (1993).

19. Schwille, F. Dense Chlorinated Solvents in Porous and Fractured Media: Model Experiments. pp. 146. Lewis Publishers, Inc., Chelsea, MI. (1988).

20. Kueper, B.H., W. Abbott, and G. Farquhar. "Experimental observations of multiphase flow in heterogeneous porous media". Journal of Contaminant Hydrology 5, p. 83-95 (1989).

21. Kueper, B.H. and E.O. Frind. "Two-Phase flow in heterogeneous porous media 2. Model application". Water Resources Research 27, p. 1059-1070 (1991).

22. Kueper, B.H., et al. "A field experiment to study the behavior of tetrachloroethylene below the water table: Spatial distribution of residual and pooled DNAPL". Ground Water 31, p. 756-766 (1993).

23. Brewster, M.L., et al. "Observed migration of a controlled DNAPL Release by Geophysical Methods". Ground Water 33, p. 977-987 (1995).

24. Adamson, A.W. Physical Chemistry of Surfaces. 5 ed. pp. 777. John Wiley \& Sons Inc., New York. (1990).

25. ASTM. "ASTM D1331-89. Standard test method for surface and interfacial tension of solutions of surface-active agents" in 1994 Annual Book of ASTM Standards. p. 116-118. American Society for Testing and Materials, Philadelphia. (1994).

26. Gilman, L.B. "A review of instruments for static and dynamic surface and interfacial tension measurement". 84th AOCS Annual Meeting and Exposition. Anaheim, CA: Reprint from Kruss USA, Charlotte, NC. pp. 18 pp. (1993).

27. Tate, $\mathrm{T}$. "On the magnitude of a drop of liquid formed under different circumstances". Philosophical Magazine 27, p. 176-180 (1864).

28. Looney, B.B., et al. Assessing DNAPL Contamination, A/M-Area, Savannah River Site: Phase I Results. WSRC-RP-92-1302. Westinghouse Savannah River Company, Aiken, SC, (1992). 
29. Burington, R.S. and D.C. May Jr. Handbook of Probability and Statistics with Tables. pp. 332. Handbook Publishers, Inc., Sandusky, OH. (1953).

30. Gaonkar, A.G. and R.D. Neuman. "The effect of wettability of Wilhelmy plate and du Noüy ring on interfacial tension measurements in solvent extraction systems". Journal of Colloid and Interface Science 98, p. 112-119 (1984).

31. Padday, J.F. and D.R. Russell. "The measurement of the surface tension of pure liquids and solutions". Journal of Colloid Science 15, p. 503 (1960).

32. Treiber, L.E., D.L. Archer, and W.W. Owens. "A laboratory evaluation of the wettability of fifty oil producing reservoirs". Society of Petroleum Engineers Journal 12, p. $531-540$ (1972).

33. Anderson, W.G. "Wettablility Literature Survey-Part 2: wettability measurement". Journal of Petroleum Technology 38, p. 1246-1262 (1986).

34. Pirkle, W.A., G.M. Iversen, and D.M. Tuck. The effect of an organic dye on DNAPL entry pressure into water saturated porous media. Final report submitted in completion of SCUREF Project SC-0001-EC, SCUREF Task 185, Phase II. University of South Carolina-Aiken, (1997).

35. Tuck, D.M., G.M. Iversen, and W.A. Pirkle. "Complex Organic Co-contaminant Effects on DNAPL Mobility in Saturated Porous Media". Eos 77, p. F257 (1996). 


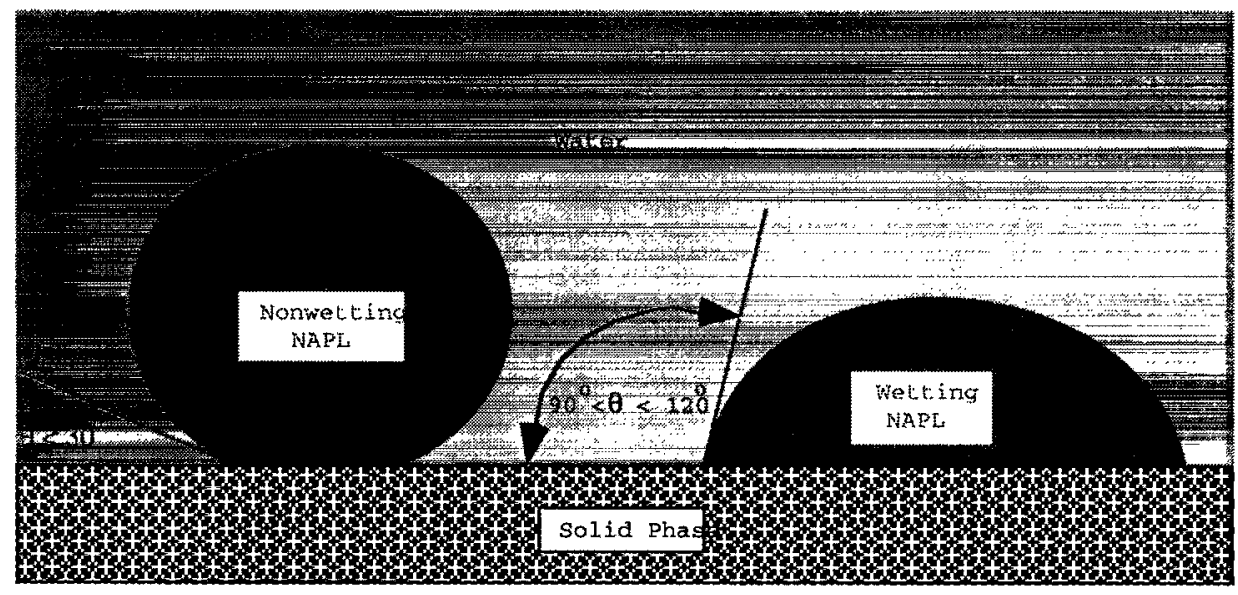

Figure 1. Contact angle illustration. Left side illustrates a strongly water-wet condition $(\theta$ $\left.<30^{\circ}\right)$. Right side illustrates a weakly NAPL-wet condition $\left(90^{\circ}<\theta<120^{\circ}\right)$.

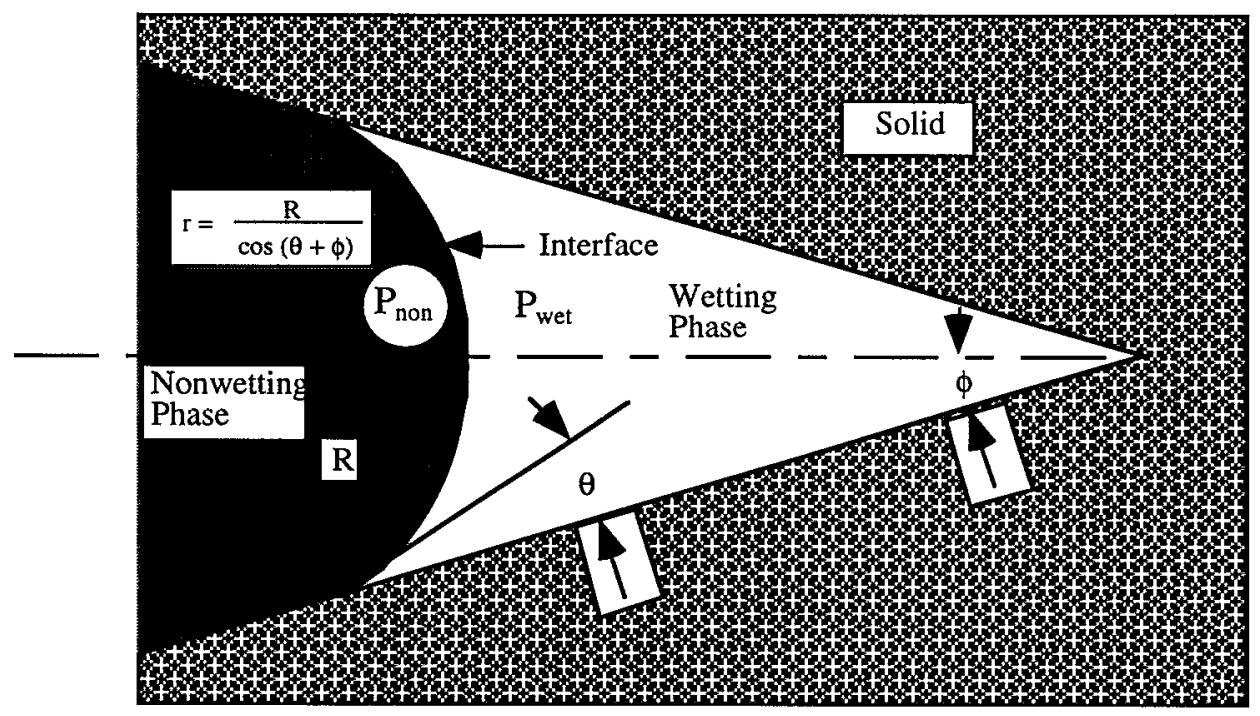

Figure 2. Relative distribution of the wetting and nonwetting phases in a conical capillary. (modified after [10] 
WSRC-TR-97-0038

Rev. 0
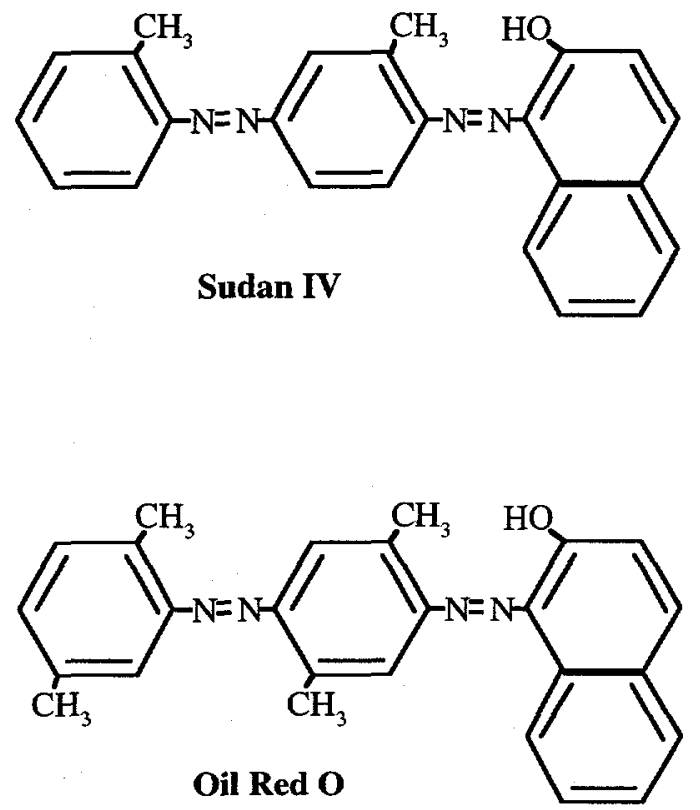

Figure 3. Chemical structures of organic dyes commonly used in multiphase flow visualization studies. 


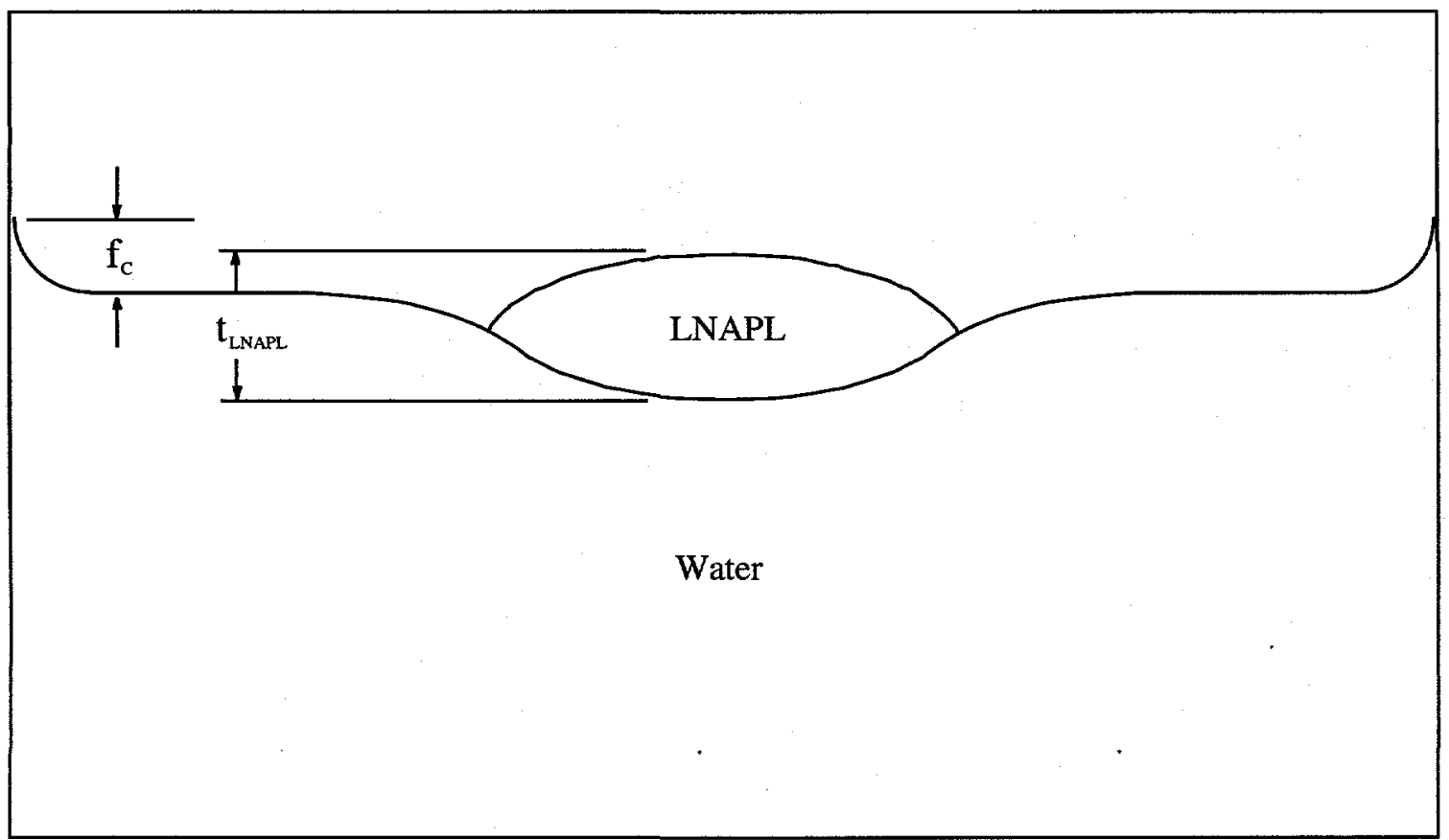

a.

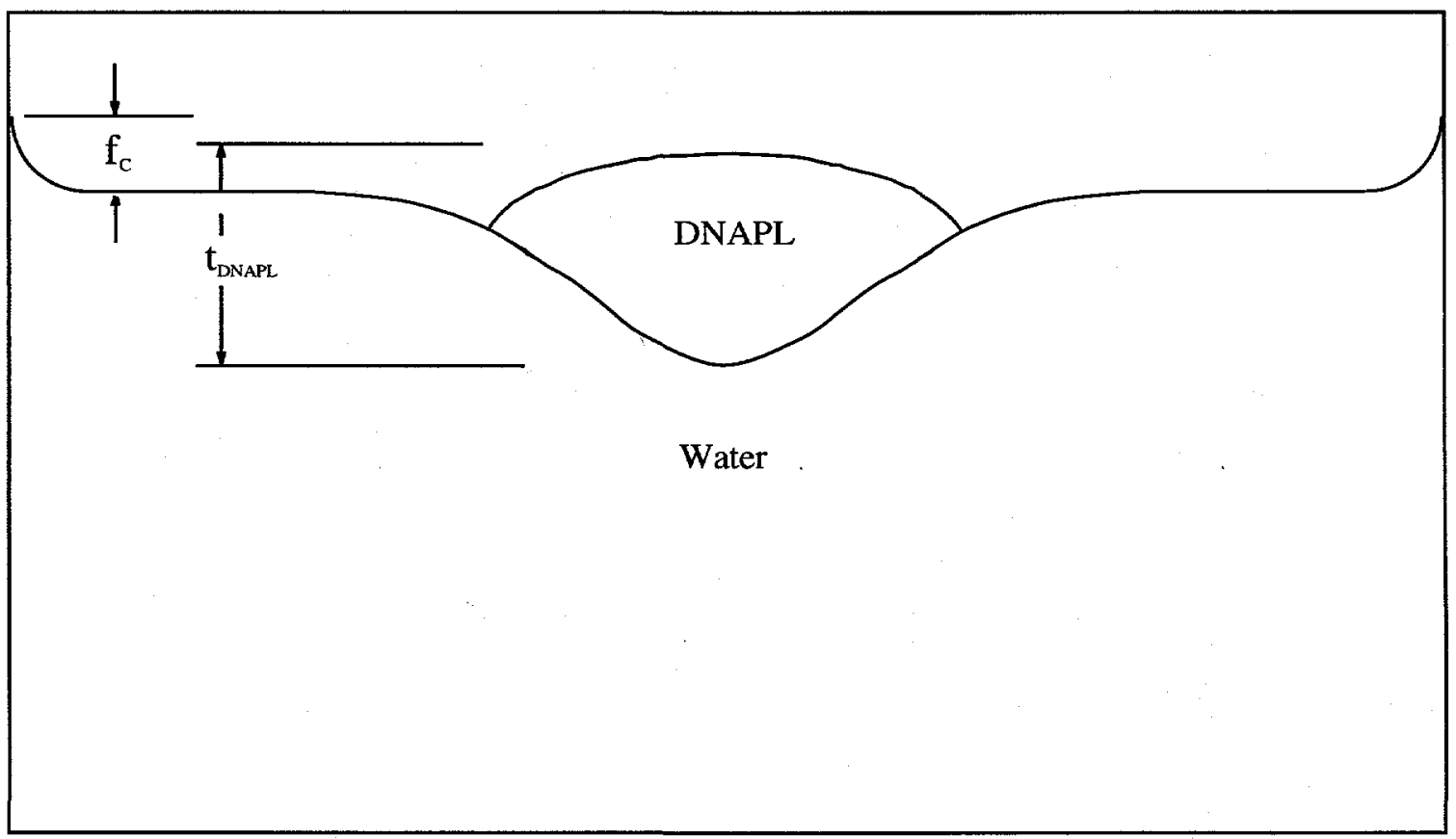

b.

Figure 4. General profiles of floating NAPL lenses. The symbol $\mathrm{f}_{\mathrm{c}}$ represents the thickness of the water capillary fringe in contact with the glass beaker. a. NAPL with density less than water, i.e., an LNAPL. b. NAPL with density greater than water, i.e., a DNAPL. 


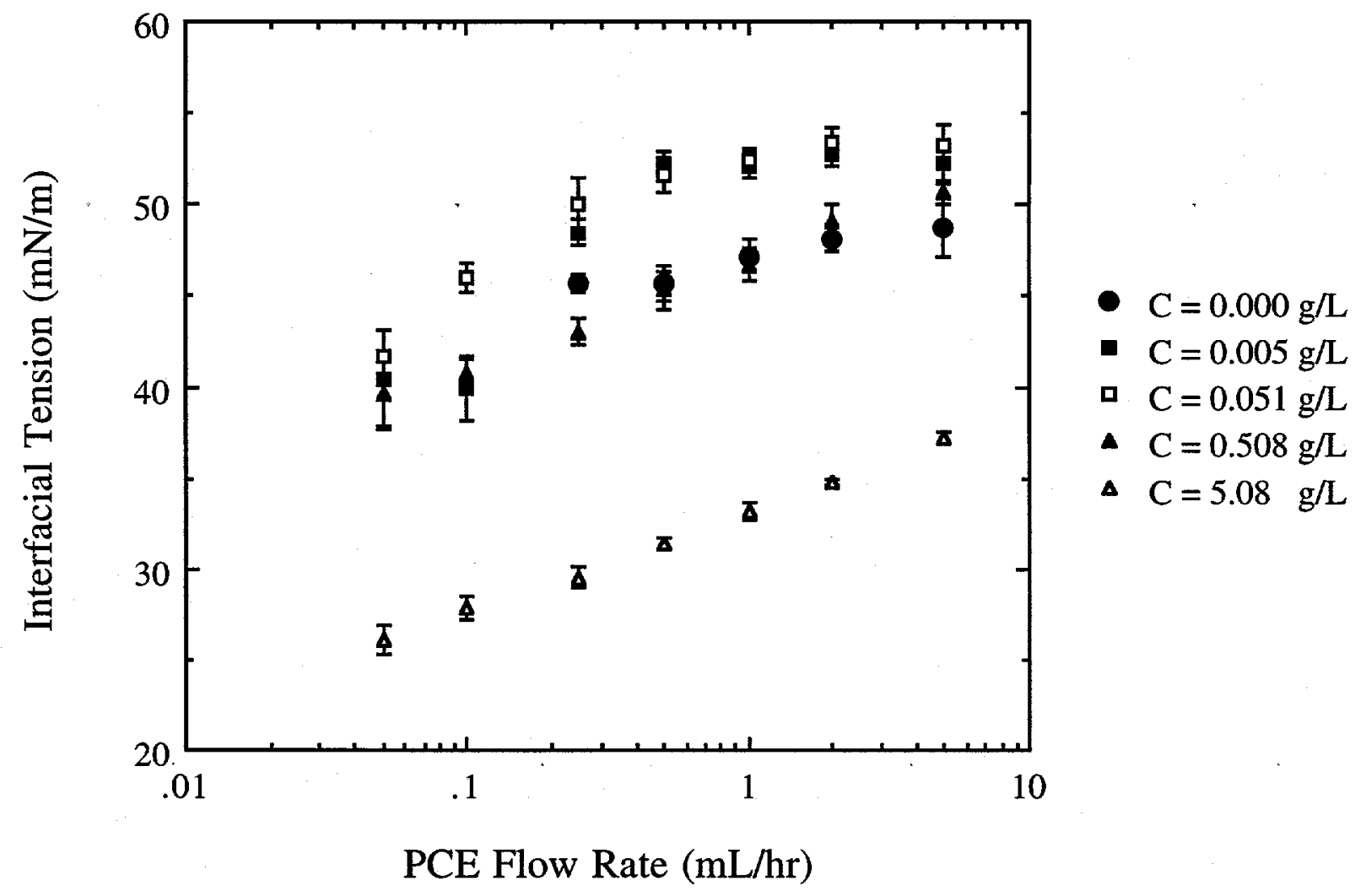

Figure 5. Dyed-PCE-water interfacial tension by drop volume technique as a function of PCE flow rate. 


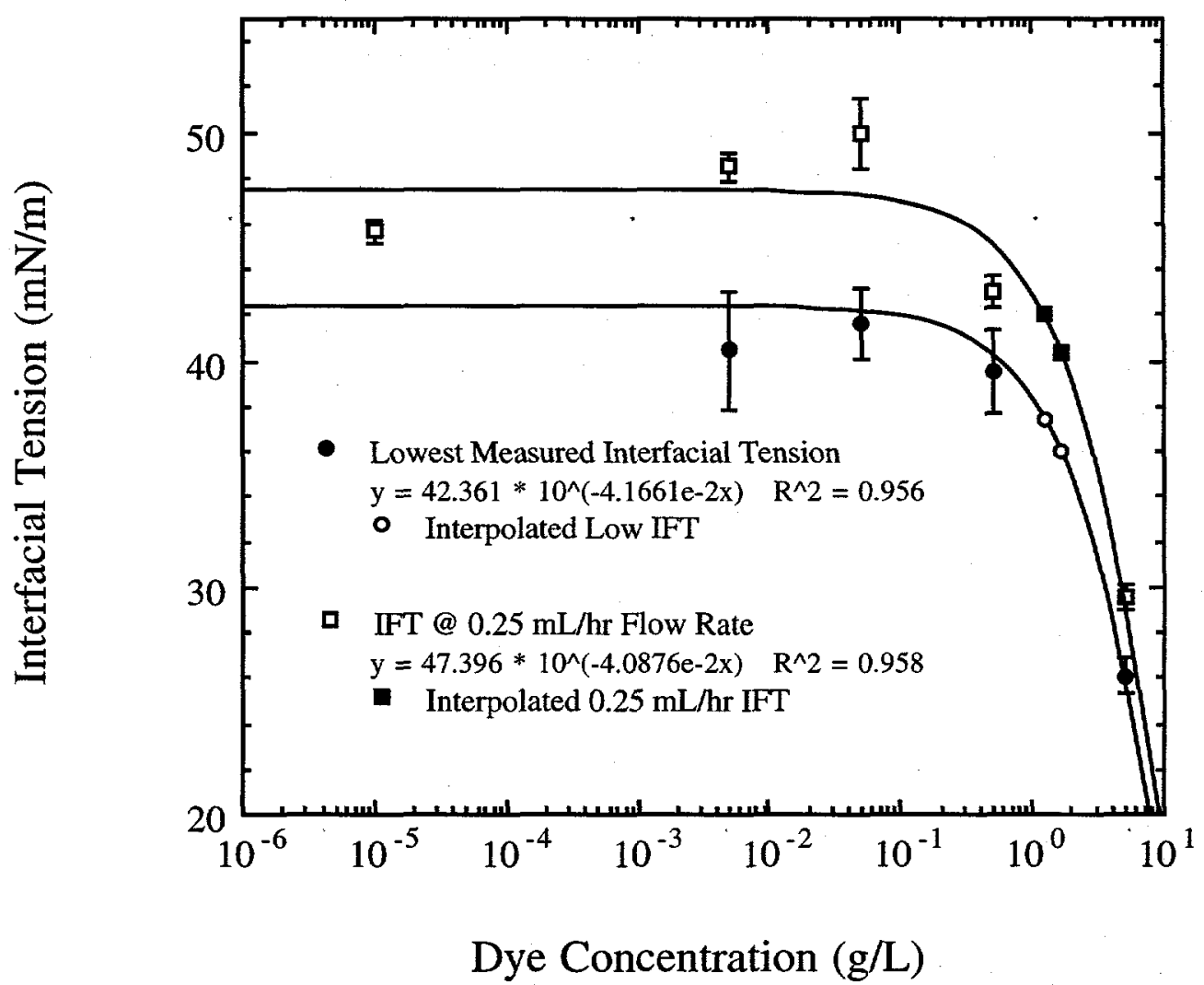

Figure 6. Lowest dyed-PCE-water interfacial tension measured by the drop volume technique. Data points for $1.26 \mathrm{~g} / \mathrm{L}$ and $1.69 \mathrm{~g} / \mathrm{L}$ were estimated by interpolation. 
WSRC-TR-97-0038

Rev. 0

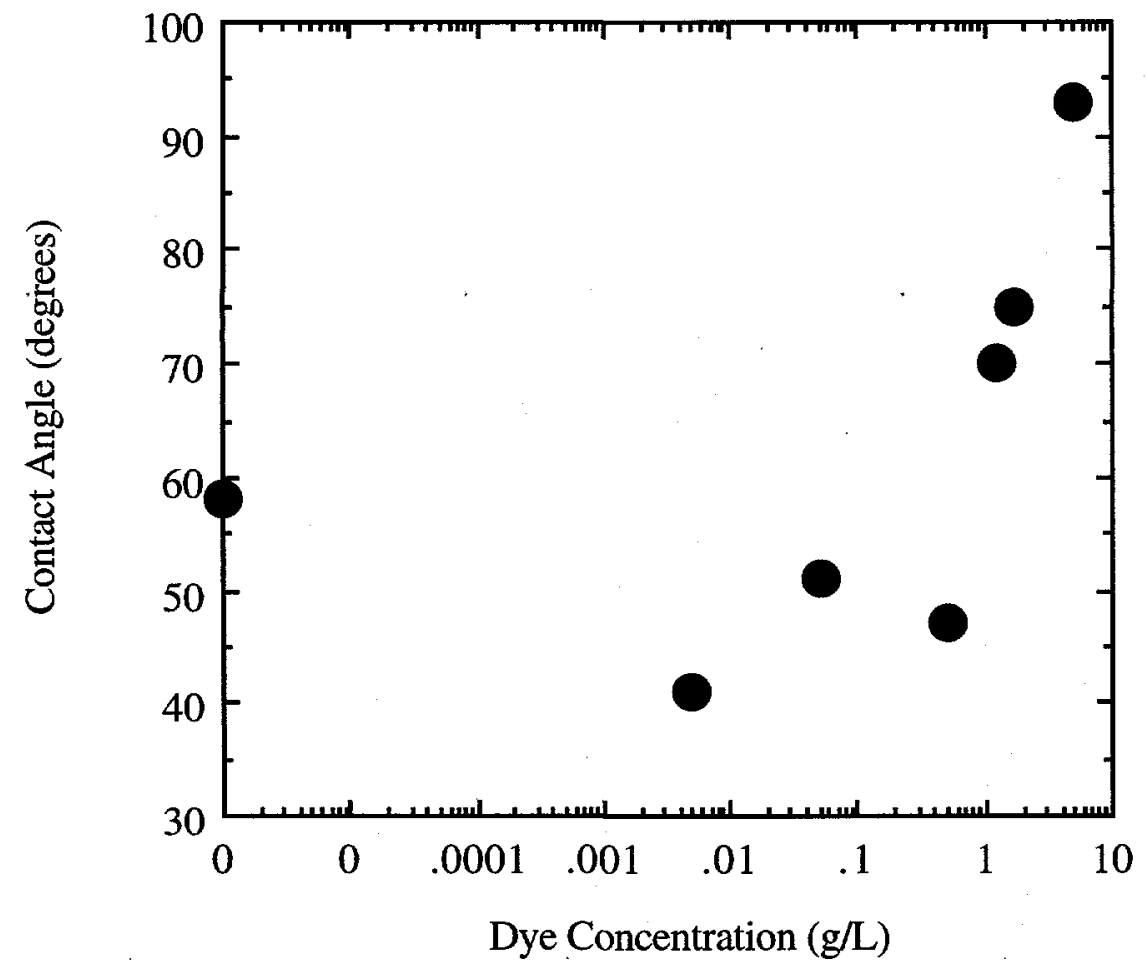

Figure 7. Contact angle between dyed-PCE, water, and glass measured through the water phase. 


\begin{tabular}{|cc|c|}
\hline Solution ID & $\begin{array}{l}\text { Sudan IV Dye } \\
\text { Concentration }(\mathrm{g} / \mathrm{L})\end{array}$ & $\begin{array}{l}\text { Solution Density } \\
(\mathrm{g} / \mathrm{mL})\end{array}$ \\
\hline $\mathrm{C} 0$ & 0.00000 & 1.6153 \\
\hline $\mathrm{C} 4$ & 0.00508 & 1.6150 \\
$\mathrm{C} 3$ & 0.0508 & 1.6158 \\
$\mathrm{C} 2$ & 0.508 & 1.6147 \\
$\mathrm{C} 1.27$ & 1.27 & 1.6145 \\
$\mathrm{C} 1.69$ & 1.69 & $\mathrm{NA}$ \\
$\mathrm{C} 1$ & 5.08 & 1.6141 \\
\hline
\end{tabular}

Table 1. Tetrachloroethylene (PCE) solutions and Sudan IV dye concentrations. NA indicates that the density was not measured.

\begin{tabular}{|cc|}
\hline $\begin{array}{c}\text { Lens Thickness } \\
\text { without Sudan IV } \\
\text { Dye (mm) }\end{array}$ & $\begin{array}{c}\text { Lens Thickness with } \\
\sim 1.5 \text { g/L Sudan IV } \\
\text { Dye (mm) }\end{array}$ \\
\hline 6.0 & 5.5 \\
6.2 & 5.5 \\
6.5 & \\
6.0 & \\
6.5 & \\
\hline
\end{tabular}

Table 2. Floating PCE lens thickness measurements. 
WSRC-TR-97-0038

Rev. 0

\begin{tabular}{|cccc|}
\hline $\begin{array}{c}\text { PCE Syringe Pump } \\
\text { Rate }(\mathrm{mL} / \mathrm{hr})\end{array}$ & $\begin{array}{c}\text { Mean Interfacial } \\
\text { Tension }(\mathrm{mN} / \mathrm{m})\end{array}$ & $\begin{array}{c}\text { Standard Deviation } \\
(\mathrm{mN} / \mathrm{m})\end{array}$ & Number of Drops \\
\hline 5.00 & 48.75 & 1.64 & 10 \\
2.00 & 48.16 & 0.74 & 10 \\
1.00 & 47.22 & 0.92 & 10 \\
0.5 & 45.66 & 0.94 & 10 \\
0.25 & 45.67 & 0.51 & 10 \\
\hline
\end{tabular}

Table 3. Mean interfacial tension between undyed PCE and water as a function of flow rate.

\begin{tabular}{|cccc|}
\hline $\begin{array}{c}\text { PCE Syringe Pump } \\
\text { Rate }(\mathrm{mL} / \mathrm{hr})\end{array}$ & $\begin{array}{c}\text { Mean Interfacial } \\
\text { Tension }(\mathrm{mN} / \mathrm{m})\end{array}$ & $\begin{array}{c}\text { Standard Deviation } \\
(\mathrm{mN} / \mathrm{m})\end{array}$ & Number of Drops \\
\hline 5.00 & 51.99 & 1.38 & 10 \\
5.00 & 52.60 & 1.18 & 10 \\
5.00 & 52.75 & 1.00 & 8 \\
2.00 & 52.691 & 0.490 & 10 \\
1.00 & 52.189 & 0.700 & 10 \\
0.50 & 52.189 & 0.700 & 10 \\
0.25 & 48.502 & 0.655 & 10 \\
0.10 & 39.849 & 1.639 & 10 \\
0.05 & 40.480 & 2.623 & 5 \\
\hline
\end{tabular}

Table 4. Mean interfacial tension between PCE and water as a function of flow rate for Sudan IV dye concentration $\mathrm{C} 4=0.00508 \mathrm{~g} / \mathrm{L}$ in PCE. 


\begin{tabular}{|cccc|}
\hline $\begin{array}{c}\text { PCE Syringe Pump } \\
\text { Rate }(\mathrm{mL} / \mathrm{hr})\end{array}$ & $\begin{array}{c}\text { Mean Interfacial } \\
\text { Tension }(\mathrm{mN} / \mathrm{m})\end{array}$ & $\begin{array}{c}\text { Standard Deviation } \\
(\mathrm{mN} / \mathrm{m})\end{array}$ & Number of Drops \\
\hline 5.00 & 53.29 & 1.07 & 10 \\
2.00 & 53.40 & 0.88 & 10 \\
1.00 & 52.49 & 0.61 & 10 \\
0.50 & 51.66 & 0.97 & 10 \\
0.25 & 49.98 & 1.57 & 10 \\
0.10 & 46.05 & 0.75 & 5 \\
0.05 & 41.65 & 1.50 & 5 \\
\hline
\end{tabular}

Table 5. Mean interfacial tension between PCE and water as a function of flow rate for Sudan IV dye concentration C3 $=0.0508 \mathrm{~g} / \mathrm{L}$ in PCE.

\begin{tabular}{|cccc|}
\hline $\begin{array}{c}\text { PCE Syringe Pump } \\
\text { Rate (mL/hr) }\end{array}$ & $\begin{array}{c}\text { Mean Interfacial } \\
\text { Tension }(\mathrm{mN} / \mathrm{m})\end{array}$ & $\begin{array}{c}\text { Standard Deviation } \\
(\mathrm{mN} / \mathrm{m})\end{array}$ & Number of Drops \\
\hline 5.00 & 50.68 & 0.65 & 10 \\
2.00 & 49.08 & 1.03 & 10 \\
1.00 & 46.70 & 0.88 & 10 \\
0.50 & 45.35 & 1.03 & 10 \\
0.25 & 43.04 & 0.70 & 10 \\
0.10 & 40.68 & 1.02 & 5 \\
0.05 & 39.52 & 1.79 & 6 \\
\hline
\end{tabular}

Table 6. Mean interfacial tension between PCE and water as a function of flow rate for Sudan IV dye concentration $\mathrm{C} 2=0.508 \mathrm{~g} / \mathrm{L}$ in PCE. 
WSRC-TR-97-0038

Rev. 0

\begin{tabular}{|cccc|}
\hline $\begin{array}{c}\text { PCE Syringe Pump } \\
\text { Rate (mL/hr) }\end{array}$ & $\begin{array}{c}\text { Mean Interfacial } \\
\text { Tension }(\mathrm{mN} / \mathrm{m})\end{array}$ & $\begin{array}{c}\text { Standard Deviation } \\
(\mathrm{mN} / \mathrm{m})\end{array}$ & Number of Drops \\
\hline 5.00 & 37.19 & 0.38 & 10 \\
2.00 & 34.78 & 0.17 & 10 \\
1.00 & 33.18 & 0.45 & 10 \\
0.50 & 31.39 & 0.37 & 10 \\
0.25 & 29.51 & 0.56 & 10 \\
0.10 & 27.89 & 0.65 & 6 \\
0.05 & 26.08 & 0.80 & 5 \\
\hline
\end{tabular}

Table 7. Mean interfacial tension between PCE and water as a function of flow rate for Sudan IV dye concentration $\mathrm{C} 1=5.08 \mathrm{~g} / \mathrm{L}$ in PCE.

\begin{tabular}{|cccc|}
\hline $\begin{array}{c}\text { Dye Concentration } \\
(\mathrm{g} / \mathrm{L})\end{array}$ & $\begin{array}{c}\text { Contact Angle } \\
\text { through PCE } \\
\text { (degrees) }\end{array}$ & $\begin{array}{c}\text { Estimated Maximum } \\
\text { Error (degrees) }\end{array}$ & $\begin{array}{c}\text { Contact Angle } \\
\text { through Water } \\
\text { (degrees) }\end{array}$ \\
\hline 0.00000 & 122. & 3 & 58 \\
0.00508 & 139 & 3 & 41 \\
0.0508 & 129 & 3 & 51 \\
0.508 & 133 & 3 & 47 \\
1.27 & 110 & 3 & 70 \\
1.69 & 105 & 3 & 75 \\
5.08 & 87 & 3 & 93 \\
\hline
\end{tabular}

Table 8. Contact angle in the Sudan IV-dyed-PCE-water-glass system. 
Appendix A.

Krüss USA Report

prepared by

Dr. Christopher Rulison

November 27, 1995 


\section{Sample Analysis Report}

Prepared for: David Tuck, Ph.D. - Westinghouse Savannah River Company

Prepared by: $\quad$ Christopher Rulison, Ph.D. - Krũss USA

Date: $\quad$ November 27, 1995

\section{Background}

On November 13th and 14th, tests were performed on the following samples at Krüss USA in Charlotte, North Carolina.

C1 - A 5.08g/L solution of dye in perchloroethylene which was pre-equilibrated with water

C2 - A $0.508 \mathrm{~g} / \mathrm{L}$ solution of dye in perchloroethylene which was pre-equilibrated with water

C3 - A $0.0508 \mathrm{~g} / \mathrm{L}$ solution of dye in perchloroethylene which was pre-equilibrated with water

C4 - A $0.00508 \mathrm{~g} / \mathrm{L}$ solution of dye in perchloroethylene which was pre-equilibrated with water

PCE - "Pure" perchloroethylene which was pre-equilibrated with water

$X 1$ - A mixture of 1 part $C 1$ and 3 parts $P C E$, thus producing a perchloroethylene solution with a dye concentration of $1.27 \mathrm{~g} / \mathrm{L}$

$X 2$ - A mixture of 1 part $C 1$ and 2 parts $P C E$, thus producing a perchloroethylene solution with a dye concentration of $1.69 \mathrm{~g} / \mathrm{L}$

D1 - A two phase system containing approximately $23 \%$ Dowfax $\mathrm{C} 6 \mathrm{~L}$ (sodium hexyl diphenyloxide disulfonate), water, and perchloroethylene

D2 - A pre-equilibrated two phase system containing 9.14\% Dowfax C6L, water, and perchloroethylene

D3 - A pre-equilibrated two phase system containing 4.57\% Dowfax C6L, water, and perchloroethylene

D4 - A pre-equilibrated two phase system containing $1.828 \%$ Dowfax C6L, water, and perchloroethylene 


\section{Drop volume tests}

The series $\{P C E, C 1, C 2, C 3, C 4\}$ was tested for dynamic interfacial tension against the water (with which it was pre-equilibrated) using a Krüss Drop Volume Tensiometer (DVT10). A variety of flow rates were studied, and three fundamentally different drop volume designs were employed. For each test the density of the perchloroethylene phase was assumed to be $1.62 \mathrm{~g} / \mathrm{cm}^{3}$ and the density of the aqueous phase was assumed to be $0.998 \mathrm{~g} / \mathrm{cm}^{3}$.

The principle of drop volume interfacial tensiometry is that the interfacial tension (the energy per unit area necessary to expand the region of contact) between two immiscible liquids can be determined from a balance of the forces which act on a drop of one of the liquids suspended in a continuous phase of the other liquid. Much of the credit for the development of this concept is attributed to Tate ${ }^{1}$ who more than a century ago introduced the equation:

$$
\gamma=\frac{V_{D} \Delta \rho g}{\pi d}
$$

where $\gamma=$ the interfacial tension between the liquids, $V_{D}=$ the volume of the drop, $\Delta \rho=$ the difference in density between the drop liquid and the continuous liquid, $g$ $=$ gravity, $d=$ the diameter of the tip on which the drop is suspended, and $\pi$ has its standard mathematical meaning.

Since it is a balance of the forces acting on a drop in the upward and downward directions, this form of Tate's equation only applies to a drop on a thin walled capillary tip which is precisely at the volume required for spontaneous detachment. See figure 1 , which is a schematic representation of a drop formed on a syringe tip in a drop volume experiment. 


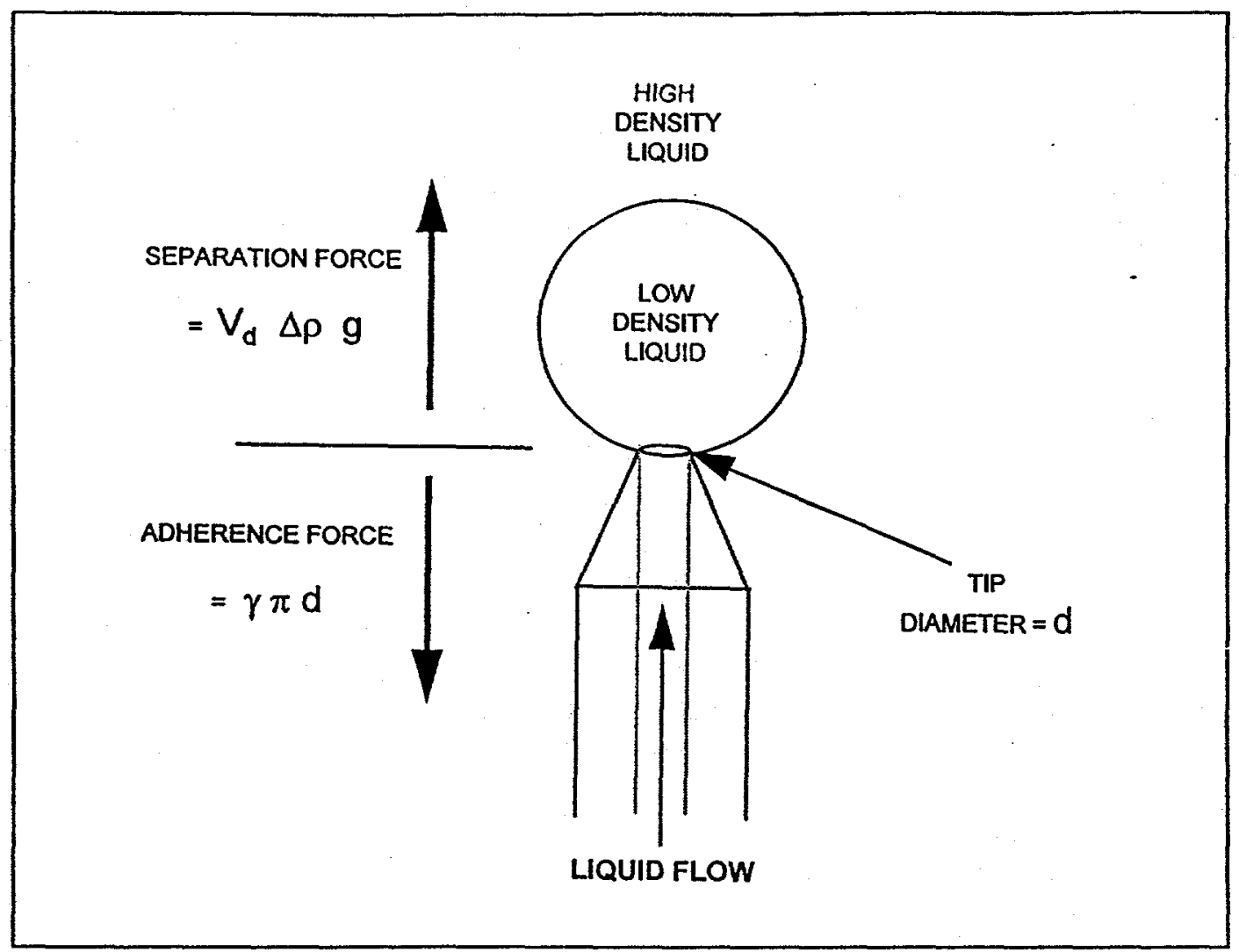

Figure 1

Assume that the drop in figure 1 is formed on a proper capillary and has the precise volume at which Tate's law applies. If the drop had any more volume, the separation force would overcome the adherence force and the drop would detach from the tip and rise through the continuous phase. If the drop had less volume, the adherence force would be greater than the separation force and the drop would not spontaneously detach.

Please note that this description has focuses on the lower density liquid being the drop phase and a higher density liquid being the continuous phase. The Krüss Drop Volume Tensiometer, DVT-10, can be operated either in this configuration or in the opposite configuration, wherein the higher density liquid is the drop phase. This "opposite" configuration is analogous in terms of the Tate's law equation except that the tip is pointed downward into the less dense, continuous phase. The adherence force then acts in the upward direction and the separation force acts in the downward direction.

An examination of Tate's equation shows that, for a given experiment, all values other than the volume of the drop and the interfacial tension are constants. Therefore, by pumping liquid at a fixed flow rate through the tip and detecting the volume of each 
drop at its point of detachment, the interfacial tension between virtually any pair of immiscible liquids can be measured. The Krüss Drop Volume Tensiometer DVT-10 operates on this principle. The system employs a precision syringe pump and a specially designed tip which precisely controls droplet formation and eliminates the need for Tate's law correction factors. Drops are grown at various rates on the tip and their detachment from the tip is detected by an infrared LED/photodiode device. Resultant values of interfacial tension are calculated by the DVT-10 (one for each drop produced). Collection of this data using a personal computer with DVT-10 software facilitates data analysis.

The three sets of experiments were done with the PCE/water system. The first set was done with the PCE as the continuous phase, water as the drop phase, and a tungsten carbide tip $(0.0254 \mathrm{~cm}$ ID opening diameter). The following data was obtained:

$\begin{array}{llll}\begin{array}{l}\text { Flow } \\ \text { Rate }\end{array} & \begin{array}{l}\text { Number of } \\ \text { Drops }\end{array} & \begin{array}{l}\text { Relative } \\ \text { Standard Deviation }\end{array} & \begin{array}{l}\text { Mean Surface } \\ \text { Tension }\end{array} \\ 5.0 \mathrm{ml} / \mathrm{hr} & 5 & 3.70 \% & 31.10 \mathrm{mN} / \mathrm{m} \\ 2.0 & 10 & 3.46 & 25.12 \\ 1.0 & 10 & 2.73 & 22.13 \\ 0.5 & 10 & 2.62 & 19.14\end{array}$

However, under these conditions the PCE was in contact with a rubber O-ring during the experiment. The literature value for the interfacial tension between pure perchloroethylene and water is approximately $48 \mathrm{mN} / \mathrm{m}$. Therefore, we suspected that the PCE was leaching material from the O-ring during these experiments, and attributed these somewhat low values to that leaching. This data should be discarded.

A second series of experiments was thus performed in the same manner (PCE continuous phase, tungsten carbide tip), but with a Kalrez (a much more resistant rubber) O-ring. The results of this second set of experiments are as follows:

\begin{tabular}{llll}
$\begin{array}{l}\text { Flow } \\
\text { Rate }\end{array}$ & $\begin{array}{l}\text { Number of } \\
\text { Drops }\end{array}$ & $\begin{array}{l}\text { Relative } \\
\text { Standard Deviation }\end{array}$ & $\begin{array}{l}\text { Mean Surface } \\
\text { Tension }\end{array}$ \\
\hline $5.0 \mathrm{ml} / \mathrm{hr}$ & 10 & $2.99 \%$ & $46.37 \mathrm{mN} / \mathrm{m}$ \\
2.0 & 10 & 2.06 & 47.64 \\
1.0 & 10 & 2.48 & 45.95 \\
0.5 & 10 & 2.00 & 44.75
\end{tabular}


We considered this set of experiments to be more reliable (closer to the literature value and less dependent on flow rate). However, we decided that no contact between the PCE phase and any rubber part would be more desirable. Therefore, this data was also discarded.

No contract between the PCE and rubber could be achieved by running the experiments with the aqueous phase as the continuous phase and the perchloroethylene phase as the drop phase. This is the method we used for testing PCE a third time, as well as for all of the drop volume tests on samples C1, C2, C3, and $\mathrm{C} 4$. We also found that when using perchloroethylene as the drop phase, a tungsten carbide tip was not appropriate. The perchloroethylene tended to wet the outside of the tip, thus causing us to have an uncontrollable effective tip diameter. Therefore, we switched to an alumina tip of the same diameter $(0.0254 \mathrm{~cm})$. This eliminated the wetting problem.

The results of drop testing using the alumina tip, using the perchloroethylene phase as drop phase configuration, and assuming that all of the perchloroethylene phases had densities $=1.62 \mathrm{~g} / \mathrm{cm}^{3}$ while all of the water phases had densities $=0.998$ $\mathrm{g} / \mathrm{cm}^{3}$, are summarized in figure 2 . All of these results were obtained at room temperature. The raw data from which figure 2 was constructed is included in the appendix to this report.

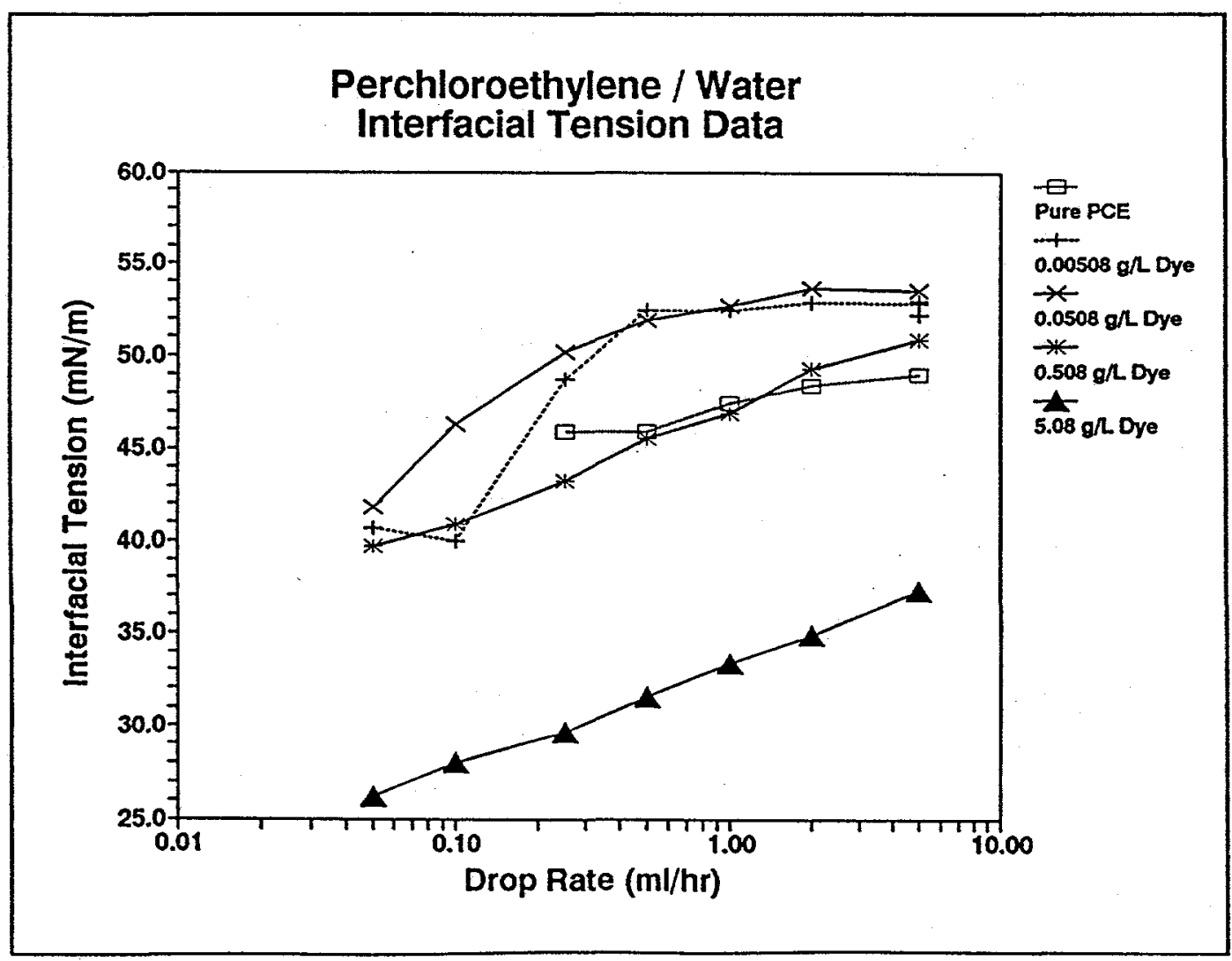

Figure 2 
To interpret the results shown in figure 2, consider what dynamic interfacial tension might be telling us about the properties of the dye (solute) that we are studying. Solutes can be either interfacially active or interfacially inactive. Interfacially active solutes are thermodynamically driven to the boundaries of solutions in which they are contained. Surfactants in water are a common example of interfacially active solutes. Figure 3 represents (in highly schematic format) dynamic interfacial tension studies with interfacially active solutes.

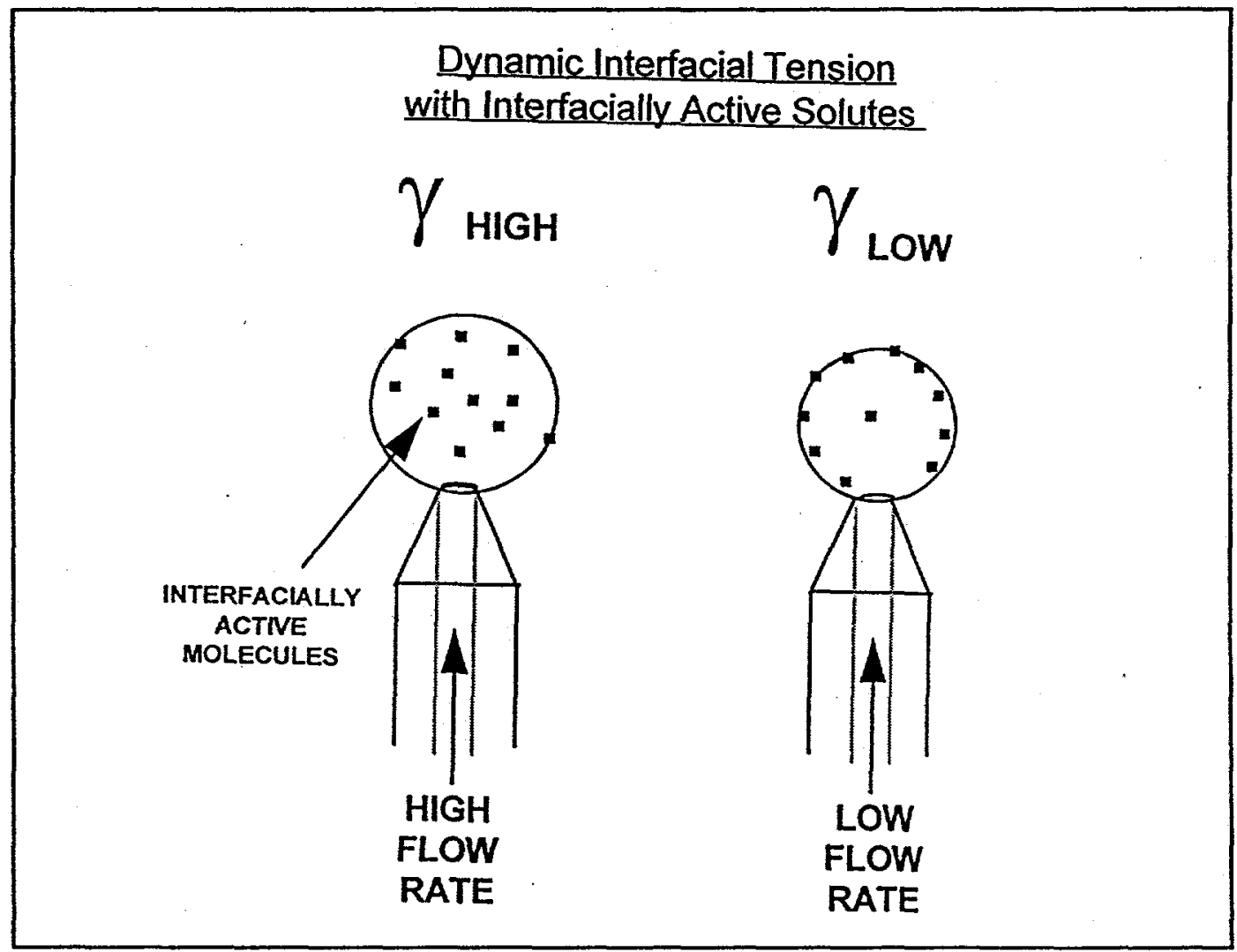

Figure 3

Consider the small black squares in figure 3 to be interfacially active molecules. If a drop is formed rather quickly (at a high flow rate) the active molecules do not have sufficient time to diffuse to and adsorb at the interface substantially. Therefore, the measured interfacial tension is high, relative to what it would be if the drop was formed more slowly. If the drop was formed more slowly (at a low flow rate), the active molecules have more time to absorb at the interface before the interfacial tension is measured. The measured interfacial tension is thus lower. 
Now consider interfacially inactive solutes. In this case, it is more thermodynamically favorable not to have solute molecules at the interface. In other words, thermodynamically inactive molecules increase interfacial tension if they are contained at interfaces. When a drop containing interfacially inactive solute molecules is formed quickly, some of these molecules may (by random chance) be at or near the interface. The interfacial tension between the two liquids being studied may then be even higher in interfacial tension than it would be if the liquids were "pure", due to the presence of the solute. If lower flow rates are studied, time is provided for the inactive solute molecules to diffuse away from the interface and into the bulk of the phase in which they are contained. This decreases interfacial tension. This situation is depicted in figure 4.

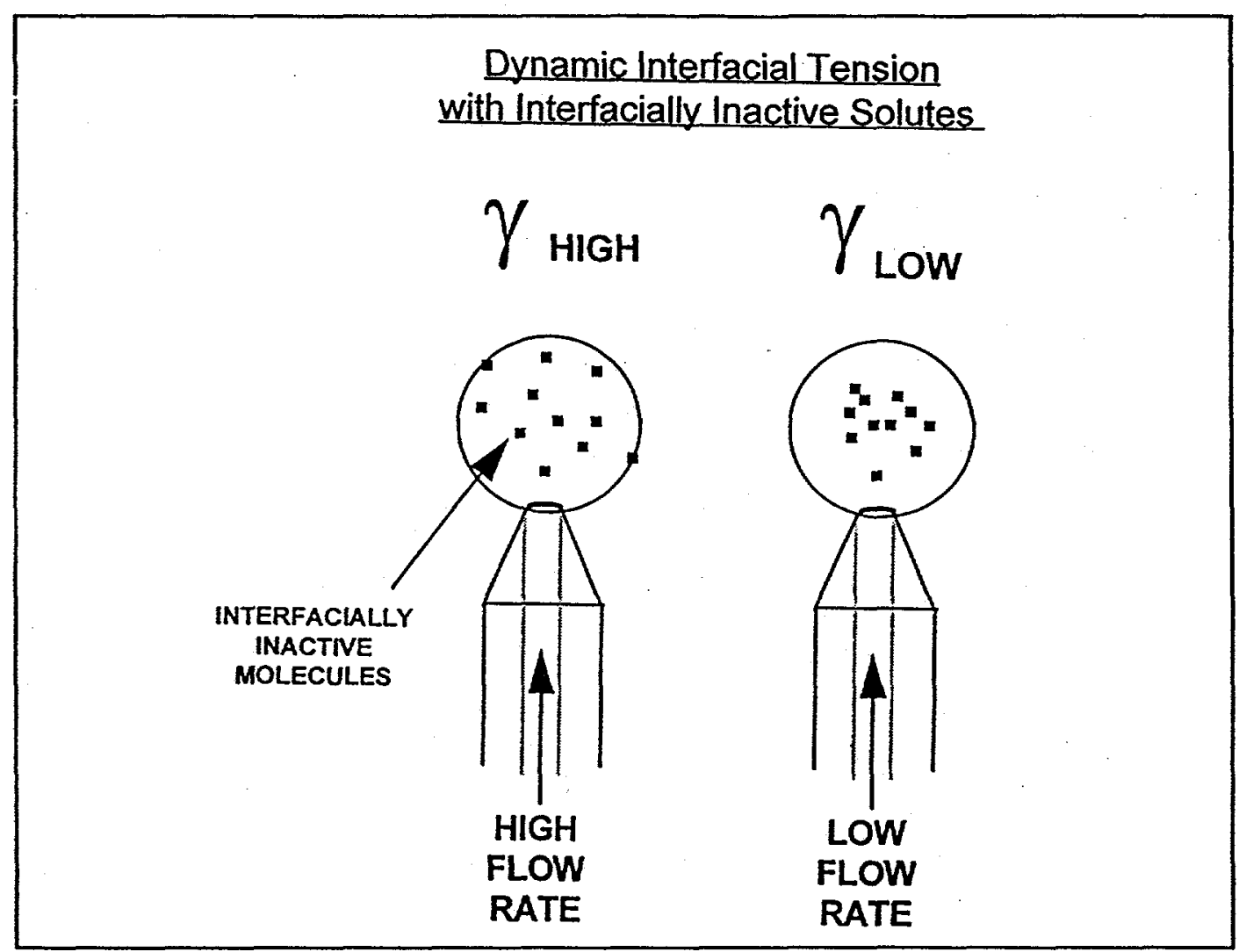

Figure 4

From these explanations two things become evident.

(1) Solutes (including dyes) can either raise or lower the interfacial tension between two liquids depending on whether they are interfacially active or interfacially inactive. 
(2) It is generally true that, whether or not our solutes are interfacially active or interfacially inactive, interfacial tension will decrease with decreasing drop formation rate.

What does this tell us about the dynamic interfacial tension results that we have in figure 2? It tells us two things mainly.

(1) Considering the "pure" PCE data, we see a decrease in interfacial tension with decreasing flow rate, the magnitude of which is approximately $\pm 3.0 \mathrm{mN} / \mathrm{m}$ over the range of flow rates studied. This suggests that there are slight impurities in the PCE.

(2) The data on the dye solutions suggests that the dye is both interfacially active and interfacially inactive. At low dye concentrations $10.00508 \mathrm{~g} / \mathrm{L}, 0.0508 \mathrm{~g} / \mathrm{L}$, and even $0.508 \mathrm{~g} / \mathrm{L}$ ) and high drop formation rates the dye increases the interfacial tension between PCE and water, suggesting that the dye is interfacially inactive. This would correlate with the dye being very hydrophobic. Viewing the samples also suggests that this is the case, because the partitioning of the dye between the PCE and the aqueous phase strongly favors the PCE phase. On the other hand, studies at low drop formation rates and higher dye concentrations $(5.08 \mathrm{~g} / \mathrm{L})$ suggest that the dye is interfacially active, since it lowers the interfacial tension between the PCE and the water.

How can this behavior be explained? Three possible explanations come to my mind.

(1) The dye is not a single molecular species. It is at least a two component species. One component (call it "A") is very hydrophobic and interfacially inactive. It drives the interfacial tension up at high flow rates, because it does not have sufficient time to diffuse away from the developing interface. A second component (call it "B") is interfacially active. It diffuses to developing interfaces (as the drop formation time allows) and decreases interfacial tension.

1 could envision this scenario being the result of the dye having been synthesized by a bi-phase or multi-phase technique, using surfactant-like materials as a stabilizing material for the synthesis. The dye product would then be component " $A$ " with an impurity being the surfactant component " $B$ ". I could also envision the dye being a collection of isomers, each of which might have different interfacial activities. The purity of your dye might perhaps be explored by HPLC. I'd be interested to know what (if any) data you have on the purity of the dye. 
Following the two component scenario a bit further. We can safely assume that component " $A$ " is the more predominate. However, component " $B$ " is strongly driven to replace any component " $A$ " that might be at a developing interface. At dye low concentrations and fast drop formation rates " $A$ " dominates the interface. "B" replaces it as time allows (at lower drop formation times). At higher concentrations (say the $5.08 \mathrm{~g} / \mathrm{L}$ concentration) and fast rates " $A$ " should still dominate the interface, if we could form drops fast enough to see its effect. We have to form drops faster to see the effects of " $A$ " at high dye concentrations because, although the concentration of " $B$ " is only increased proportionately to the concentration of " $A$ " when dye concentration is increased, the amount of available "A" in the bulk of the drop matters less in terms of interfacial tension than does the amount of available " $B$ ". In'our tests at $5.08 \mathrm{~g} / \mathrm{L}$ we did not explore rates which were fast enough to see the effects of "A". At $0.508 \mathrm{~g} / \mathrm{L}$ we did, but just barely.

(2) A second scenario, which could explain the behavior of the dye without going to a two component model, is that the dye molecules have a thermodynamically most stable conformation at an interface that is different than their thermodynamically most stable conformation in the bulk. Such things have been reported for surface active polymeric materials. In this scenario the dye molecules at the interface alter their conformation over time, thus explaining the decrease in interfacial tension with decreasing drop formation rate profiles, and the decreasing interfacial tension with increasing concentration profiles. At high flow rates, a portion of the dye molecules are "caught" in a conformation not conducive to being at the developing interface. Interfacial tension is thus high (even higher than for the pure liquids). At low flow rates, the molecules have time to rearrange to provide for a lowering of interfacial tension.

Alteratively, the dye molecules might also change conformations in the bulk as a function of concentration (possibly taking on a more surface active conformation at high concentrations). This is not overly unusual behavior for molecules which contain chromophores. It could be explored by seeing if the UV and/or FTIR spectra for this dye shift based on concentration.

(3) A third explanation, and the one that I recommend for you to explore first, is that the dye is just interfacially active. It is not inactive, and it does not really increase the interfacial tension between PCE and water. This is what you suspected in the first place, and it does not necessarily mean that the data that we obtained is bad, only that it is misinterpreted.

Remember that the use of Tate's equation requires that values for $\Delta \rho, r$, and $g$ be defined. We have, so far, assumed that the density of each of the dye solutions was $1.62 \mathrm{~g} / \mathrm{cm}^{3}$ (and that the density of each aqueous phase was 
$\left.0.998 \mathrm{~g} / \mathrm{cm}^{3}\right)$. What if this is a bad assumption?

Using this assumption we obtained $52.24 \mathrm{mN} / \mathrm{m}$ as the interfacial tension between the $0.00508 \mathrm{~g} / \mathrm{L}(\mathrm{C} 4)$ solution and water at $5 \mathrm{ml} / \mathrm{hr}$. However, what if PCE with this amount of dye in it has a density of $1.58 \mathrm{~g} / \mathrm{cm}^{3}$ instead of $1.62 \mathrm{~g} / \mathrm{cm}^{3}$ ? I don't think that this is totally unreasonable. The correct interfacial tension for the C4/water system would then be:

$$
52.24 \frac{1.58-0.998}{1.62-.998}=48.9 \mathrm{mN} / \mathrm{m}
$$

This would be very comparable to the "pure" PCE/water value (obtained using $1.62 \mathrm{~g} / \mathrm{cm}^{3}$ as the density) of $48.9 \mathrm{mN} / \mathrm{m}$.

I think you should determine the correct densities for each of your systems, and possibly correct all of the data for density. This might reveal that the dye only acts as an interfacially active solute, thus making it unnecessary to explore scenarios 1 and 2 above. On the other hand, the interfacial contact angle data (reported below) suggests that scenarios 1 and 2 will need to be considered. It implies that low concentrations of dye really do increase the interfacial tension between PCE/water.

\section{Interfacial contact angle tests}

Interfacial contact angle tests were performed using a Krüss Goniometer model G10. For each experiment a drop of perchloroethylene solution was placed on a glass slide which was submerged in water that had been pre-equilibrated with "pure" PCE. The contact angle was measured through the PCE phase as depicted in figure 5 below.

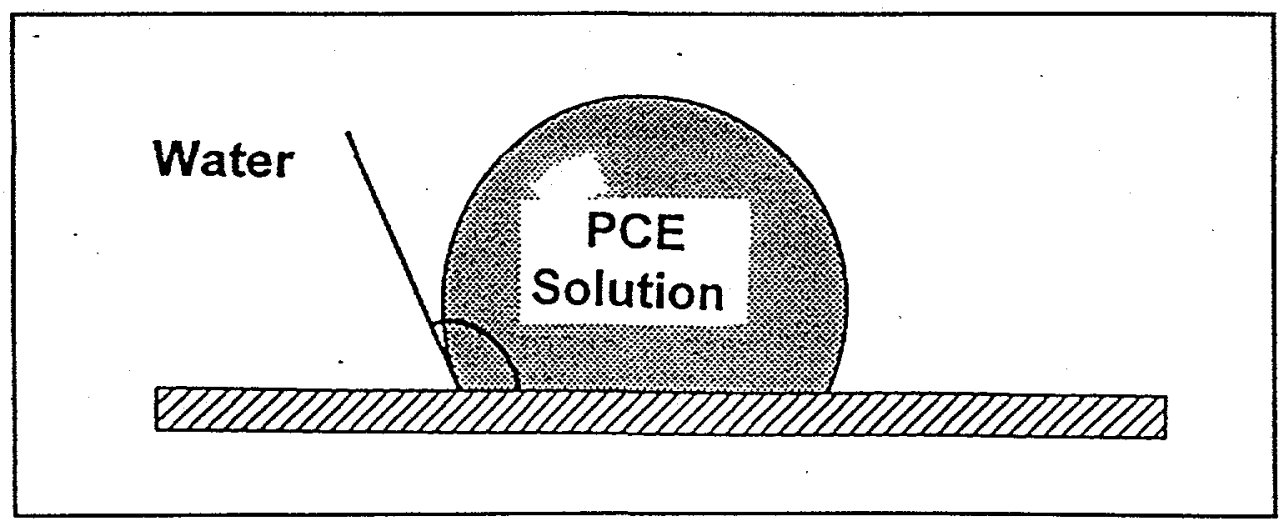

Figure 5 
Seven solutions were tested $\{C 1, C 2, C 3, C 4, P C E, X 1$, and $X 2\}$. The contact angle values obtained were:

Solution

PCE

C4

C3

$\mathrm{C} 2$

$\mathrm{X} 1$

$\mathrm{X} 2$

C1
Dye Concentration

0

$0.00508 \mathrm{~g} / \mathrm{L}$

$0.0508 \quad \mathrm{~g} / \mathrm{L}$

$0.508 \quad \mathrm{~g} / \mathrm{L}$

$1.27 \quad \mathrm{~g} / \mathrm{L}$

$1.69 \mathrm{~g} / \mathrm{L}$

5.08

Contact Angle

$122^{\circ} \pm 3^{\circ}$

$139^{\circ} \pm 3^{\circ}$

$129^{\circ} \pm 3^{\circ}$

$133^{\circ} \pm 3^{\circ}$

$110^{\circ} \pm 3^{\circ}$

$105^{\circ} \pm 3^{\circ}$

$87^{\circ} \pm 3^{\circ}$

This data is also plotted in figure 6.

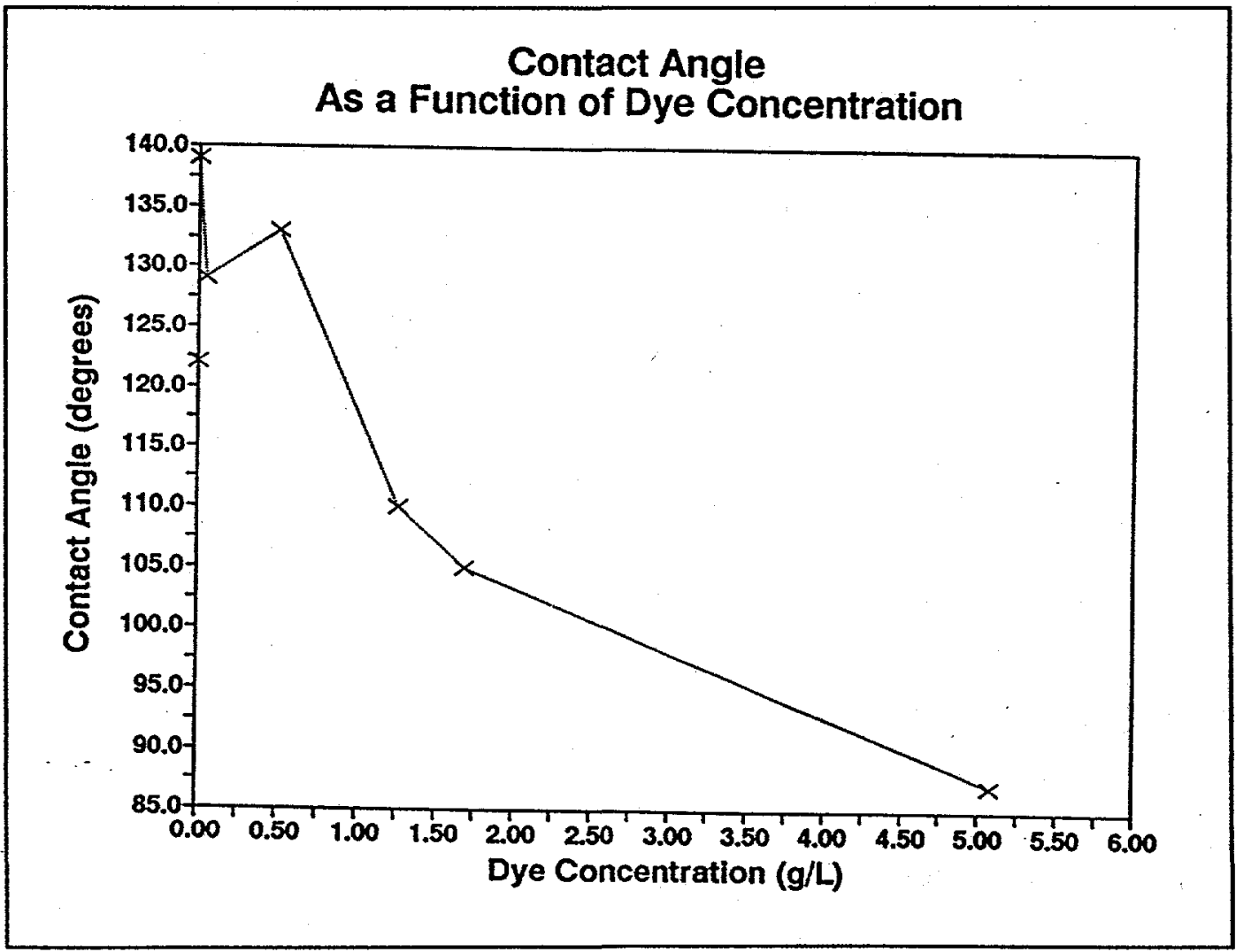

Figure 6 
The interfacial contact angle reflects the ability (or lack there of) of the PCE to spontaneously displace water from a glass surface. Angles less than $90^{\circ}$ indicate that the displacement is spontaneous. Angles greater than $90^{\circ}$ indicate that the displacement will not occur without energy input.

That the interfacial contact angle is greater for low dye concentrations than it is for PCE alone, suggests that the dye is making the PCE less able to wet the glass at low concentrations. At high dye concentrations the PCE/dye solutions become morecapable of wetting the glass than the PCE alone is. This is very reminiscent of the drop volume data for these solutions at say $5 \mathrm{ml} / \mathrm{hr}$, wherein low concentrations of dye increased interfacial tension while high concentrations of dye decreased it.

\section{Spinning drop data}

We also determined the interfacial tensions between four two phase systems containing Dowfax C6L, PCE, and water. The Dowfax concentration was altered throughout the series. For this work a Krûss Spinning Drop Tensiometer SITEO4 was used. The principle of spinning drop tensiometry is that if two immiscible liquids are spun in a capillary with the more dense phase being continuous and the less dense phase present as a droplet, then the droplet will become elliptical within the capillary. If this procedure is carried out such that the long radius of the droplet is at least four times the short radius, and the droplet does not touch the capillary walls, then the interfacial tension between the two liquids can be calculated from:

$$
\sigma=\frac{r^{3} \Delta \rho \omega^{2}}{4}
$$

wherein $r=$ the short radius of the drop, $\Delta \rho=$ the difference in density between the two liquids, and $\approx=$ the angular velocity of the spin.

The following data was obtained on the Dowfax systems:

\begin{tabular}{lccc}
$\begin{array}{l}\text { Dowfax } \\
\text { Concentration }\end{array}$ & $\begin{array}{c}\text { Spin Velocity } \\
(\mathrm{rpm})\end{array}$ & $\begin{array}{c}\text { Drop Diameter } \\
\text { (eyepiece units) }\end{array}$ & $\begin{array}{c}\text { Interfacial Tension } \\
(\mathrm{mN} / \mathrm{m})\end{array}$ \\
\cline { 5 - 5 } & 5520 & 1.25 & \\
$23 \%$ & 6922 & 1.11 & $0.81 \mathrm{mN} / \mathrm{m}$ \\
$23 \%$ & 3820 & 1.60 & $0.89 \mathrm{mN} / \mathrm{m}$ \\
$23 \%$ & 4446 & 1.42 & $0.81 \mathrm{mN} / \mathrm{m}$ \\
$23 \%$ & 2499 & 2.09 & $0.77 \mathrm{mN} / \mathrm{m}$ \\
23 & & & $0.78 \mathrm{mN} / \mathrm{m}$
\end{tabular}




$\begin{array}{llll}9.14 \% & 4445 & 1.47 & 0.85 \mathrm{mN} / \mathrm{m} \\ 9.14 \% & 5335 & 1.31 & 0.87 \mathrm{mN} / \mathrm{m} \\ 9.14 \% & 6935 & 1.11 & 0.90 \mathrm{mN} / \mathrm{m} \\ 9.14 \% & 4580 & 1.41 & 0.80 \mathrm{mN} / \mathrm{m} \\ 9.14 \% & 5556 & 1.27 & 0.86 \mathrm{mN} / \mathrm{m} \\ & & & \\ 4.57 \% & 4544 & 1.65 & 1.26 \mathrm{mN} / \mathrm{m} \\ 4.57 \% & 5635 & 1.50 & 1.46 \mathrm{mN} / \mathrm{m} \\ 4.57 \% & 4773 & 1.57 & 1.20 \mathrm{mN} / \mathrm{m} \\ 4.57 \% & 7038 & 1.25 & 1.32 \mathrm{mN} / \mathrm{m} \\ 4.57 \% & 3521 & 1.97 & 1.29 \mathrm{mN} / \mathrm{m} \\ 1.828 \% & & & \\ 1.828 \% & 4426 & 1.95 & 1.98 \mathrm{mN} / \mathrm{m} \\ 1.828 \% & 5010 & 1.83 & 2.09 \mathrm{mN} / \mathrm{m} \\ 1.828 \% & 7123 & 1.50 & 2.33 \mathrm{mN} / \mathrm{m} \\ 1.828 \% & 6289 & 1.57 & 2.08 \mathrm{mN} / \mathrm{m} \\ & 7766 & 1.35 & 2.02 \mathrm{mN} / \mathrm{m}\end{array}$

In general, the interfacial tension decreases with increasing Dowfax concentration as would be expected.

\section{DuNouy ring method}

One other set of interfacial tension experiments which were performed were DuNouy ring tests on the "pure" PCE/water system. For these experiments a Krüss Processor Tensiometer $\mathrm{K} 12$ was used. The ring used was constructed of a platinum alloy. Both the push and the pull methods were explored.

We found that it was difficult to tell if the ring was better wetted by water or PCE. We obtained some data from both the push and the pull method, which suggested that the interfacial tension between the two phases was approximately $30 \mathrm{mN} / \mathrm{m}$ and decreased with time. This data was not well understood. However, it was thought that ring wetting problems existed. The unusually high density difference between the two phases might also have been a contributing factor to the wetting problem.

\section{$\underline{\text { Reference }}$}

1. Tate, T.; Phil. Mag., 27, 176, (1864).

$$
\begin{aligned}
& \begin{array}{c}
\text { Virgingas Weathers } \\
\text { head . F ref. }
\end{array} \\
& h H_{p}: \text { Il www. sc.edu } \\
& \text { Philosophical Magazine } \\
& \text { uSC- Thomes Cupor Lil. back to } 1840
\end{aligned}
$$


Date Data Collected: November 14, 1995

Experiment Title: pcelwater

Experimenter: chris

Comments :

\section{PARAMETERS}

Continuous Phase Density: $1.620 \mathrm{~g} / \mathrm{CC}$

Dispersed Phase Density: $0.998 \mathrm{~g} / \mathrm{cc}$

Orifice Diameter:

Syringe Diameter:

Flow Rate:

Drop Limit:

$0.0254 \mathrm{~cm}$

$2.3000 \mathrm{~cm}$

$5.000 \mathrm{~mL} /$ hour

10

DATA

Drop \# Drop Time (seconds)

Total Time (seconds)

1

4.250

4.250

4.570

8.820

4.560

13.390

4.620

18.000

4.670

22.670

4.550

27.220

4.780

32.000

4.660

36.660

4.790

41.450

Drop Volume

$(\mu \mathrm{L})$

5.900

6.350

6.330

6.410

6.490

6.320

6.640

6.470

Interfacial Tension $(\mathrm{mN} / \mathrm{m})$

45.091

48.539

48.380

48.963

49.547

48.274

50.714

49.441

6.650

50.820

10

4.720

46.170

6.560

50.077

Average Drop Volume:

Mean Interfacial Tension:

$6.413 \mu \mathrm{L}$

Final Standard Deviation:

$48.985 \mathrm{mN} / \mathrm{m}$

Relative Standard Deviation:

$+/-1.643 \mathrm{mN} / \mathrm{m}$

$12: 31: 39 \mathrm{PM}$

$11 / 22 / 95$

PCE into $\mathrm{H}_{2} \mathrm{O}$

$5 m / / H R$ 
Date Data Collected: November 14, 1995

Experiment Title: pcelwater

Experimenter: chris

Comments :

PARAMETERS

Continuous Phase Density: $1.620 \mathrm{~g} / \mathrm{CC}$

Dispersed Phase Density:

Orifice Diameter:

$0.998 \mathrm{~g} / \mathrm{CC}$

Syringe Diameter:

$0.0254 \mathrm{~cm}$

Flow Rate:

Drop Limit:

$2.3000 \mathrm{~cm}$

$2.000 \mathrm{~mL} /$ hour

10

DATA

Drop

1

Drop Time (seconds)

11.350

11.210

11.260

11.530

11.220

11.710

11.290

11.630

11.330

11.490
Total Time (seconds)

11.350

22.560

33.820

45.350

56.560

68.270

79.550

91.180

102.510

114.000
Drop Volume $(\mu \mathrm{L})$

6.310

6.230

6.260

6.410

6.230

6.500

6.270

6.460

6.290

6.380
Interfacial Tension $(\mathrm{mN} / \mathrm{m})$

48.168

47.552

47.786

48.932

47.595

49.674

47.892

49.335

48.083

48.762

Average Drop Volume:

Mean Interfacial Tension:

$6.333 \mu \mathrm{L}$

Final Standard Deviation: $+/-0.750 \mathrm{mN} / \mathrm{m}$

Relative Standard Deviation: $1.550 \%$

$12: 39: 14$ PM

$11 / 22 / 95$

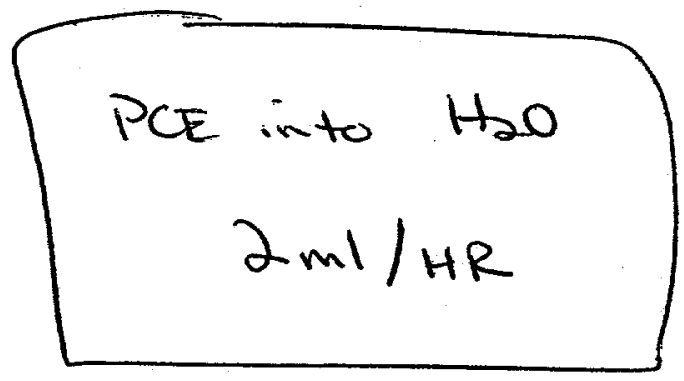


Date Data Collected: November 14, 1995

Experiment Title: pcelwater

Experimenter: chris

Comments :

PARAMETERS

Continuous Phase Density: $1.620 \mathrm{~g} / \mathrm{CC}$

Dispersed Phase Density:

Orifice Diameter:

$0.998 \mathrm{~g} / \mathrm{CC}$

Syringe Diameter:

$0.0254 \mathrm{~cm}$

$2.3000 \mathrm{~cm}$

Flow Rate:

Drop Limit:

$1.000 \mathrm{~mL} /$ hour

10

DATA

Drop \# Drop Time (seconds)

1

2

3

4

5

6

7

8

9

10
22.030

23.000

21.910

22.860

22.160

22.130

22.760

22.040

22.800

21.930
Total Time (seconds)

22.030

45.030

66.940

89.800

111.950

134.080

156.850

178.890

201.690

223.610
Drop Volume $(\mu \mathrm{L})$

6.120

6.390

6.090

6.350

6.150

6.150

6.320

6.120

6.330

6.090
Interfacial Tension $(\mathrm{mN} / \mathrm{m})$

46.746

48.804

46.491

48.497

47.011

46.958

48.306

46.778

48.369

46.523

Average Drop Volume:

Mean Interfacial Tension:

$6.211 \mu \mathrm{L}$

Final Standard Deviation: $+/-0.923 \mathrm{mN} / \mathrm{m}$

Relative standard Deviation: $1.945 \%$

$12: 40: 06 \mathrm{PM} \quad 11 / 22 / 95$

PCE into Ho

$\operatorname{Im} / / a r$ 
Date Data Collected: November 14, 1995

Experiment Title: pcelwater

Experimenter: chris

Comments :

PARAMETERS

Continuous Phase Density: $1.620 \mathrm{~g} / \mathrm{CC}$

Dispersed Phase Density: $0.998 \mathrm{~g} / \mathrm{CC}$

Orifice Diameter:

$0.0254 \mathrm{~cm}$

Syringe Diameter:

Flow Rate:

Drop Limit:

$2.3000 \mathrm{~cm}$

$0.500 \mathrm{~mL} /$ hour

10

DATA

Drop \#

Drop Time (seconds)

1

2

3

4

5

6

7

8

9

10
43.710

41.500

42.800

43.220

42.430

43.800

43.120

43.290

44.700

43.950
Total Time

(seconds)

43.710

85.200

128.000

171.230

213.660

257.460

300.570

343.860

388.560

432.520
Drop Volume $(\mu \mathrm{L})$

6.070

5.760

5.940

6.000

5.890

6.080

5.990

6.010

6.210

6.100
Interfacial Tension $(\mathrm{mN} / \mathrm{m})$

46.369

44.025

45.409

45.860

45.017

46.470

45.743

45.929

47.425

46.635

Average Drop Volume:

Mean Interfacial Tension:

$6.007 \mu \mathrm{L}$

Final Standard Deviation:

$45.888 \mathrm{mN} / \mathrm{m}$

Relative Standard Deviation:

$+1-$

$0.941 \mathrm{mN} / \mathrm{m}$

$12: 40: 49 \mathrm{PM}$

$11 / 22 / 95$

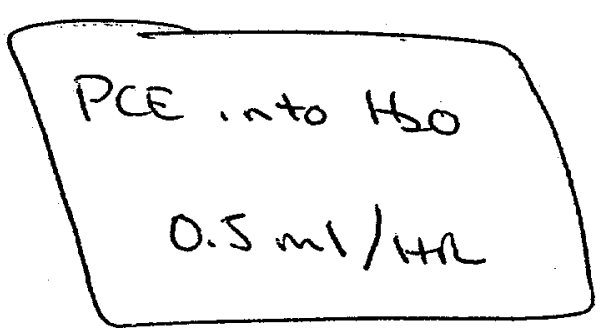


Date Data Collected: November 14, 1995

Experiment Title: pcelwater

Experimenter: chris

Comments :

PARAMETERS

Continuous Phase Density: $1.620 \mathrm{~g} / \mathrm{cC}$

Dispersed Phase Density: $0.998 \mathrm{~g} / \mathrm{CC}$

Orifice Diameter:

Syringe Diameter:

Flow Rate:

Drop Limit:

$0.0254 \mathrm{~cm}$

$2.3000 \mathrm{~cm}$

$0.250 \mathrm{~mL} /$ hour

10

DATA

$\begin{array}{cr}\text { Drop \# } & \begin{array}{r}\text { Drop Time } \\ \text { (seconds) }\end{array} \\ 1 & 85.690 \\ 2 & 85.470 \\ 3 & 85.360 \\ 4 & 86.510 \\ 5 & 86.010 \\ 6 & 87.460 \\ 7 & 86.890 \\ 8 & 86.000 \\ 9 & 87.460 \\ 10 & 88.270\end{array}$

Total Time (seconds)

85.690

171.160

256.520

343.030

429.030

516.490

603.380

689.370

776.830

865.110
Drop Volume $(\mu \mathrm{L})$

5.950

5.940

5.930

6.010

5.970

6.070

6.030

5.970

6.070

6.130
Interfacial Tension $(\mathrm{mN} / \mathrm{m})$ 45.457

45.340

45.282

45.889

45.624

46.393

46.094

45.619

46.396

46.828

Average Drop Volume:

$6.008 \mu \mathrm{L}$

Mean Interfacial Tension: $45.892 \mathrm{mN} / \mathrm{m}$

Final Standard Deviation: $+/-0.520 \mathrm{mN} / \mathrm{m}$

Relative Standard Deviation: $1.133 \%$

$12: 41: 47 \mathrm{PM} \quad 11 / 22 / 95$

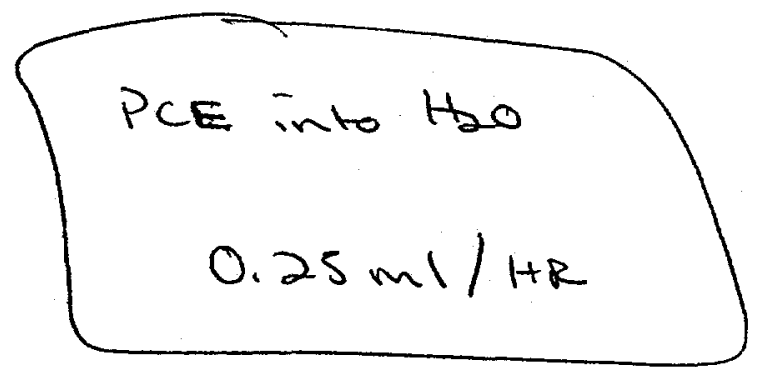


Date Data Collected: November 14, 1995

Experiment Title: npcelwater

Experimenter: chris

Comments :

PARAMETERS

Continuous Phase Density: $1.620 \mathrm{~g} / \mathrm{CC}$

Dispersed Phase Density: $0.998 \mathrm{~g} / \mathrm{CC}$

Orifice Diameter:

Syringe Diameter:

$0.0254 \mathrm{~cm}$

Flow Rate:

Drop Limit:

$2.3000 \mathrm{~cm}$

$5.000 \mathrm{~mL} / \mathrm{hour}$

10

DATA

Drop \# Drop Time Total Time (seconds)

1

5.040

2

4.970

5.040

4.920

10.010

5.010

14.930

4.950

19.940

5.070

24.890

5.010

29.960

5.000

34.970

Drop Volume

$(\mu \mathrm{L})$

7.000

6.900

6.830

6.960

6.880

7.050

6.950

6.940
Interfacial Tension $(\mathrm{mN} / \mathrm{m})$

53.473

52.677

52.199

53.154

52.518

53.844

53.101

53.048

Average Drop Volume:

Mean Interfacial Tension:

$6.938 \mu \mathrm{L}$

Final Standard Deviation:

$53.002 \mathrm{mN} / \mathrm{m}$

Relative Standard Deviation:

$+/-0.528 \mathrm{mN} / \mathrm{m}$

$11: 16: 11 \mathrm{AM} \quad 11 / 22 / 95$

$$
\begin{aligned}
& \text { PCE } C_{4}=0.00508 \mathrm{gll} \text { DYE SOLUTION } \\
& 5 m / / 1+R
\end{aligned}
$$


Date Data Collected: November 14, 1995

Experiment Title: npcelwater

Experimenter: chris

Comments :

PARAMETERS

Continuous Phase Density: $1.620 \mathrm{~g} / \mathrm{CC}$

Dispersed Phase Density: $0.998 \mathrm{~g} / \mathrm{cC}$

Orifice Diameter:

Syringe Diameter:

$0.0254 \mathrm{~cm}$

Flow. Rate:

Drop Limit:

$2.3000 \mathrm{~cm}$

$5.000 \mathrm{~mL} /$ hour

10

DATA

Drop \# Drop Time Total Time (seconds)

1

2

3

4

5

6

7

8

9

10
5.110

4.760

5.100

5.020

4.820

4.930

4.860

4.840

5.020
4.780
5.110

9.870

14.970

19.760

24.770

29.590

34.520

39.380

44.220

49.240 (seconds)
Drop Volume ( $\mu \mathrm{L})$

7.100

6.610

7.080

6.650

6.970

6.690

6.850

6.750

6.720

6.980
Interfacial Tension $(\mathrm{mN} / \mathrm{m})$

54.215

50.502

54.109

50.767

53.207

51.085

52.305

51.563

51.351

53.313

Average Drop Volume:

$6.839 \mu \mathrm{L}$

Mean Interfacial Tension:

Final Standard Deviation:

$52.242 \mathrm{mN} / \mathrm{m}$

Relative Standard Deviation: $2.651 \%$

$11 / 22 / 95$

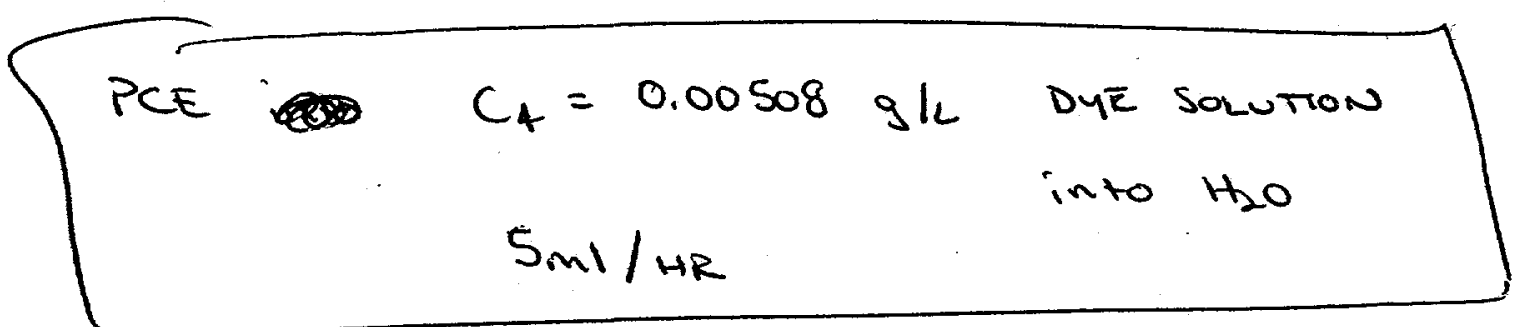


Date Data Collected: November 14, 1995

Experiment Title: npcelwater

Experimenter: chris

Comments:

PARAMETERS

Continuous Phase Density: $1.620 \mathrm{~g} / \mathrm{CC}$

Dispersed Phase Density: $0.998 \mathrm{~g} / \mathrm{CC}$

Orifice Diameter: $\quad 0.0254 \mathrm{~cm}$

Syringe Diameter: $\quad 2.3000 \mathrm{~cm}$

Flow Rate:

Drop Limit:

$2.000 \mathrm{~mL} / \mathrm{hour}$

10

DATA

$\begin{array}{crrrr}\text { Drop \# } & \begin{array}{r}\text { Drop Time } \\ \text { (seconds) }\end{array} & \begin{array}{r}\text { Total Time } \\ \text { (seconds) }\end{array} & \begin{array}{c}\text { Drop Volume } \\ (\mu \mathrm{L})\end{array} & \begin{array}{r}\text { Interfacial } \\ (\mathrm{mN} / \mathrm{m})\end{array} \\ 1 & 12.380 & 12.380 & 6.880 & 52.539 \\ 2 & 12.450 & 24.830 & 6.920 & 52.836 \\ 3 & 12.540 & 37.370 & 6.960 & 53.197 \\ 4 & 12.380 & 49.750 & 6.880 & 52.539 \\ 5 & 12.600 & 62.340 & 7.000 & 53.451 \\ 6 & 12.440 & 74.780 & 6.910 & 52.794 \\ 7 & 12.500 & 87.280 & 6.940 & 53.048 \\ 8 & 12.550 & 99.830 & 6.970 & 53.239 \\ 9 & 12.260 & 112.080 & 6.810 & 52.008 \\ 10 & 12.660 & 124.740 & 7.030 & 53.706\end{array}$

Average Drop Volume: $6.930 \mu \mathrm{L}$

Mean Interfacial Tension: $\quad 52.936 \mathrm{mN} / \mathrm{m}$

Final Standard Deviation: $+/-0.499 \mathrm{mN} / \mathrm{m}$

Relative Standard Deviation: $0.942 \%$

$12: 28: 25 \mathrm{PM}$

$11 / 22 / 95$

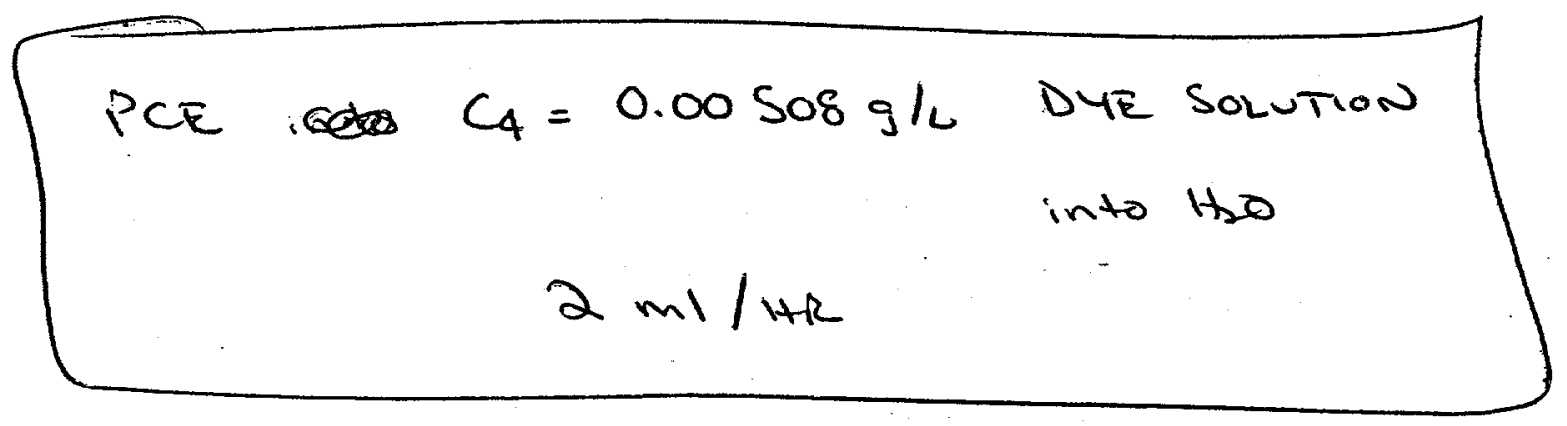


Date Data Collected: November 14, 1995

Experiment Title: npcelwater

Experimenter: chris

Comments:

PARAMETERS

Continuous Phase Density: $1.620 \mathrm{~g} / \mathrm{CC}$

Dispersed Phase Density: $0.998 \mathrm{~g} / \mathrm{CC}$

Orifice Diameter:

$0.0254 \mathrm{~cm}$

Syringe Diameter:

$2.3000 \mathrm{~cm}$

Flow Rate:

Drop Limit:

$1.000 \mathrm{~mL} /$ hour

10

DATA

Drop \#

1

2

3

4

5

6

7

8

9

10
Drop Time (seconds)

24.860

24.650

24.620

25.360

24.170

25.070

24.410

24.750

24.510

24.730
Total Time

(seconds)

24.860

49.510

74.130

99.490

123.660

148.730

173.140

197.890

222.400

247.130
Drop Volume

$(\mu \mathrm{L})$

6.900

6.850

6.840

7.040

6.710

6.960

6.780

6.880

6.810

6.870
Interfacial Tension $(\mathrm{mN} / \mathrm{m})$

52.740

52.305

52.252

53.812

51.287

53.197

51.786

52.518

52.008

52.475

Average Drop Volume:

Mean Interfacial Tension:

$6.865 \mu \mathrm{L}$

Final Standard Deviation: $+/-0.711 \mathrm{mN} / \mathrm{m}$

Relative Standard Deviation: $1.356 \%$

$12: 29: 12 \mathrm{PM}$

$11 / 22 / 95$

\section{PCE $\begin{aligned} C_{4} & =0.00508 \\ & I_{\mathrm{ml}} / \mathrm{H}\end{aligned}$}


Date Data Collected: November 14, 1995

Experiment Title: npcelwater

Experimenter: chris

Comments :

PARAMETERS

Continuous Phase Density: $1.620 \mathrm{~g} / \mathrm{CC}$

Dispersed Phase Density: $0.998 \mathrm{~g} / \mathrm{CC}$

Orifice Diameter: $\quad 0.0254 \mathrm{~cm}$

Syringe Diameter: $\quad 2.3000 \mathrm{~cm}$

Flow Rate: $\quad 0.500 \mathrm{~mL} /$ hour

Drop Limit:

10

DATA

$\begin{array}{crrcc}\text { Drop \# } & \begin{array}{r}\text { Drop Time } \\ \text { (seconds) }\end{array} & \begin{array}{r}\text { Total Time } \\ \text { (seconds) }\end{array} & \begin{array}{c}\text { Drop Volume } \\ (\mu \mathrm{L})\end{array} & \begin{array}{c}\text { Interfacial Tension } \\ (\mathrm{mN} / \mathrm{m})\end{array} \\ 1 & 24.860 & 24.860 & 6.900 & 52.740 \\ 2 & 24.650 & 49.510 & 6.850 & 52.305 \\ 3 & 24.620 & 74.130 & 6.840 & 52.252 \\ 4 & 25.360 & 99.490 & 7.040 & 53.812 \\ 5 & 24.170 & 123.660 & 6.710 & 51.287 \\ 6 & 25.070 & 148.730 & 6.960 & 53.197 \\ 7 & 24.410 & 173.140 & 6.780 & 51.786 \\ 8 & 24.750 & 197.890 & 6.880 & 52.518 \\ 9 & 24.510 & 222.400 & 6.810 & 52.008 \\ 10 & 24.730 & 247.130 & 6.870 & 52.475\end{array}$

Average Drop Volume: $\quad 6.865 \mu \mathrm{L}$

Mean Interfacial Tension: $\quad 52.438 \mathrm{mN} / \mathrm{m}$

Final Standard Deviation: $+/-0.711 \mathrm{mN} / \mathrm{m}$

Relative Standard Deviation: $1.356 \%$

$12: 30: 15 \mathrm{PM}$

$11 / 22 / 95$

This data was not correct.

The next page counts. I 
- haj 10.0s tRAM KRUSS USA

TO

18037257673 P. 12

Date Data Collected: November 14, 1995

Experiment Title: npcelwater

Experimenter: chris

Comments:

PARAMETERS

Continuous Phase Density: $1.620 \mathrm{~g} / \mathrm{cc}$

Dispersed Phase Density: $0.998 \mathrm{~g} / \mathrm{Cc}$

Orifice Diameter:

Syringe Diameter:

Flow Rate:

$0.0254 \mathrm{~cm}$

Drop Limit:

$2.3000 \mathrm{~cm}$

$0.500 \mathrm{~mL} /$ hour

DATA

Drop

$\begin{array}{ll}1 & 49.630 \\ 2 & 49.320 \\ 3 & 49.250 \\ 4 & 49.830 \\ 5 & 48.860 \\ 6 & 50.120 \\ 7 & 49.200 \\ 8 & 49.210 \\ 9 & 49.990 \\ 10 & 49.460\end{array}$

Total Time (seconds)

49.630

98.950

148.200

198.030

246.890

297.010

346.210

395.420

445.410

494.870
Drop Volume

$(\mu \mathrm{L})$

6.920

6.850

6.840

6.920

6.930

6.960

6.830

6.830

6.940

6.870
Interfacial Tension $(\mathrm{mN} / \mathrm{m})$

52.645

52.326

52.263

52.249

51.839

53.176

52.927

52.210

53.037

52.475

$\begin{array}{ll}\text { Average Drop Volume: } & 6.889 \mu \mathrm{L} \\ \text { Mean Interfacial Tension: } & 52.515 \mathrm{mN} / \mathrm{m}\end{array}$

Final Standard Deviation: $+/=0.402 \mathrm{mN} / \mathrm{m}$

Relative Standard Deviation: $0.765 \%$

$15: 57: 48$

$3 / 27 / 97$

PE CH $=0.00508 \mathrm{~g} / \mathrm{L}$ DYE SOLuTion

InTO WATER

$0.5 \mathrm{ml} / \mathrm{Hz}$

Correct results for this run

received by FAX from Kris USA $3 / 27 / 97$ 
Date Data Collected: November 14, 1995

Experiment Title: npcelwater

Experimenter: chris

Comments :

PARAMETERS

Continuous Phase Density: $1.620 \mathrm{~g} / \mathrm{CC}$

Dispersed Phase Density: $0.998 \mathrm{~g} / \mathrm{CC}$

Orifice Diameter:

$0.0254 \mathrm{~cm}$

Syringe Diameter:

$2.3000 \mathrm{~cm}$

Flow Rate:

Drop Limit:

$0.250 \mathrm{~mL} /$ hour

10

DATA

$\begin{array}{cr}\text { Drop \# } & \begin{array}{r}\text { Drop Time } \\ \text { (seconds) }\end{array} \\ 1 & 93.530 \\ 2 & 91.990 \\ 3 & 91.700 \\ 4 & 89.830 \\ 5 & 91.180 \\ 6 & 90.760 \\ 7 & 92.650 \\ 8 & 90.880 \\ 9 & 93.710 \\ 10 & 92.460\end{array}$

Total Time (seconds)

93.530

185.520

277.220

367.050

458.230

548.980

641.640

732.520

826.220

918.680
Drop Volume $(\mu \mathrm{L})$

6.490

6.390

6.370

6.240

6.330

6.300

6.430

6.310

6.510

6.420
Interfacial Tension $(\mathrm{mN} / \mathrm{m})$

49.613

48.799

48.645

47.653

48.369

48.144

49.152

48.210

49.709

49.051

Average Drop Volume:

Mean Interfacial Tension:

$6.380 \mu \mathrm{L}$

Final Standard Deviation:

$48.735 \mathrm{mN} / \mathrm{m}$

$12: 30: 46$ PM $11 / 22 / 95$

PCE $C_{4}=0.00508 \mathrm{~g} / \mathrm{L}$ DYE SOLN.

$0.250 \mathrm{~m} / \mathrm{HR}$ into Hoo 
Date Data Collected: November 14, 1995

Experiment Title: npcelwater

Experimenter: chris

Comments :

PARAMETERS

Continuous Phase Density: $1.620 \mathrm{~g} / \mathrm{CC}$

Dispersed Phase Density: $0.998 \mathrm{~g} / \mathrm{CC}$

Orifice Diameter: $\quad 0.0254 \mathrm{~cm}$

Syringe Diameter: $\quad 2.3000 \mathrm{~cm}$

Flow Rate: $\quad 0.100 \mathrm{~mL} /$ hour

Drop Limit:

10

DATA

$\begin{array}{ccccc}\text { Drop \# } & \begin{array}{c}\text { Drop Time } \\ \text { (seconds) }\end{array} & \begin{array}{c}\text { Total Time } \\ \text { (seconds) }\end{array} & \begin{array}{c}\text { Drop Volume } \\ (\mu \mathrm{L})\end{array} & \begin{array}{c}\text { Interfacial } \\ (\mathrm{mN} / \mathrm{m})\end{array} \\ 1 & 197.730 & 197.730 & 5.490 & 41.957 \\ 2 & 177.100 & 374.830 & 4.920 & 37.579 \\ 3 & 177.830 & 552.660 & 4.940 & 37.733 \\ 4 & 181.900 & 734.550 & 5.050 & 38.597 \\ 5 & 186.070 & 920.620 & 5.170 & 39.482 \\ 6 & 193.300 & 1113.920 & 5.370 & 41.017 \\ 7 & 194.940 & 1308.860 & 5.420 & 41.366 \\ 8 & 187.380 & 1496.240 & 5.210 & 39.761 \\ 9 & 192.820 & 1689.060 & 5.360 & 40.914 \\ 10 & 197.180 & 1886.240 & 5.480 & 41.840\end{array}$

Average Drop Volume: $5.240 \mu \mathrm{L}$

Mean Interfacial Tension: $\quad 40.025 \mathrm{mN} / \mathrm{m}$

Final Standard Deviation: + $/-1.641 \mathrm{mN} / \mathrm{m}$

Relative Standard Deviation: $4.100 \%$

$11: 13: 41 \mathrm{AM}$

$11 / 22 / 95$

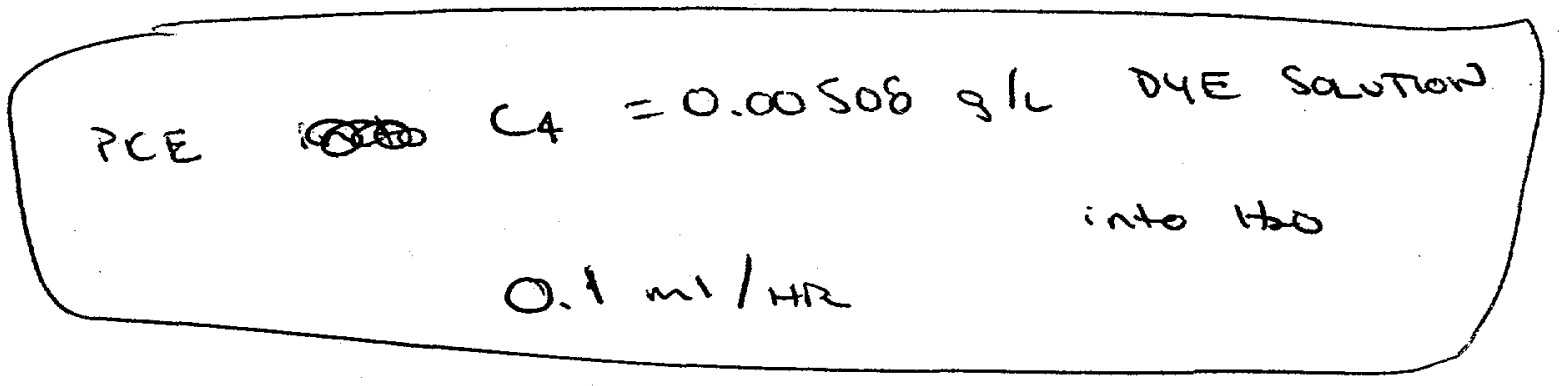


Date Data Collected: November 14, 1995

Experiment Title: npcelwater

Experimenter: chris

Comments :

PARAMETERS

Continuous Phase Density: $1.620 \mathrm{~g} / \mathrm{cc}$

Dispersed Phase Density: $0.998 \mathrm{~g} / \mathrm{cc}$

Orifice Diameter:

$0.0254 \mathrm{~cm}$

Syringe Diameter:

$2.3000 \mathrm{~cm}$

Flow Rate:

Drop Limit:

$0.050 \mathrm{~mL} /$ hour

10

DATA

Drop \#

$$
\begin{gathered}
\text { Drop Time } \\
\text { (seconds) }
\end{gathered}
$$

Total Time (seconds)

420.830

817.910

1184.470

1547.990

1916.390
Drop Volume $(\mu \mathrm{L})$

5.840

5.520

5.090

5.050

5.120
Interfacial Tension $(\mathrm{mN} / \mathrm{m})$

44.648

42.129

38.891

38.569

39.086

Average Drop Volume:

Mean Interfacial Tension:

Final Standard Deviation:

$5.323 \mu \mathrm{L}$

$40.664 \mathrm{mN} / \mathrm{m}$

Relative Standard Deviation:

$2.648 \mathrm{mN} / \mathrm{m}$

$11: 14: 36$ AM

$11 / 22 / 95$

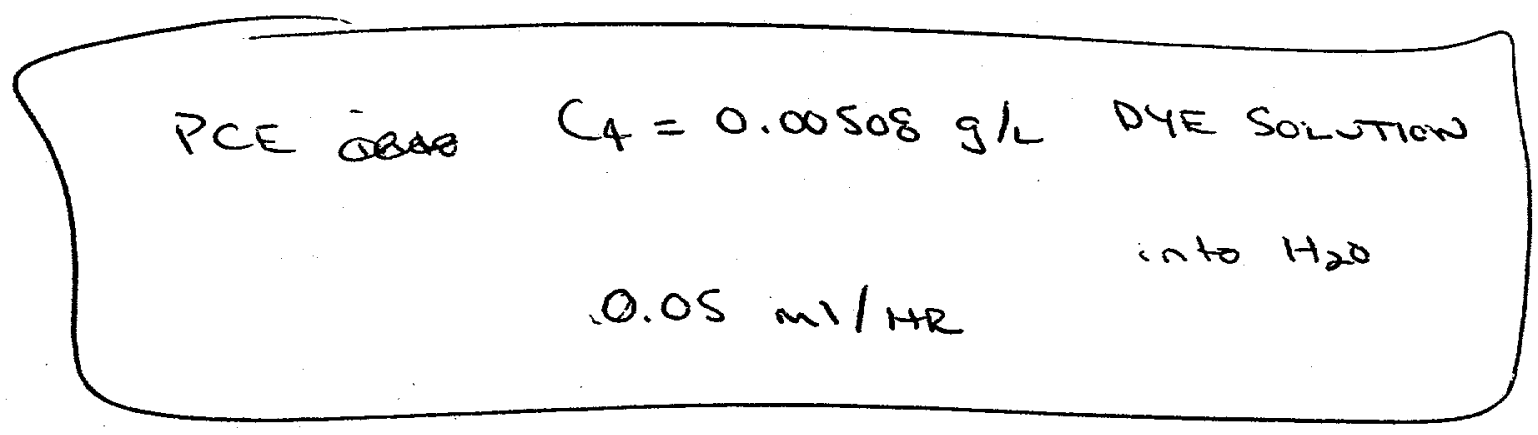


Date Data Collected: November 14, 1995

Experiment Title:

Experimenter:

Comments:

PARAMETERS

Continuous Phase Density: $1.620 \mathrm{~g} / \mathrm{CC}$

Dispersed Phase Density: $0.998 \mathrm{~g} / \mathrm{CC}$

Orifice Diameter:

$0.0254 \mathrm{~cm}$

Syringe Diameter:

$2.3000 \mathrm{~cm}$

Flow Rate:

Drop Limit:

$5.000 \mathrm{~mL} /$ hour

10

DATA

Drop \# Drop Time

$\begin{array}{lc} & \text { (seconds) } \\ 1 & 3.520 \\ 2 & 3.530 \\ 3 & 3.530 \\ 4 & 3.510 \\ 5 & 3.540 \\ 6 & 3.610 \\ 7 & 3.520 \\ 8 & 3.500 \\ 9 & 3.480 \\ 10 & 3.490\end{array}$

Total Time

(seconds)

3.520

7.050

10.580

14.090

17.620

21.230

24.750

28.250

31.730

35.220
Drop Volume $(\mu \mathrm{L})$

4.880

4.900

4.900

4.880

4.910

5.010

4.900

4.850

4.830

4.850
Interfacial Tension $(\mathrm{mN} / \mathrm{m})$

37.293

37.452

37.452

37.240

37.505

38.248

37.399

37.081

36.922

37.028

Average Drop Volume:

$4.891 \mu \mathrm{L}$

Mean Interfacial Tension:

$37.362 \mathrm{mN} / \mathrm{m}$

Final Standard Deviation: $+/-0.369 \mathrm{mN} / \mathrm{m}$

Relative Standard Deviation: $0.988 \%$

$10: 42: 00 \mathrm{AM} \quad 11 / 22 / 95$

PCE $C_{1}=5.08 \mathrm{~g} / \mathrm{L}$ DYE SOLUTION

$5 m / / 1+R$ into Ho 
Date Data Collected: November 14, 1995 Experiment Title:

Experimenter:

Comments :

PARAMETERS

Continuous Phase Density: $1.620 \mathrm{~g} / \mathrm{cc}$

Dispersed Phase Density: $0.998 \mathrm{~g} / \mathrm{CC}$

Orifice Diameter:

$0.0254 \mathrm{~cm}$

Syringe Diameter:

$2.3000 \mathrm{~cm}$

Flow Rate:

Drop Limit:

$2.000 \mathrm{~mL} / \mathrm{hour}$

10

DATA

Drop \# Drop Time Total Time (seconds)

1

2

3

4

5

6

7

8

9

10
8.270

8.250

8.200

8.180

8.190

8.200

8.240

8.250

8.230

8.310 (seconds)

8.270

16.520

24.720

32.900

41.090

49.290

57.530

65.780

74.020

82.330
Drop Volume ( $\mu \mathrm{L})$

4.590

4.580

4.560

4.540

4.550

4.560

4.580

4.580

4.580

4.620
Interfacial Tension $(\mathrm{mN} / \mathrm{m})$

35.097

34.991

34.821

34.715

34.736

34.821

34.969

35.012

34.948

35.266

Average Drop Volume:

Mean Interfacial Tension:

$4.574 \mu \mathrm{L}$

$34.938 \mathrm{mN} / \mathrm{m}$

Final Standard Deviation:

Relative Standard Deviation:

$+/-0.170 \mathrm{mN} / \mathrm{m}$

$0.487 \%$

$10: 40: 35 \mathrm{AM}$

$11 / 22 / 95$

$$
\text { PCE } \begin{aligned}
C_{1} & =5.08 \mathrm{~g} / \mathrm{L} \text { DYE } \\
2 \mathrm{ml} / \mathrm{HR} & \text { into } \mathrm{H}_{2} \mathrm{O}
\end{aligned}
$$


Date Data Collected: November 14, 1995 Experiment Title:

Experimenter:

Comments :

PARAMETERS

Continuous Phase Density: $1.620 \mathrm{~g} / \mathrm{CC}$

Dispersed Phase Density: $0.998 \mathrm{~g} / \mathrm{CC}$

Orifice Diameter: $\quad 0.0254 \mathrm{~cm}$

Syringe Diameter: $\quad 2.3000 \mathrm{~cm}$

Flow Rate:

Drop Limit:

$1.000 \mathrm{~mL} /$ hour

10

DATA

Drop \# Drop Time Total Time (seconds)

1

2

3

4

5

6

7

8

9

10
15.120

15.690

15.780

15.770

15.840

15.810

15.810

15.760

15.810

15.720 (seconds)

15.120

30.810

46.590

62.360

78.190

94.000

109.810

125.570

141.380

157.090
Drop Volume $(\mu \mathrm{L})$

4.200

4.360

4.380

4.380

4.400

4.390

4.390

4.380

4.390

4.370
Interfacial Tension $(\mathrm{mN} / \mathrm{m})$

32.084

33.282

33.484

33.463

33.601

33.537

33.548

33.452

33.537

33.346

Average Drop Volume:

$4.364 \mu \mathrm{L}$

Mean Interfacial Tension:

$33.333 \mathrm{mN} / \mathrm{m}$

Final Standard Deviation:

$+/-0.450 \mathrm{mN} / \mathrm{m}$

Relative Standard Deviation:

$1.349 \%$

$10: 39: 14$ AM

$11 / 22 / 95$

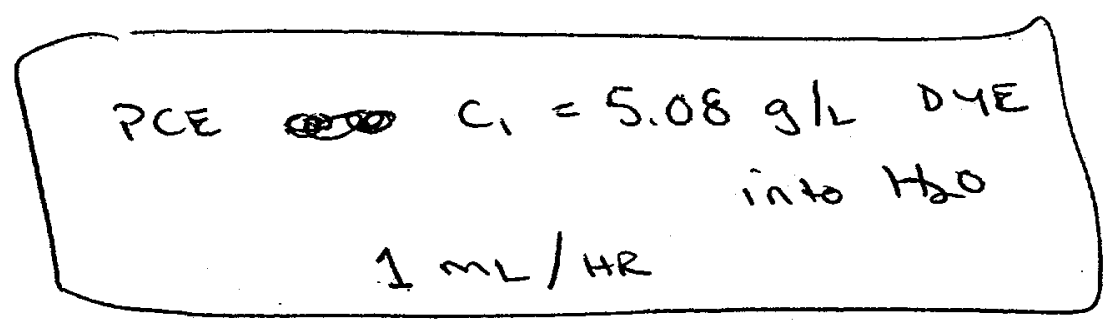


Date Data Collected: November 14, 1995

Experiment Title:

Experimenter:

Comments :

PARAMETERS

Continuous Phase Density: $1.620 \mathrm{~g} / \mathrm{cc}$

Dispersed Phase Density: $0.998 \mathrm{~g} / \mathrm{CC}$

Orifice Diameter:

$0.0254 \mathrm{~cm}$

Syringe Diameter:

$2.3000 \mathrm{~cm}$

Flow Rate:

Drop Limit:

$0.500 \mathrm{~mL} /$ hour

10

DATA

Drop

$\begin{array}{lr} & \text { (seconds) } \\ 1 & 30.090 \\ 2 & 30.080 \\ 3 & 29.620 \\ 4 & 29.690 \\ 5 & 29.780 \\ 6 & 29.930 \\ 7 & 29.990 \\ 8 & 29.560 \\ 9 & 29.410 \\ 10 & 29.030\end{array}$

Total Time

(seconds)

30.090

60.170

89.780

119.470

149.250

179.180

209.170

238.730

268.130

297.160

Drop Volume
$(\mu \mathrm{L})$
4.180
4.180
4.110
4.120
4.140
4.160
4.170
4.110
4.080
4.030

Interfacial Tension $(\mathrm{mN} / \mathrm{m})$

31.919

31.914

31.420

31.500

31.595

31.749

31.818

31.362

31.198

30.800

Average Drop Volume:

$4.127 \mu \mathrm{L}$

Mean Interfacial Tension:

$31.528 \mathrm{mN} / \mathrm{m}$

Final Standard Deviation: $+/-0.353 \mathrm{mN} / \mathrm{m}$

Relative Standard Deviation: $1.118 \%$

$10: 43: 57 \mathrm{AM}$

$11 / 22 / 95$

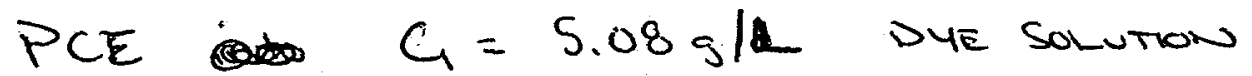

$0.5 \mathrm{ml} / \mathrm{HR}$

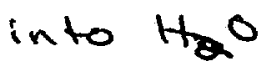


Date Data Collected: November 14, 1995

Experiment Title:

Experimenter:

Comments :

PARAMETERS

Continuous Phase Density: $1.620 \mathrm{~g} / \mathrm{CC}$

Dispersed Phase Density: $0.998 \mathrm{~g} / \mathrm{CC}$

Orifice Diameter:

Syringe Diameter:

Flow Rate:

Drop Limit:

$0.0254 \mathrm{~cm}$

$2.3000 \mathrm{~cm}$

$0.250 \mathrm{~mL} /$ hour

DATA

Drop \# Drop Time (seconds)

$\begin{array}{ll}1 & 55.940 \\ 2 & 57.010 \\ 3 & 56.750 \\ 4 & 56.270 \\ 5 & 55.680 \\ 6 & 57.320 \\ 7 & 55.620 \\ 8 & 54.380 \\ 9 & 53.960 \\ 10 & 55.910\end{array}$

Total Time (seconds)

55.940

112.950

169.700

225.960

281.640

338.960

394.580

448.960

502.920

558.830
Drop Volume $(\mu \mathrm{L})$

3.880

3.960

3.940

3.910

3.870

3.980

3.860

3.780

3.750

3.880
Interfacial Tension $(\mathrm{mN} / \mathrm{m})$

29.672

30.243

30.105

29.848

29.537

30.405

29.505

28.848

28.625

29.659

Average Drop Volume: $\quad 3.881 \mu \mathrm{L}$

Mean Interfacial Tension: $\quad 29.645 \mathrm{mN} / \mathrm{m}$

Final Standard Deviation: $+/-0.567 \mathrm{mN} / \mathrm{m}$

Relative Standard Deviation: $1.913 \%$

$10: 45: 29 \mathrm{AM}$

$11 / 22 / 95$

$C_{1}=5.08 \mathrm{~g} / \mathrm{L}$ DYE SOLuTion into $H_{0}$

$0.25 \mathrm{mi} / \mathrm{H}+\mathrm{R}$ 
Date Data Collected: November 14, 1995

Experiment Title:

Experimenter:

Comments :

PARAMETERS

Continuous Phase Density: $1.620 \mathrm{~g} / \mathrm{CC}$

Dispersed Phase Density: $0.998 \mathrm{~g} / \mathrm{CC}$

Orifice Diameter:

$0.0254 \mathrm{~cm}$

Syringe Diameter:

$2.3000 \mathrm{~cm}$

Flow Rate:

Drop Limit:

$0.100 \mathrm{~mL} /$ hour

10

DATA

$\begin{array}{cr}\text { Drop \# } & \begin{array}{r}\text { Drop Time } \\ \text { (seconds) }\end{array} \\ 1 & 132.550 \\ 2 & 126.220 \\ 3 & 131.380 \\ 4 & 135.270 \\ 5 & 132.890 \\ 6 & 133.790\end{array}$
Total Time (seconds)
132.550
258.770
390.140
525.410
658.300
792.080

Drop Volume $(\mu \mathrm{L})$

3.680

3.510

3.650

3.760

3.690

3.720
Interfacial Tension $(\mathrm{mN} / \mathrm{m})$
28.126
26.782
27.877
28.702
28.198
28.388

Average Drop Volume:

Mean Interfacial Tension:

$3.667 \mu \mathrm{L}$

$28.012 \mathrm{mN} / \mathrm{m}$

Final Standard Deviation: $+/-0.663 \mathrm{mN} / \mathrm{m}$

Relative Standard Deviation: $2.366 \%$

$10: 47: 18$ AM

$11 / 22 / 95$

PCE $C_{1}=5.08 \mathrm{~g} / \mathrm{L}$ DHE SOLUTION into $\mathrm{H}_{2} \mathrm{O}$

$0.1 \mathrm{~m} / \mathrm{HR}$ 
Date Data Collected: November 14, 1995

Experiment Title:

Experimenter:

Comments:

\section{PARAMETERS}

Continuous Phase Density: $1.620 \mathrm{~g} / \mathrm{CC}$

Dispersed Phase Density: $0.998 \mathrm{~g} / \mathrm{CC}$

Orifice Diameter:

$0.0254 \mathrm{~cm}$

Syringe Diameter:

$2.3000 \mathrm{~cm}$

Flow Rate:

Drop Limit:

$0.050 \mathrm{~mL} /$ hour

10

DATA

$\begin{array}{rrrcc}\text { Drop \# } & \begin{array}{c}\text { Drop Time } \\ \text { (seconds) }\end{array} & \begin{array}{c}\text { Total Time } \\ \text { (seconds) }\end{array} & \begin{array}{c}\text { Drop Volume } \\ (\mu L)\end{array} & \begin{array}{c}\text { Interfacial Tension } \\ (\mathrm{mN} / \mathrm{m})\end{array} \\ 1 & 247.120 & 247.120 & 3.430 & 26.218 \\ 2 & 254.180 & 501.290 & 3.530 & 26.967 \\ 3 & 244.480 & 745.770 & 3.400 & 25.938 \\ 4 & 253.660 & 999.430 & 3.520 & 26.912 \\ 5 & 235.170 & 1234.590 & 3.270 & 24.950\end{array}$

Average Drop Volume:

Mean Interfacial Tension:

$3.429 \mu \mathrm{L}$

Final Standard Deviation: $+/-0.826 \mathrm{mN} / \mathrm{m}$

Relative Standard Deviation: $3.151 \%$

$10: 47: 59$ AM $\quad 11 / 22 / 95$

PCE $C_{1}=5.08 \mathrm{~g} / \mathrm{L}$ DYE SOLUTION

into $\mathrm{H}_{2} \mathrm{O}$

$0.05 \mathrm{in} / \mathrm{HR}$ 
Date Data Collected: November 14, 1995

Experiment Title: npcelwater

Experimenter: chris

Comments :

PARAMETERS

Continuous Phase Density: $1.620 \mathrm{~g} / \mathrm{CC}$

Dispersed Phase Density: $0.998 \mathrm{~g} / \mathrm{CC}$

Orifice Diameter:

$0.0254 \mathrm{~cm}$

Syringe Diameter:

$2.3000 \mathrm{~cm}$

Flow Rate:

Drop Limit:

$5.000 \mathrm{~mL} /$ hour

10

DATA

Drop

1
2
3
4
5
6
7
8
9
10

1

2

3

4

5

6

7

8

10

$$
\begin{gathered}
\text { Drop Time } \\
\text { (seconds) } \\
4.890 \\
5.110 \\
5.070 \\
4.980 \\
5.190 \\
4.910 \\
5.110 \\
5.050 \\
5.010 \\
5.160
\end{gathered}
$$

Total Time (seconds)

4.890

9.990

15.060

20.040

25.230

30.140

35.250

40.300

45.310

50.470
Drop Volume $(\mu \mathrm{L})$

6.790

7.090

7.030

6.920

7.210

6.810

7.100

7.010

6.960

7.170
Interfacial Tension $(\mathrm{mN} / \mathrm{m})$

51.881

54.162

53.738

52.836

55.064

52.040

54.215

53.579

53.154

54.746

Average Drop Volume:

Mean Interfacial Tension:

$7.009 \mu \mathrm{L}$

Final Standard Deviation: $+/-1.070 \mathrm{mN} / \mathrm{m}$

Relative Standard Deviation: $1.999 \%$
$11: 02: 26$ AM
$11 / 22 / 95$

PCE $C_{3}=0.0508 \mathrm{gl}$ DUE SOLN.

$5 m / / H R$ into $H_{0}$ 
Date Data Collected: November 14, 1995

Experiment Title: npcelwater

Experimenter: chris

Comments:

PARAMETERS

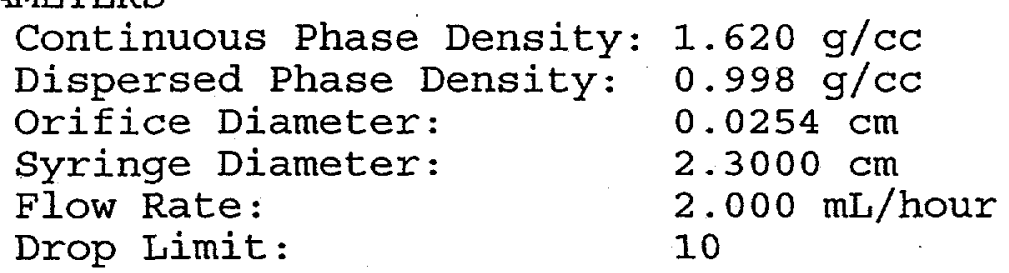

DATA

$\begin{array}{cr}\text { Drop \# } & \begin{array}{r}\text { Drop Time } \\ \text { (seconds) }\end{array} \\ 1 & 12.760 \\ 2 & 12.530 \\ 3 & 12.540 \\ 4 & 12.980 \\ 5 & 12.290 \\ 6 & 12.820 \\ 7 & 12.680 \\ 8 & 12.680 \\ 9 & 12.760 \\ 10 & 12.390\end{array}$

Total Time (seconds)

12.760

25.280

37.820

50.800

63.090

75.900

88.580

101.270

114.030

126.420
Drop Volume $(\mu \mathrm{L})$

7.090

6.960

6.960

7.210

6.830

7.120

7.050

7.040

7.090

6.880
Interfacial Tension $(\mathrm{mN} / \mathrm{m})$

54.130

53.154

53.197

55.085

52.157

54.385

53.833

53.812

54.152

52.581

Average Drop Volume:

Mean Interfacial $7.023 \mu \mathrm{L}$

Final Standard Deviation: $+/-0.880 \mathrm{mN} / \mathrm{m}$

Relative Standard Deviation: $1.640 \%$

$11: 03: 07 \mathrm{AM}$

$11 / 22 / 95$

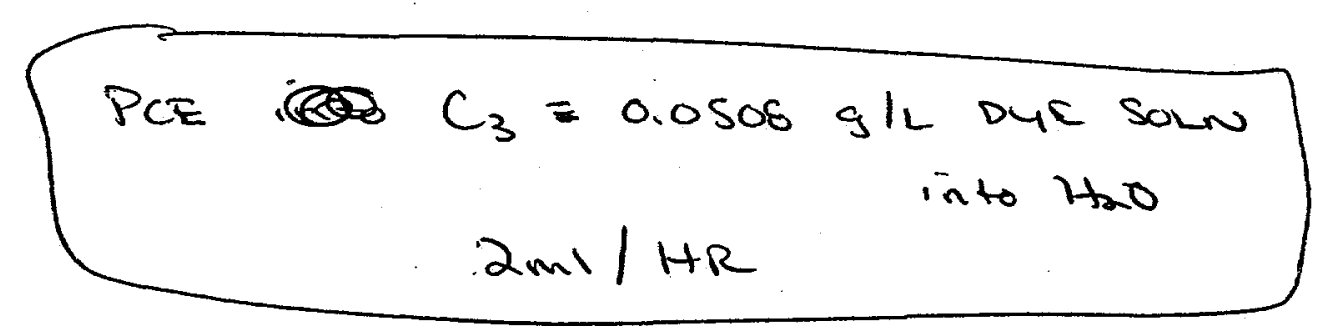


Date Data Collected: November 14, 1995

Experiment Title:

Experimenter:

Comments :

PARAMETERS

Continuous Phase Density: $1.620 \mathrm{~g} / \mathrm{CC}$

Dispersed Phase Density: $0.998 \mathrm{~g} / \mathrm{CC}$

Orifice Diameter: $0.0254 \mathrm{~cm}$

Syringe Diameter: $\quad 2.3000 \mathrm{~cm}$

Flow Rate:

Drop Limit:

$1.000 \mathrm{~mL} /$ hour

10

DATA

$\begin{array}{crrcc}\text { Drop \# } & \begin{array}{r}\text { Drop Time } \\ \text { (seconds) }\end{array} & \begin{array}{r}\text { Total Time } \\ \text { (seconds) }\end{array} & \begin{array}{c}\text { Drop Volume } \\ (\mu \mathrm{L})\end{array} & \begin{array}{r}\text { Interfacial Tension } \\ (\mathrm{mN} / \mathrm{m})\end{array} \\ 1 & 24.650 & 24.650 & 6.850 & 52.305 \\ 2 & 25.070 & 49.720 & 6.960 & 53.186 \\ 3 & 25.200 & 74.920 & 7.000 & 53.473 \\ 4 & 24.550 & 99.470 & 6.820 & 52.104 \\ 5 & 25.050 & 124.520 & 6.960 & 53.154 \\ 6 & 24.390 & 148.910 & 6.770 & 51.743 \\ 7 & 25.210 & 174.120 & 7.000 & 53.494 \\ 8 & 24.570 & 198.690 & 6.830 & 52.146 \\ 9 & 24.900 & 223.590 & 6.920 & 52.836 \\ 10 & 24.920 & 248.520 & 6.920 & 52.889\end{array}$

Average Drop Volume:

$6.903 \mu \mathrm{L}$

Mean Interfacial Tension:

$52.733 \mathrm{mN} / \mathrm{m}$

Final Standard Deviation: $+/-0.619 \mathrm{mN} / \mathrm{m}$

Relative Standard Deviation:

$1.173 \%$

$11: 03: 35$ AM $\quad 11 / 22 / 95$

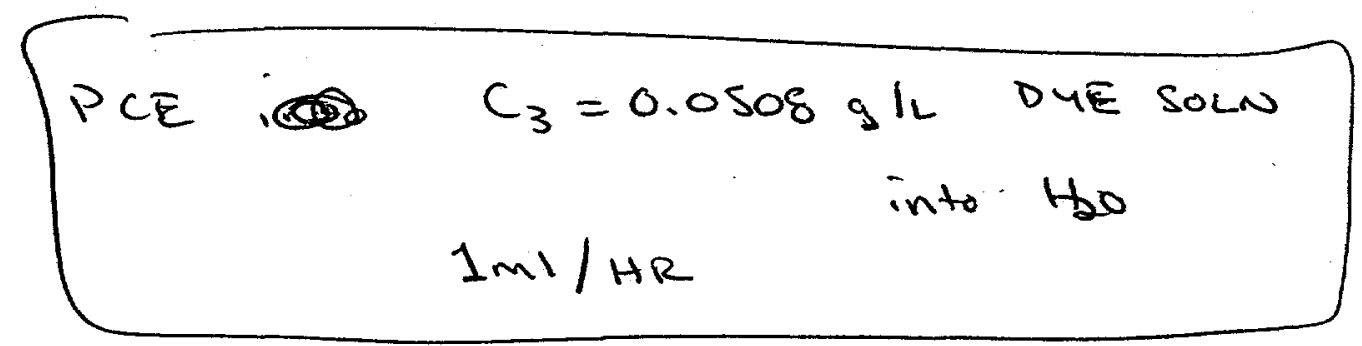


Date Data Collected: November 14, 1995

Experiment Title:

Experimenter:

Comments:

PARAMETERS

Continuous Phase Density: $1.620 \mathrm{~g} / \mathrm{Cc}$

Dispersed Phase Density:

Orifice Diameter:

$0.998 \mathrm{~g} / \mathrm{CC}$

Syringe Diameter:

$0.0254 \mathrm{~cm}$

Flow Rate:

Drop Limit:

$2.3000 \mathrm{~cm}$

$0.500 \mathrm{~mL} /$ hour

10

DATA

Drop

1

2

3

4

5

6

7

8

9

10

$$
\begin{array}{r}
\text { Drop Time } \\
\text { (seconds) } \\
48.980 \\
47.900 \\
50.140 \\
48.890 \\
48.320 \\
49.660 \\
48.160 \\
49.510 \\
47.560 \\
50.140
\end{array}
$$

Total Time (seconds)

48.980

96.880

147.020

195.910

244.230

293.890

342.050

391.560

439.120

489.270
Drop Volume

$(\mu \mathrm{L})$

6.800

6.650

6.960

6.790

6.710

6.900

6.690

6.880

6.610

6.960
Interfacial Tension $(\mathrm{mN} / \mathrm{m})$

51.966

50.815

53.197

51.870

51.271

52.682

51.096

52.534

50.459

53.202

Average Drop Volume:

Mean Interfacial Tension:

$6.795 \mu \mathrm{L}$

$51.909 \mathrm{mN} / \mathrm{m}$

Final Standard Deviation: $+/-0.983 \mathrm{mN} / \mathrm{m}$

Relative Standard Deviation: $1.893 \%$

$11: 03: 59 \mathrm{AM}$

$11 / 22 / 95$

PCE $C_{3}=0.0508 \mathrm{~g} / \mathrm{L}$ DYE SON

into Ho

$0.5 \mathrm{~m} / \mathrm{Hr}$ 
Date Data Collected: November 14, 1995

Experiment Title:

Experimenter:

Comments :

PARAMETERS

Continuous Phase Density: $1.620 \mathrm{~g} / \mathrm{CC}$

Dispersed Phase Density: $0.998 \mathrm{~g} / \mathrm{CC}$

Orifice Diameter:

Syringe Diameter:

$0.0254 \mathrm{~cm}$

Flow Rate:

Drop Limit:

$2.3000 \mathrm{~cm}$

$0.250 \mathrm{~mL} /$ hour

10

DATA

Drop \# Drop Time Total Time

- (seconds)

97.680

92.230

97.850

91.580

97.510

91.770

97.350

91.630

96.900

92.130 (seconds)

97.680

189.910

287.770

379.350

476.860

568.630

665.980

757.620

854.520

946.650
Drop Volume $(\mu \mathrm{L})$

6.780

6.400

6.800

6.360

6.770

6.370

6.760

6.360

6.730

6.400
Interfacial Tension $(\mathrm{mN} / \mathrm{m})$

51.817

48.926

51.910

48.582

51.727

48.685

51.642

48.611

51.404

48.876

Average Drop Volume:

Mean Interfacial Tension:

$6.574 \mu \mathrm{L}$

Final Standard Deviation: $+/-1.571 \mathrm{mN} / \mathrm{m}$

Relative Standard Deviation: $3.129 \%$

$11: 04: 56 \mathrm{AM} \quad 11 / 22 / 95$

PLE CQ $C_{3}=0.0508 \mathrm{~g} / \mathrm{L}$ DYE SOLN

$0.250 \mathrm{ml} / \mathrm{HR}$

into Ho 
Date Data Collected: November 14, 1995

Experiment Title:

Experimenter:

Comments :

PARAMETERS

Continuous Phase Density: $1.620 \mathrm{~g} / \mathrm{cc}$

Dispersed Phase Density: $0.998 \mathrm{~g} / \mathrm{CC}$

Orifice Diameter: $\quad 0.0254 \mathrm{~cm}$

Syringe Diameter: $\quad 2.3000 \mathrm{~cm}$

Flow Rate:

Drop Limit:

$0.100 \mathrm{~mL} /$ hour

10

DATA

Drop \#

1

2

3

4

5
Drop Time (seconds)

217.770

218.820

223.250

213.470

216.740
Total Time (seconds)

217.770

436.590

659.830

873.300

1090.040
Drop Volume $(\mu \mathrm{L})$

6.050

6.080

6.200

5.930

6.020
Interfacial Tension $(\mathrm{mN} / \mathrm{m})$

46.209

46.431

47.371

45.297

45.990

Average Drop Volume:

Mean Interfacial Tension:

Final Standard Deviation:

$6.056 \mu \mathrm{L}$

$46.259 \mathrm{mN} / \mathrm{m}$

Relative Standard Deviation: $1.627 \%$
$11: 05: 33 \mathrm{AM}$
$11 / 22 / 95$

\section{PCE $C_{3}=0.0508 \mathrm{~g} / \mathrm{L}$ DYE SOLTTON \\ $0.100 \mathrm{ml} / \mathrm{HR}$}


Date Data Collected: November 14, 1995

Experiment Title:

Experimenter:

Comments :

PARAMETERS

Continuous Phase Density: $1.620 \mathrm{~g} / \mathrm{CC}$

Dispersed Phase Density: $0.998 \mathrm{~g} / \mathrm{Cc}$

Orifice Diameter: $\quad 0.0254 \mathrm{~cm}$

Syringe Diameter: $\quad 2.3000 \mathrm{~cm}$

Flow Rate:

Drop Limit:

$0.050 \mathrm{~mL} / \mathrm{hour}$

10

DATA

Drop \# Drop Time Total Time

1

(seconds)

411.000

397.780

(seconds)

411.000

398.530

808.780

372.550

1207.310

Drop Volume

$(\mu \mathrm{L})$

5.710

5.520

5.540

1579.860

5.170

5.450

Interfacial Tension $(\mathrm{mN} / \mathrm{m})$

43.605

42.203

42.283

39.526

1972.180

41.624

Average Drop Volume:

Mean Interfacial Tension:

$5.478 \mu \mathrm{L}$

Final Standard Deviation: $+/-1.487 \mathrm{mN} / \mathrm{m}$

Relative Standard Deviation: $3.553 \%$

$11: 06: 29 \mathrm{AM}$

$11 / 22 / 95$

PCE $C_{3}=0.0508 \mathrm{~g} / \mathrm{L}$ DYE SOLVTION

$0.050 \mathrm{mi} / \mathrm{H}$

into 1 so 
Date Data Collected: November 14, 1995

Experiment Title:

Experimenter:

Comments :

PARAMETERS

Continuous Phase Density: $1.620 \mathrm{~g} / \mathrm{CC}$

Dispersed Phase Density: $0.998 \mathrm{~g} / \mathrm{CC}$

Orifice Diameter:

$0.0254 \mathrm{~cm}$

Syringe Diameter:

Flow Rate:

Drop Limit:

$2.3000 \mathrm{~cm}$

$5.000 \mathrm{~mL} / \mathrm{hour}$

10

DATA

Drop

1

$$
\text { Drop Time }
$$

Total Time

(seconds)

4.720

4.880

4.720

9.600

4.710

14.310

4.840

19.150

4.730

23.880

4.840

28.720

4.770

33.490

4.860

38.350

4.840

43.190

Drop Volume

6.560

6.770

6.540

6.720

6.570

Interfacial Tension

$(\mathrm{mN} / \mathrm{m})$

50.077

51.722

49.971

51.351

6.720

50.184

6.620

51.351

6.750

50.608

48.000

6.720

51.563

4.810

6.690

51.351

51.085

Average Drop Volume:

Mean Interfacial Tension:

Final Standard Deviation:

$6.667 \mu \mathrm{L}$

$50.926 \mathrm{mN} / \mathrm{m}$

Relative Standard Deviation:

$+/-0.657 \mathrm{mN} / \mathrm{m}$

$10: 48: 38$ AM

$11 / 22 / 95$

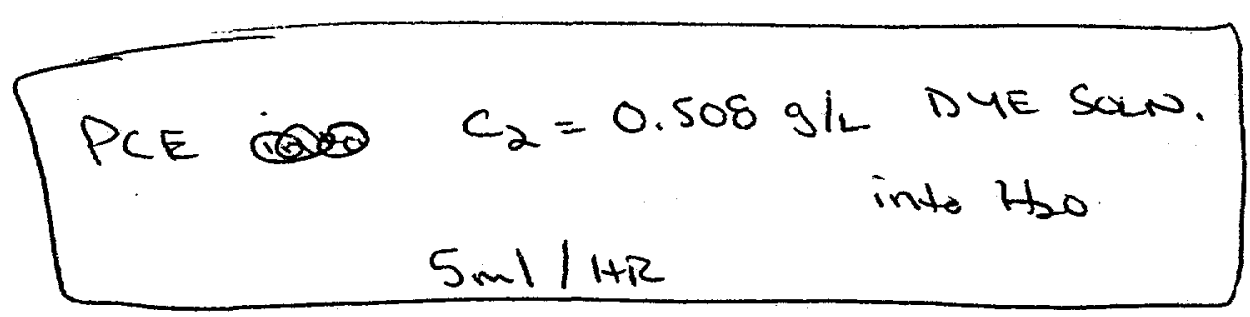


Date Data Collected: November 14, 1995

Experiment Title:

Experimenter:

Comments:

PARAMETERS

Continuous Phase Density: $1.620 \mathrm{~g} / \mathrm{CC}$

Dispersed Phase Density: $0.998 \mathrm{~g} / \mathrm{CC}$

Orifice Diameter: $\quad 0.0254 \mathrm{~cm}$

Syringe Diameter: $\quad 2.3000 \mathrm{~cm}$

Flow Rate:

Drop Limit:

$2.000 \mathrm{~mL} /$ hour

10

DATA

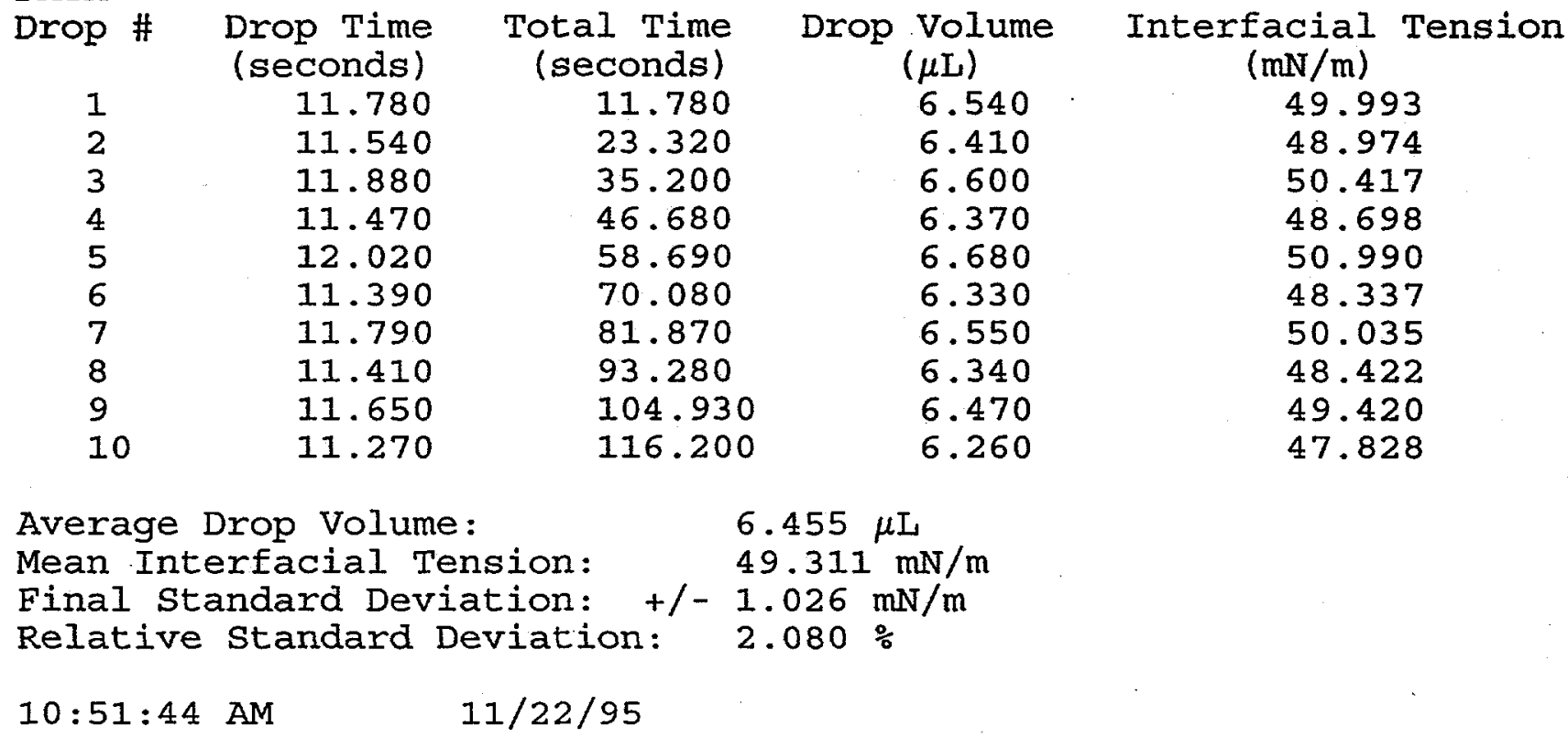

$$
\text { PCE } \begin{gathered}
C_{2}=0.508 \mathrm{~g} / \mathrm{L} \text { DYE SOLN. } \\
2 \mathrm{ml} / \mathrm{HR} \quad \text { into Ho }
\end{gathered}
$$


Date Data Collected: November 14, 1995

Experiment Title:

Experimenter:

Comments :

PARAMETERS

Continuous Phase Density: $1.620 \mathrm{~g} / \mathrm{cc}$

Dispersed Phase Density: $0.998 \mathrm{~g} / \mathrm{CC}$

Orifice Diameter:

$0.0254 \mathrm{~cm}$

Syringe Diameter:

$2.3000 \mathrm{~cm}$

Flow Rate:

Drop Limit:

$1.000 \mathrm{~mL} /$ hour

10

DATA

Drop

1

\# Drop Time (seconds)

Total Time (seconds)

21.900

21.890

21.990

21.930

22.590

21.550

22.290

22.240

21.770

22.970
21.900

43.790

65.780

87.710

110.300

131.850

154.140

176.370

198.140

221.110
Drop Volume $(\mu L)$

6.080

6.080

6.110

6.090

6.270

5.990

6.190

6.180

6.050

6.380
Interfacial Tension $(\mathrm{mN} / \mathrm{m})$

46.470

46.438

46.661

46.544

47.924

45.728

47.298

47.181

46.194

48.741

Average Drop Volume:

$6.142 \mu \mathrm{L}$

Mean Interfacial Tension:

$46.918 \mathrm{mN} / \mathrm{m}$

Final Standard Deviation:

$+/-0.890 \mathrm{mN} / \mathrm{m}$

Relative Standard Deviation:

$1.896 \%$

$10: 52: 48$ AM

$11 / 22 / 95$

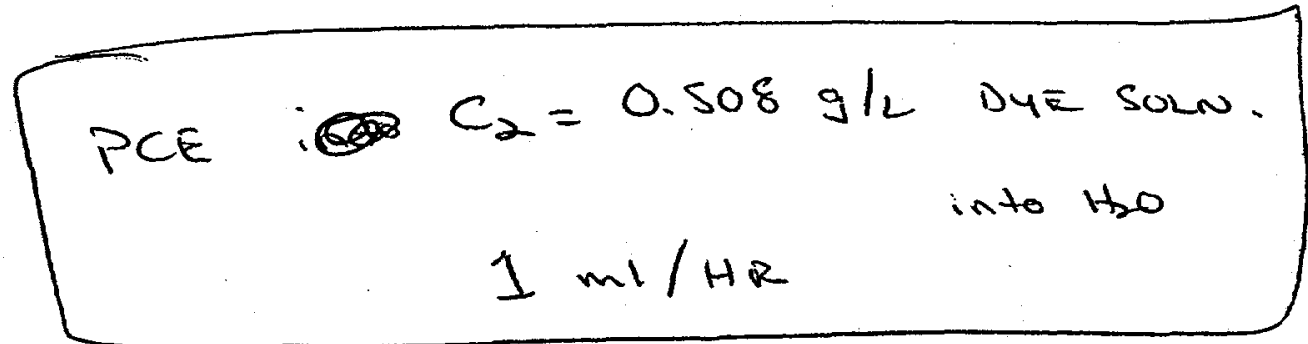


Date Data Collected: November 14, 1995

Experiment Title:

Experimenter:

Comments :

PARAMETERS

Continuous Phase Density: $1.620 \mathrm{~g} / \mathrm{cc}$

Dispersed Phase Density: $0.998 \mathrm{~g} / \mathrm{CC}$

Orifice Diameter: $\quad 0.0254 \mathrm{~cm}$

Syringe Diameter: $\quad 2.3000 \mathrm{~cm}$

Flow Rate:

Drop Limit:

$0.500 \mathrm{~mL} /$ hour

DATA

Drop \# Drop Time

Total Time

Drop Volume

Interfacial Tension

(seconds) (seconds)

$(\mu \mathrm{L})$

$(\mathrm{mN} / \mathrm{m})$

42.760

5.940

86.990

6.140

128.110

5.710

45.367

$171.070 \quad 5.970$

46.926

43.627

45.579

46.730

215.120
$257.220 \quad 5.120$
300.260

44.672

300.260

5.980

45.664

46.014

44.587

46.449

Average Drop Volume:

Mean Interfacial Tension: $45.561 \mathrm{mN} / \mathrm{m}$

Final Standard Deviation: $+/-1.041 \mathrm{mN} / \mathrm{m}$

Relative Standard Deviation: $2.285 \%$

$10: 54: 58 \mathrm{AM}$

$11 / 22 / 95$

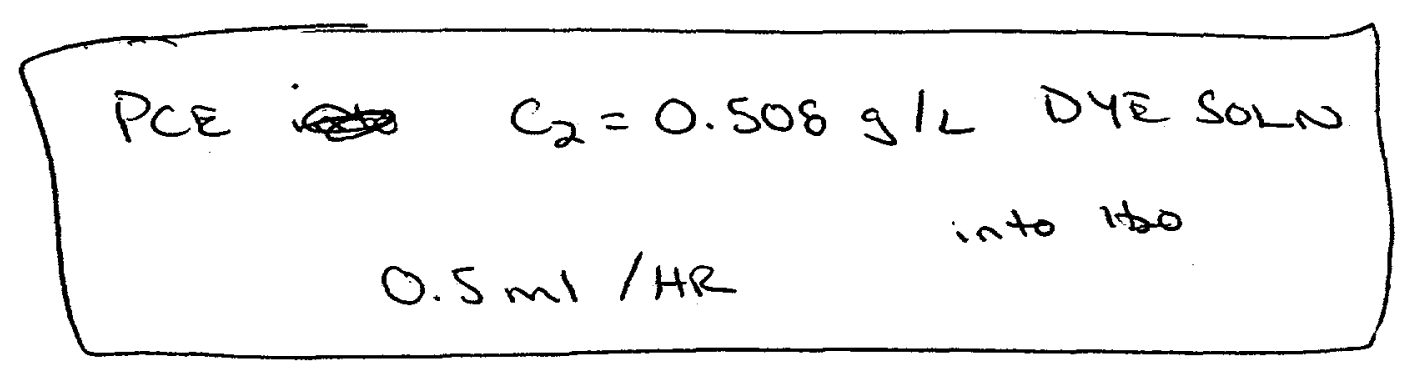


Date Data Collected: November 14, 1995

Experiment Title:

Experimenter:

Comments :

PARAMETERS

Continuous Phase Density: $1.620 \mathrm{~g} / \mathrm{cc}$

Dispersed Phase Density: $0.998 \mathrm{~g} / \mathrm{cc}$

Orifice Diameter:

$0.0254 \mathrm{~cm}$

Syringe Diameter:

$2.3000 \mathrm{~cm}$

Flow Rate:

Drop Limit :

$0.250 \mathrm{~mL} /$ hour

10

DATA

Drop \# Drop Time (seconds)

$\begin{array}{ll}1 & 81.420 \\ 2 & 82.570 \\ 3 & 83.250 \\ 4 & 80.950 \\ 5 & 79.490 \\ 6 & 82.230 \\ 7 & 80.280 \\ 8 & 80.450 \\ 9 & 81.260 \\ 10 & 83.450\end{array}$

Total Time (seconds)

81.420

163.990

247.240

328.190

407.680

489.910

570.180

650.640

731.900

815.350
Drop Volume $(\mu \mathrm{L})$

5.650

5.730

5.780

5.620

5.520

5.710

5.570

5.590

5.640

5.800
Interfacial Tension $(\mathrm{mN} / \mathrm{m})$

43.189

43.802

44.163

42.942

42.168

43.622

42.587

42.677

43.107

44.269

Average Drop Volume:

Mean Interfacial Tension:

$5.662 \mu \mathrm{L}$

Final Standard Deviation: $+/-0.697 \mathrm{mN} / \mathrm{m}$

Relative Standard Deviation: $1.611 \%$

\section{$10: 56: 29 \mathrm{AM}$ \\ $11 / 22 / 95$}

$P C E \quad C_{2}=0.508 \mathrm{~g} / \mathrm{L}$

DUE SOLNTION

into Ho

$0.25 \leftrightarrow m / / H R$ 
Date Data Collected: November 14, 1995 Experiment Title:

Experimenter:

Comments :

\section{PARAMETERS}

Continuous Phase Density: $1.620 \mathrm{~g} / \mathrm{cc}$

Dispersed Phase Density: $0.998 \mathrm{~g} / \mathrm{CC}$

Orifice Diameter:

Syringe Diameter:

$0.0254 \mathrm{~cm}$

Flow Rate:

Drop Limit:

$2.3000 \mathrm{~cm}$

$0.100 \mathrm{~mL} / \mathrm{hour}$

10

DATA

Drop \# $\begin{aligned} & \text { Drop Time } \\ & \text { (seconds) }\end{aligned}$

1

2

3

4

5
190.940

192.390

186.780

200.100

193.110
Total Time (seconds)

$$
190.940
$$

383.330

570.100

770.200

963.300
Drop Volume $(\mu \mathrm{L})$

5.300

5.340

5.190

5.560

5.360
Interfacial Tension $(\mathrm{mN} / \mathrm{m})$

40.516

40.823

39.632

42.459

40.977

Average Drop Volume:

Mean Interfacial Tension:

Final Standard Deviation:

$5.352 \mu \mathrm{L}$

Relative Standard Deviation:

$40.881 \mathrm{mN} / \mathrm{m}$

$10: 57: 25 \mathrm{AM}$

$11 / 22 / 95$

$$
\begin{aligned}
& \text { PCE } C_{2}=0.508 \mathrm{~g} / \mathrm{L} \text {. DUE SOLN. } \\
& 0.1 \mathrm{ml} / \mathrm{Hr} \\
& \text { into Ho }
\end{aligned}
$$


Date Data Collected: November 14, 1995

Experiment Title:

Experimenter:

Comments:

PARAMETERS

Continuous Phase Density: $1.620 \mathrm{~g} / \mathrm{CC}$

Dispersed Phase Density: $0.998 \mathrm{~g} / \mathrm{CC}$

Orifice Diameter: $\quad 0.0254 \mathrm{~cm}$

Syringe Diameter: $\quad 2.3000 \mathrm{~cm}$

Flow Rate:

Drop Limit:

$0.050 \mathrm{~mL} /$ hour

10

DATA

Drop \#

$$
\begin{aligned}
& \text { Drop Time } \\
& \text { (seconds) } \\
& 391.760 \\
& 383.890 \\
& 365.710 \\
& 371.080 \\
& 346.200 \\
& 387.070
\end{aligned}
$$

Total Time (seconds)

391.760

775.650

1141.360

$1512: 440$

1858.630

2245.700

Drop Volume

$(\mu \mathrm{L})$

5.440

5.330

5.080

5.150

4.810

5.380
Interfacial Tension $(\mathrm{mN} / \mathrm{m})$

41.564

40.729

38.800

39.370

36.730

41.066

Average Drop Volume:

Mean Interfacial Tension:

$5.198 \mu \mathrm{L}$

Final Standard Deviation:

$39.710 \mathrm{mN} / \mathrm{m}$

Relative Standard Deviation:

$+/-1.797 \mathrm{mN} / \mathrm{m}$

$10: 59: 38 \mathrm{AM} \quad 11 / 22 / 95$

$10: 59: 38 \mathrm{AM} \quad 11 / 22 / 95$

$4.524 \%$

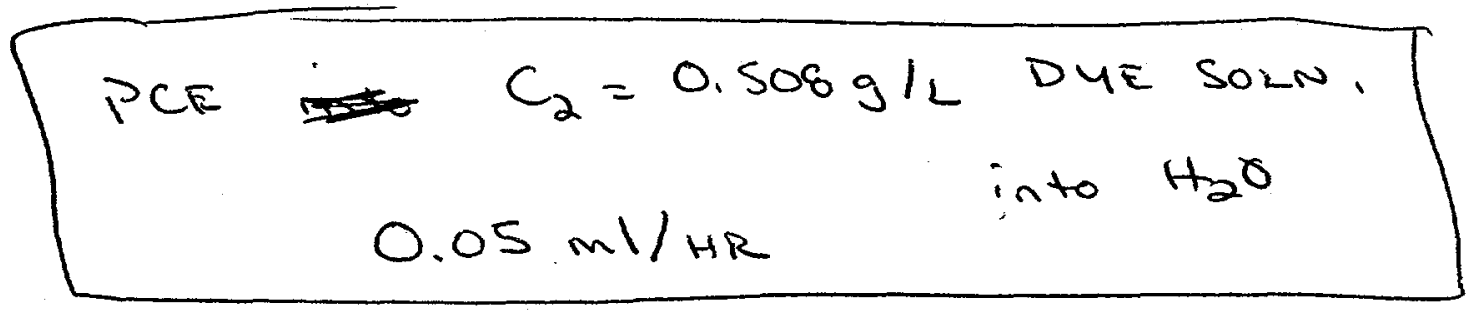


Appendix B.

Wilhelmy Plate Interfacial Tension Measurements of M-Area DNAPL

June 1994 
28

$7 / 26 / 94$

nato

MSB- 3D DNAPL phase IFT

DNAPL - Water IFT withemy Plate method Kriuss Procesar Terriniter K/Z

demonetration $7 / 2 c / 94$ by hee Bilmen of thriss USA

P/IFT

Equilibstal Wates with DNAPL - $9.59 \mathrm{~m} / \mathrm{m}$

7 resh tap wates with DNAPL phree -

Plate method - problems with formution of the intesface?

lowes IFT - serge of asmeremed inlues 4.15 to 3.59

Ring-Push method - ist toy- birke throgh interfue

$\rightarrow$ delicate interfree

7ixed Rinin Mettral

$\rightarrow$ Modified rete of pash to ty to.

siminize chame of breataing the

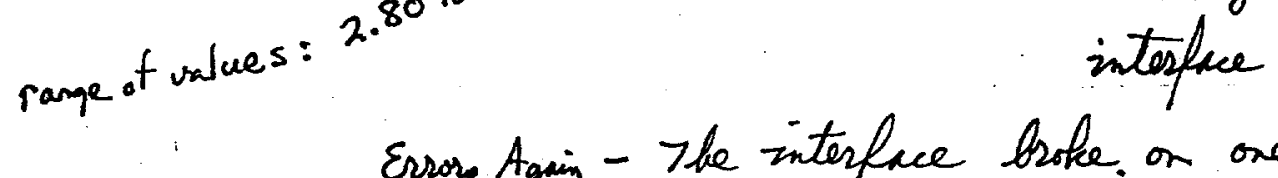

Erroos Again - The interfrce broke on ore side this time.

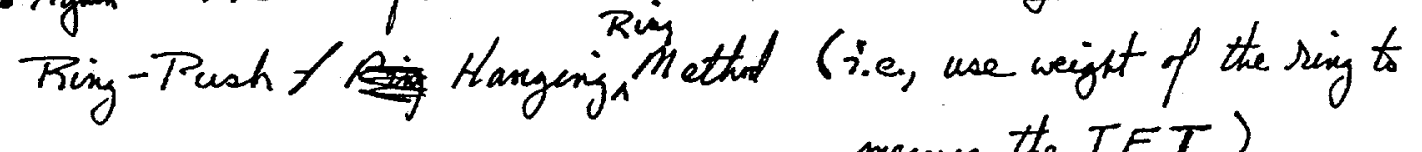
menare the IFT)

ring borke through the intesface again

Pall ring up throngt the interfue:

$$
\text { Ring-Pull Method-IFT - }
$$

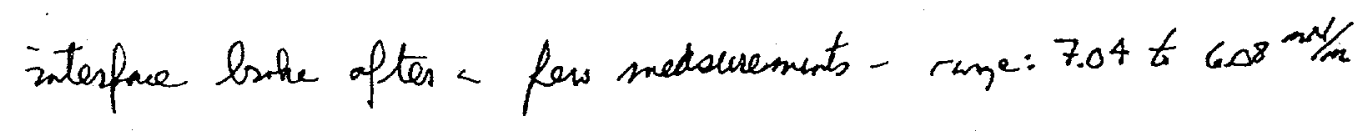


Date $\quad 7 / 20 / 94$

Inte-facial Tersion Menswemerts - Krüss USA Denonstration by Lee Gilman

The following output is Pom the Kreiss Processor Tessionaten K/Z.

The data are IFT mecurvenents between very well oquilifirtal

$D N A P L$ prom $M S B-3 D$ and the ground water in tht well. The emulsified phase which separated the two phuses was semoved prioi to
the andigois.

KRUESS PROCESGOR TEISIONETER K12 U4.83

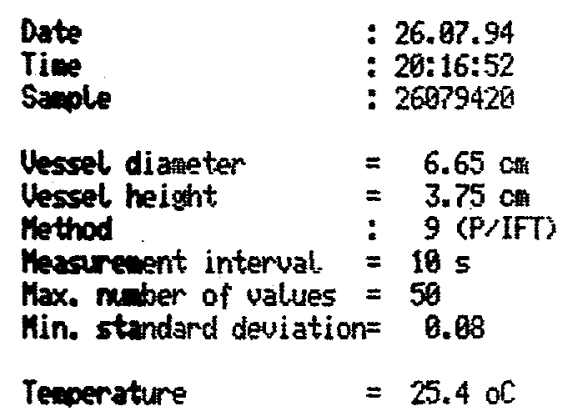

Value Average Deviation Tive

(AN) of 5 val. of 5 val. hrian:ss

9.98 00:02:53

9.88 19:03:65

$9.81 \quad 00: 03: 18$

9.76

$9.71 \quad 9.83 \quad 0.11 \quad 00: 93: 44$

$9.68 \quad 9.77 \quad 0.06 \quad 96: 03: 57$

Tewperature

$$
=25.5 \text { or }
$$

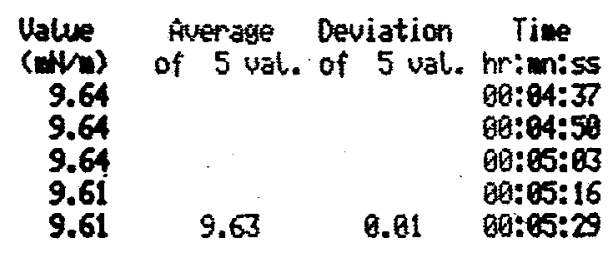

Teuperature

$=25.50 \mathrm{C}$

\begin{tabular}{|c|c|c|c|}
\hline $\begin{array}{l}\text { Ualue } \\
\text { (nN/n) } \\
9.59 \\
9.59 \\
9.59 \\
9.59 \\
9.59\end{array}$ & $\begin{array}{l}\text { Average } \\
\text { of } 5 \text { val. }\end{array}$ & $\begin{array}{l}\text { Deviation } \\
\text { of } 5 \text { val. }\end{array}$ & $\begin{array}{c}\text { Time } \\
\text { hr:min:ss } \\
08: 86: 02 \\
00: 66: 15 \\
09: 06: 28 \\
09: 06: 40 \\
09: 06: 53\end{array}$ \\
\hline
\end{tabular}

Temperature $\quad=25.5 \mathrm{oC}$

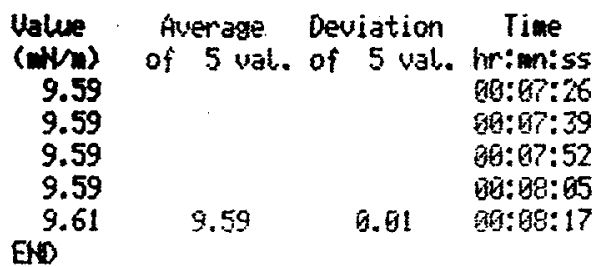

Experimenter

Date

Witness
The IFT seduced from $9.98 \mathrm{~m} / \mathrm{m}$ when the mescmenents wore fiest stuted to approcinatefy Q. $59 \mathrm{~m} / \mathrm{m}$

We attrompted to measare the IFT between the DNARL phree and clem top wates. We hid some psotlems, howeres, in that the isterface cars very frajile and was exaity frotem by the rivg when the du voun Reri methos was used. We lales hile sither evitic resilt due to an irreyalos wetting perimetes armond the plete when we applies the plate pucl methor.

The reoult of the measumements are recosded on the pelloring parge. 
Appendix C.

Recalculated Drop Volume Interfacial Tension Values 


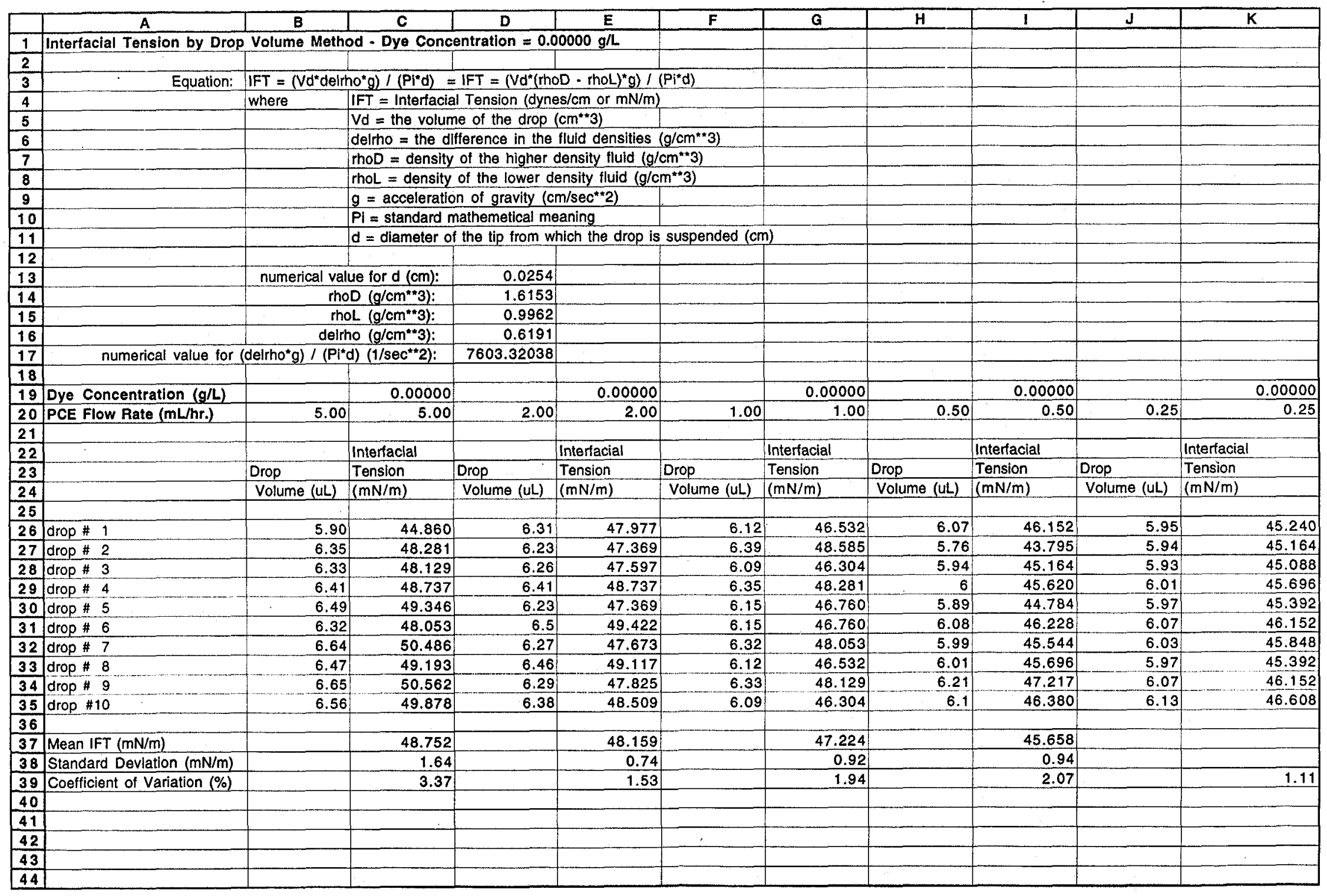




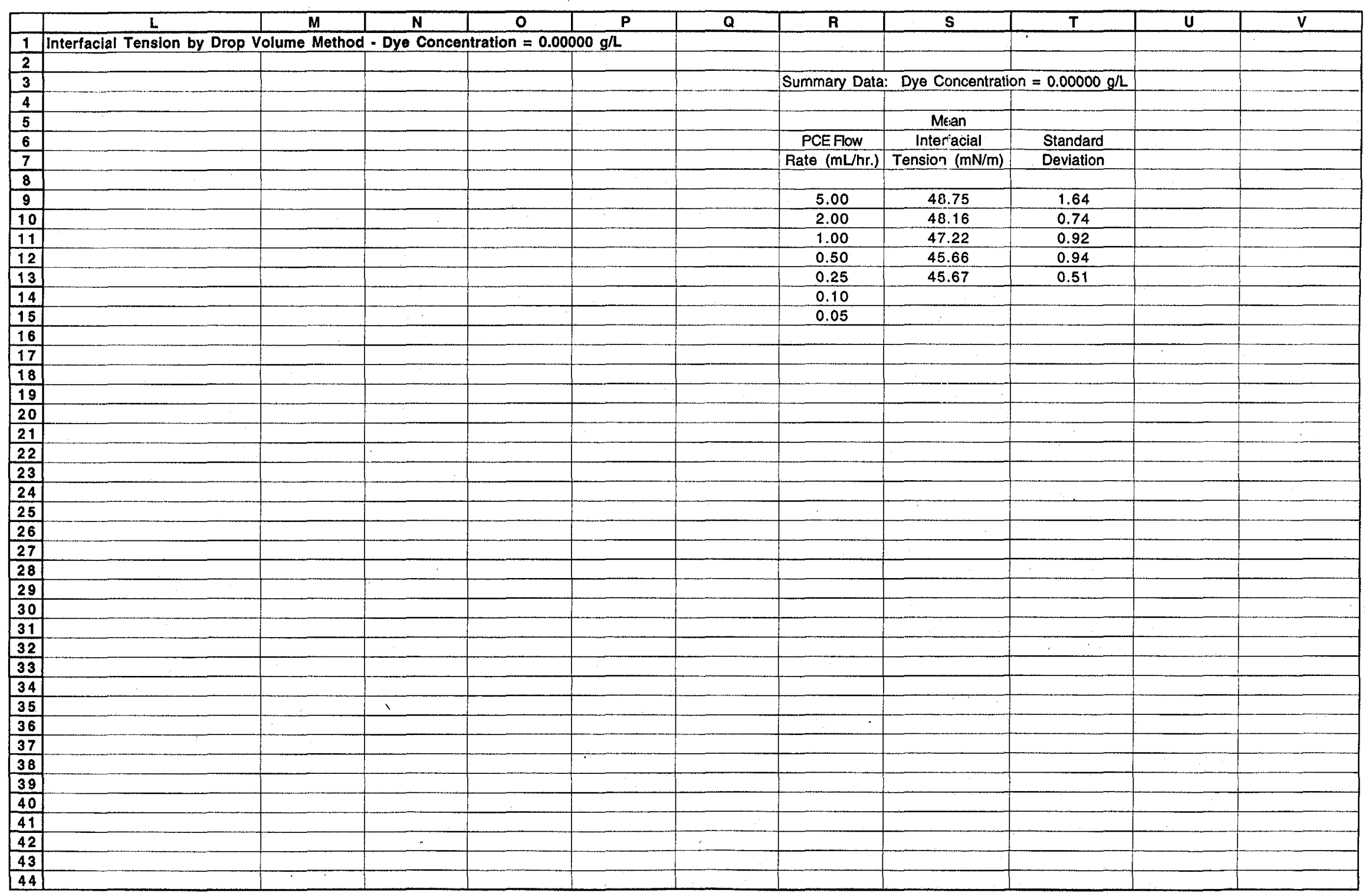




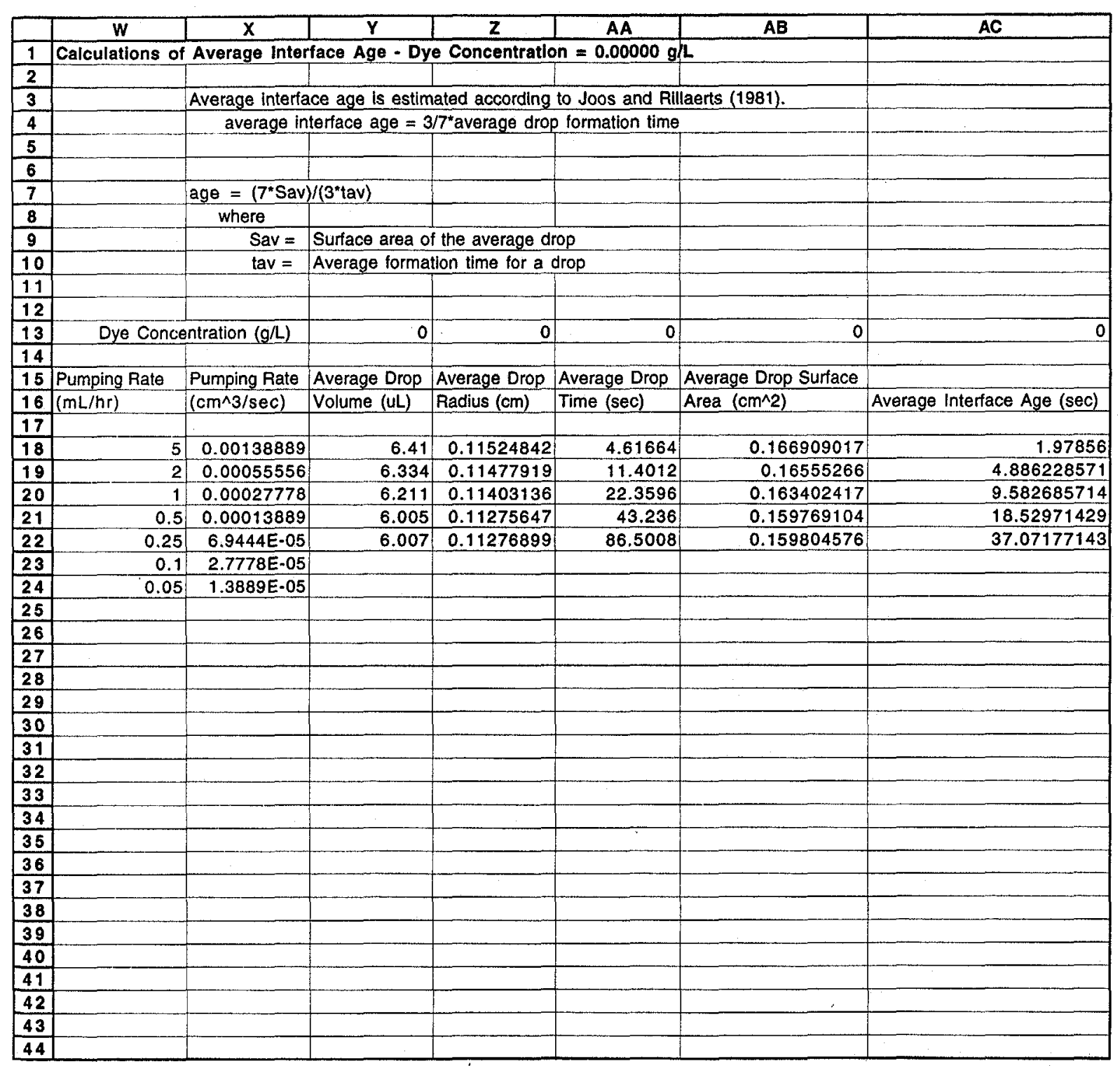




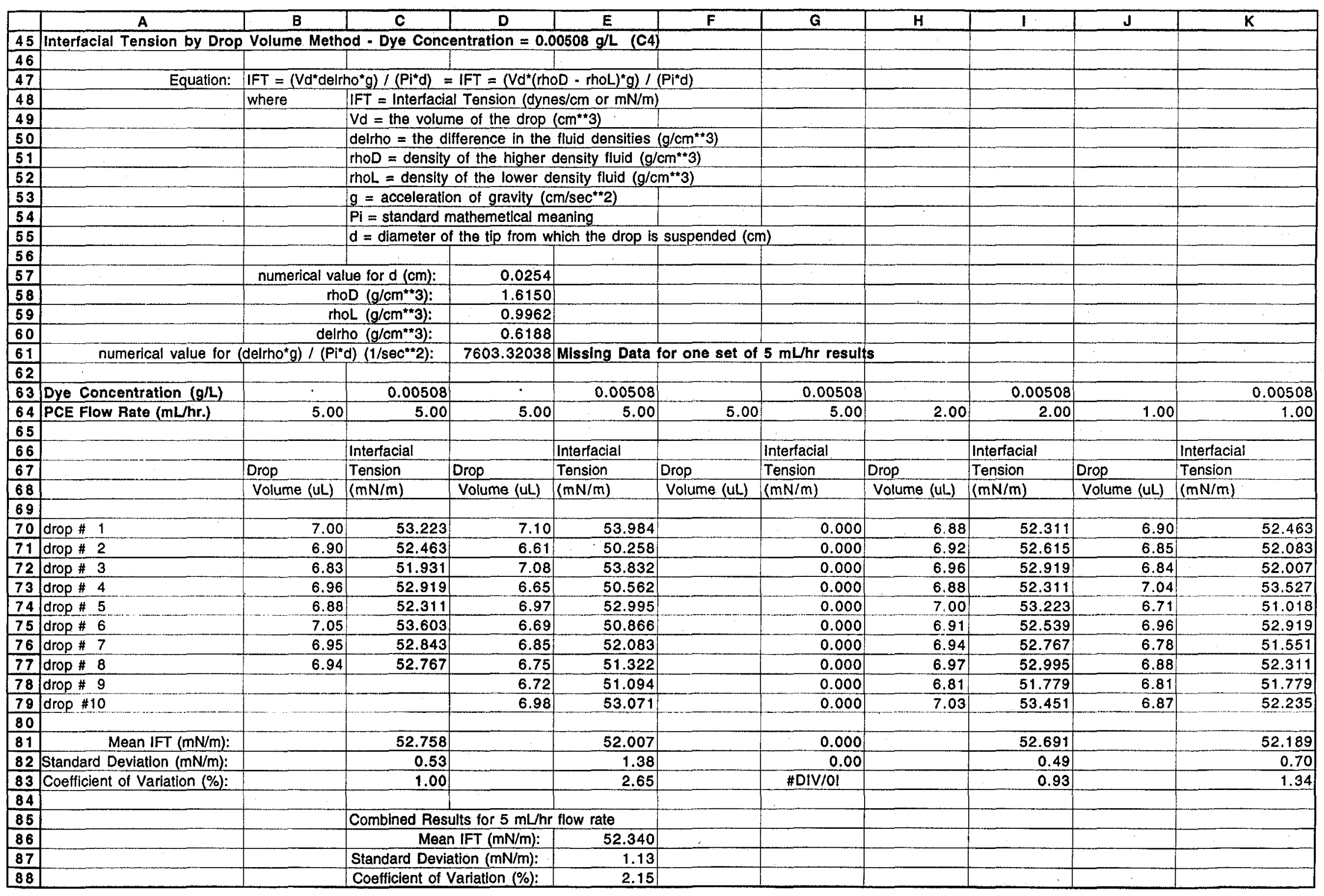




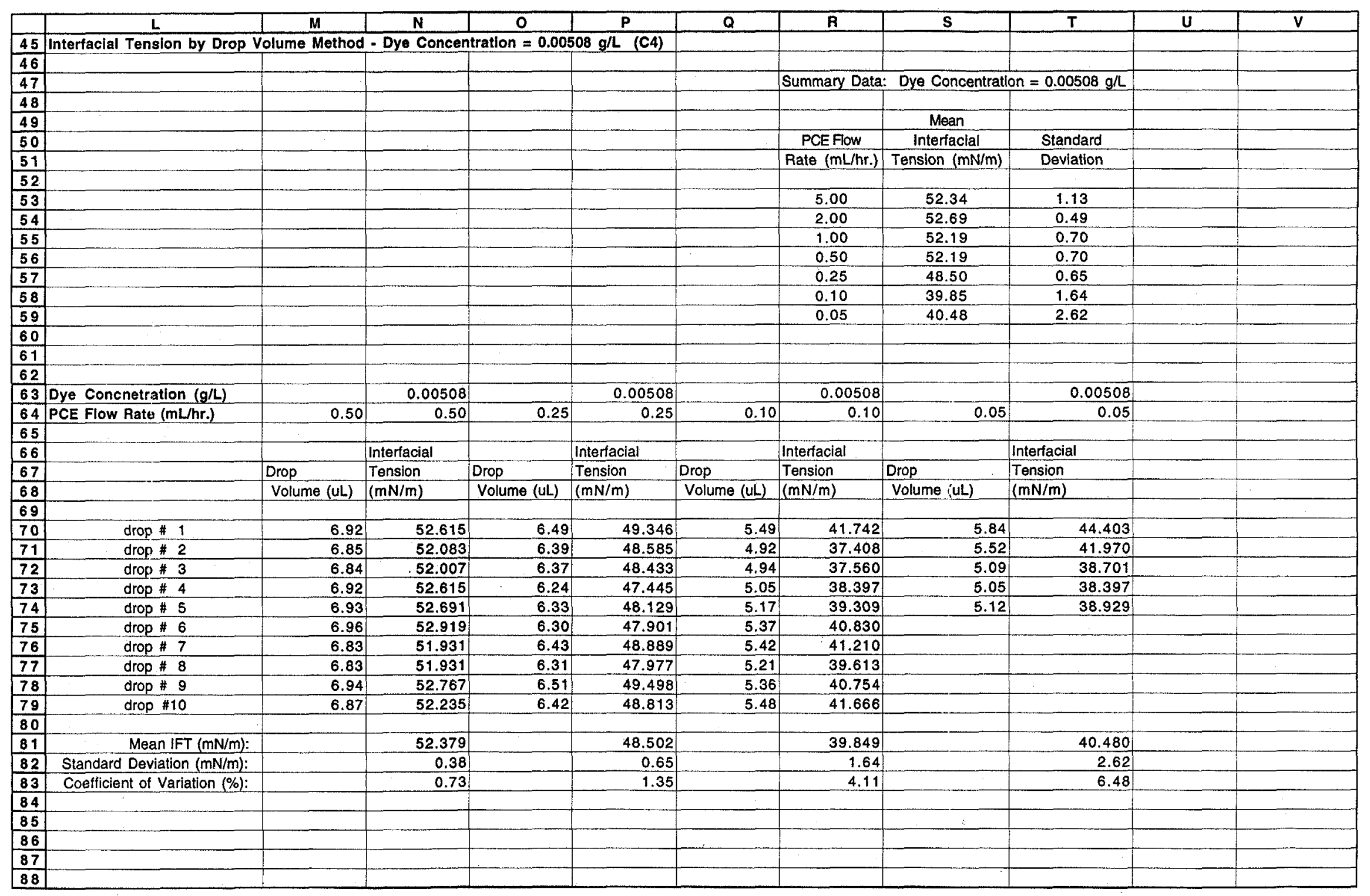




\begin{tabular}{|c|c|c|c|c|c|c|c|}
\hline & $w$ & $\mathrm{x}$ & $Y$ & $\mathbf{z}$ & AA & $\mathbf{A B}$ & $A C$ \\
\hline 45 & \multicolumn{7}{|c|}{ Calculations of Average Interface Age - Dye Concentration $=0.00508 \mathrm{~g} / \mathrm{L}$ (C4) } \\
\hline 46 & & & & & & & \\
\hline 47 & & \multirow{2}{*}{\multicolumn{5}{|c|}{ Average interface age is estimated according to Joos and Rillaerts (1981). }} & \\
\hline 48 & & \multicolumn{2}{|c|}{ average interface age $=3 / 7^{*}$ average drop formation time } & & & & \\
\hline \multicolumn{8}{|c|}{ 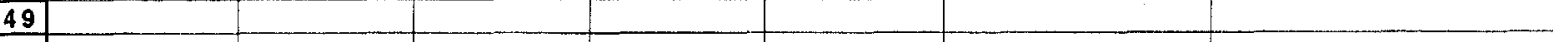 } \\
\hline 50 & & & & & & & \\
\hline 51 & & \multicolumn{2}{|c|}{ age $=\left(7^{*}\right.$ Sav $) /\left(3^{*}\right.$ tav $)$} & & & & \\
\hline 52 & & \begin{tabular}{|l|} 
where \\
\end{tabular} & & & & & \\
\hline 53 & & Sav $=$ & \multicolumn{3}{|c|}{ Surface area of the average drop } & & \\
\hline 54 & & $\operatorname{tav}=$ & \multicolumn{3}{|c|}{ Average formation time for a drop } & & \\
\hline \multicolumn{8}{|c|}{ 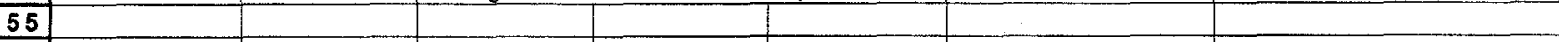 } \\
\hline 56 & & & & & & & \\
\hline 57 & \multicolumn{2}{|c|}{ Dye Concentration $(g / L)$} & 0.00508 & 0.00508 & 0.00508 & 0.00508 & 0.00508 \\
\hline \multicolumn{8}{|c|}{20} \\
\hline 59 & Pumping Rate & Pumping Rate & Average Drop & Average Drop & Average Drop & Average Drop Surface & \\
\hline 60 & $(\mathrm{~mL} / \mathrm{hr})$ & $\left(\mathrm{cm}^{\wedge} 3 / \mathrm{sec}\right)$ & Volume (uL) & Radius $(\mathrm{cm})$ & Time (sec) & Area $\left(\mathrm{cm}^{\wedge} 2\right)$ & Average Interface Age (sec) \\
\hline \multicolumn{8}{|r|}{ (1) } \\
\hline 62 & 5 & 0.00138889 & 6.88 & 0.11800899 & 4.9564 & 0.175000797 & 2.124171429 \\
\hline 63 & 2. & 0.00055556 & 6.93 & 0.11827189 & $12: 474$ & 0.175781412 & 5.346 \\
\hline 64 & 1 & 0.00027778 & 6.86 & 0.11789523 & 24.7104 & 0.17466356 & 10.59017143 \\
\hline 65 & 0.5 & 0.00013889 & 6.89 & 0.11803819 & 49.6008 & 0.175087408 & 21.25748571 \\
\hline 66 & 0.25 & $6.9444 \mathrm{E}-05$ & 6.38 & 0.11505036 & 91.8576 & 0.166335849 & 39.36754286 \\
\hline 67 & 0.1 & $2.7778 \mathrm{E}-05$ & 5.24 & 0.1077561 & 188.676 & 0.145912858 & 80.86114286 \\
\hline 68 & 0.05 & $1.3889 E-05$ & 5.32 & 0.10832195 & 383.328 & 0.147449336 & 164.2834286 \\
\hline \multicolumn{8}{|l|}{69} \\
\hline \multicolumn{8}{|l|}{70} \\
\hline 71 & & & & & & & \\
\hline \multicolumn{8}{|l|}{72} \\
\hline \multicolumn{8}{|l|}{73} \\
\hline \multicolumn{8}{|l|}{74} \\
\hline \multicolumn{8}{|l|}{75} \\
\hline \multicolumn{8}{|l|}{76} \\
\hline \multirow{2}{*}{\multicolumn{8}{|c|}{$\frac{77}{78}$}} \\
\hline \multicolumn{3}{|l|}{78} & & & & & \\
\hline \multicolumn{8}{|l|}{79} \\
\hline \multicolumn{8}{|l|}{80} \\
\hline 81 & & & & & & & \\
\hline \multicolumn{8}{|l|}{82} \\
\hline 83 & & & & & & & \\
\hline 84 & & & & & & & \\
\hline 85 & & & & & & & \\
\hline 86 & & & & & & $\dot{-}$ & \\
\hline 87 & & & & & & & \\
\hline 88 & & & & & & & \\
\hline
\end{tabular}




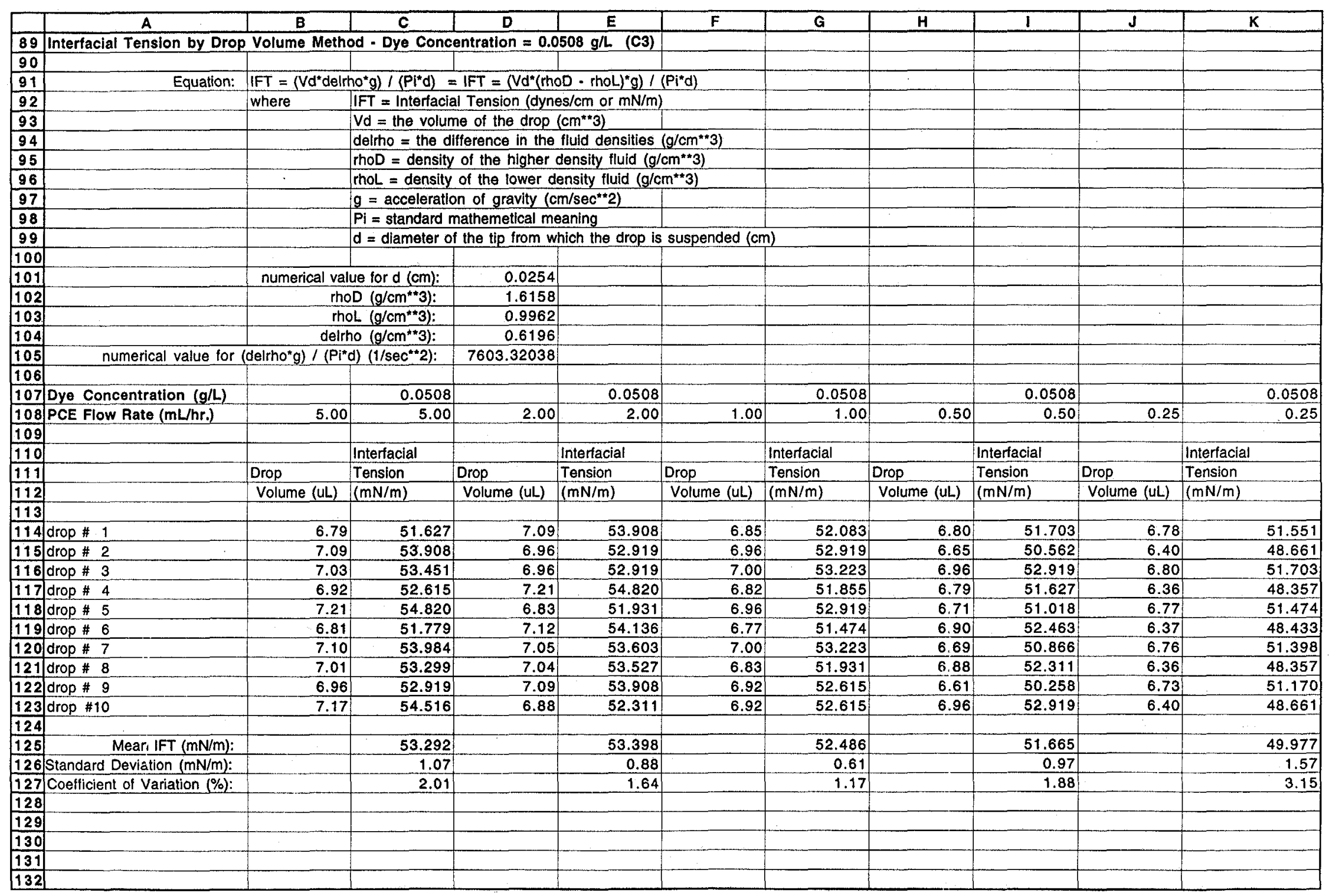




\begin{tabular}{|c|c|c|c|c|c|c|c|c|c|c|c|}
\hline & $L$ & $M$ & $\mathbf{N}$ & 0 & $\mathbf{P}$ & $\mathbf{Q}$ & $\mathbf{R}$ & 3 & $\mathbf{T}$ & $\mathbf{u}$ & v \\
\hline \multicolumn{12}{|c|}{89 Interfacial Tenslon by Drop Volume Method - Dye Concentration $=0.0508 \mathrm{~g} / \mathrm{L}$ (C3) } \\
\hline 90 & & & & & & & & & & & \\
\hline 91 & & & & & & & \multicolumn{3}{|c|}{ Summary Data: Dye Concentration $=0.0508 \mathrm{~g} / \mathrm{L}$} & & \\
\hline 92 & & & & & & & & & & & \\
\hline 93 & & & & & & & & Mean & & & \\
\hline 94 & & & & & & & PCE Flow & Intertacial & Standard & & \\
\hline 95 & & & & & & & Rate (mL/hr.) & Tension $(\mathrm{mN} / \mathrm{m})$ & Deviation. & & \\
\hline 96 & & & & & & & & & & & \\
\hline 97 & & & & & & & 5.00 & 53.29 & 1.07 & & \\
\hline 98 & & & & & & & 2.00 & 53.40 & 0.88 & & \\
\hline 99 & & & & & & & 1.00 & 52.49 & 0.61 & & \\
\hline 100 & & & & & & & 0.50 & 51.66 & 0.97 & & \\
\hline 101 & & & & & & & 0.25 & 49.98 & 1.57 & & \\
\hline 102 & & & & & & & 0.10 & 46.05 & 0.75 & & \\
\hline 103 & & & & & & & 0.05 & 41.65 & 1.50 & & \\
\hline \multicolumn{12}{|l|}{104} \\
\hline \multicolumn{12}{|l|}{105} \\
\hline \multicolumn{12}{|l|}{106} \\
\hline 107 & Dye Concnetration $(g / L)$ & & 0.0508 & & 0.0508 & & & & & & \\
\hline 108 & PCE Flow Rate (mL/hr.) & 0.10 & 0.10 & 0.05 & 0.05 & & & & & & \\
\hline \multicolumn{12}{|c|}{109} \\
\hline 110 & & & Interfacial & & Interfacial & & & & & & \\
\hline 111 & & Drop & Tension & Drop & Tension & & & & & & \\
\hline 112 & & Volume (UL) & $(\mathrm{mN} / \mathrm{m})$ & Volume (UL) & $(\mathrm{mN} / \mathrm{m})$ & & & & & & \\
\hline \multicolumn{12}{|l|}{113} \\
\hline 114 & drop \# 1 & 6.05 & 46.000 & 5.71 & 43.415 & & & & & & \\
\hline 115 & drop \# 2 & 6.08 & 46.228 & 5.52 & 41.970 & & & & & & \\
\hline 116 & drop \# 3 & 6.20 & 47.141 & 5.54 & 42.122 & & & & & & \\
\hline 117 & drop \# 4 & 5.93 & 45.088 & 5.17 & 39.309 & & & & & & \\
\hline 118 & drop \# 5 & 6.02 & 45.772 & 5.45 & 41.438 & & & & & & \\
\hline 119 & drop \# 6 & & & & & & & & & & \\
\hline 120 & drop \# 7 & & & & & & & & & & \\
\hline 121 & drop \# 8 & & & & & & & & & & \\
\hline 122 & drop \# 9 & & & & & & & & & & \\
\hline 123 & drop \#10 & & & & & & & & & & \\
\hline \multicolumn{12}{|l|}{124} \\
\hline 125 & Mean IFT $(\mathrm{mN} / \mathrm{m})$ : & & 46.046 & & 41.651 & & & & & & \\
\hline 126 & Standard Deviation $(\mathrm{mN} / \mathrm{m})$ : & & 0.75 & & 1.50 & & & & & & \\
\hline 127 & Coefficient of Variation $(\%)$ : & & 1.62 & & 3.59 & & & & & & \\
\hline \multicolumn{12}{|l|}{128} \\
\hline \multicolumn{12}{|l|}{129} \\
\hline 130 & . & & & & & 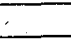 & & & & & \\
\hline \multicolumn{12}{|l|}{131} \\
\hline 132 & & & & & & & & & & & \\
\hline
\end{tabular}




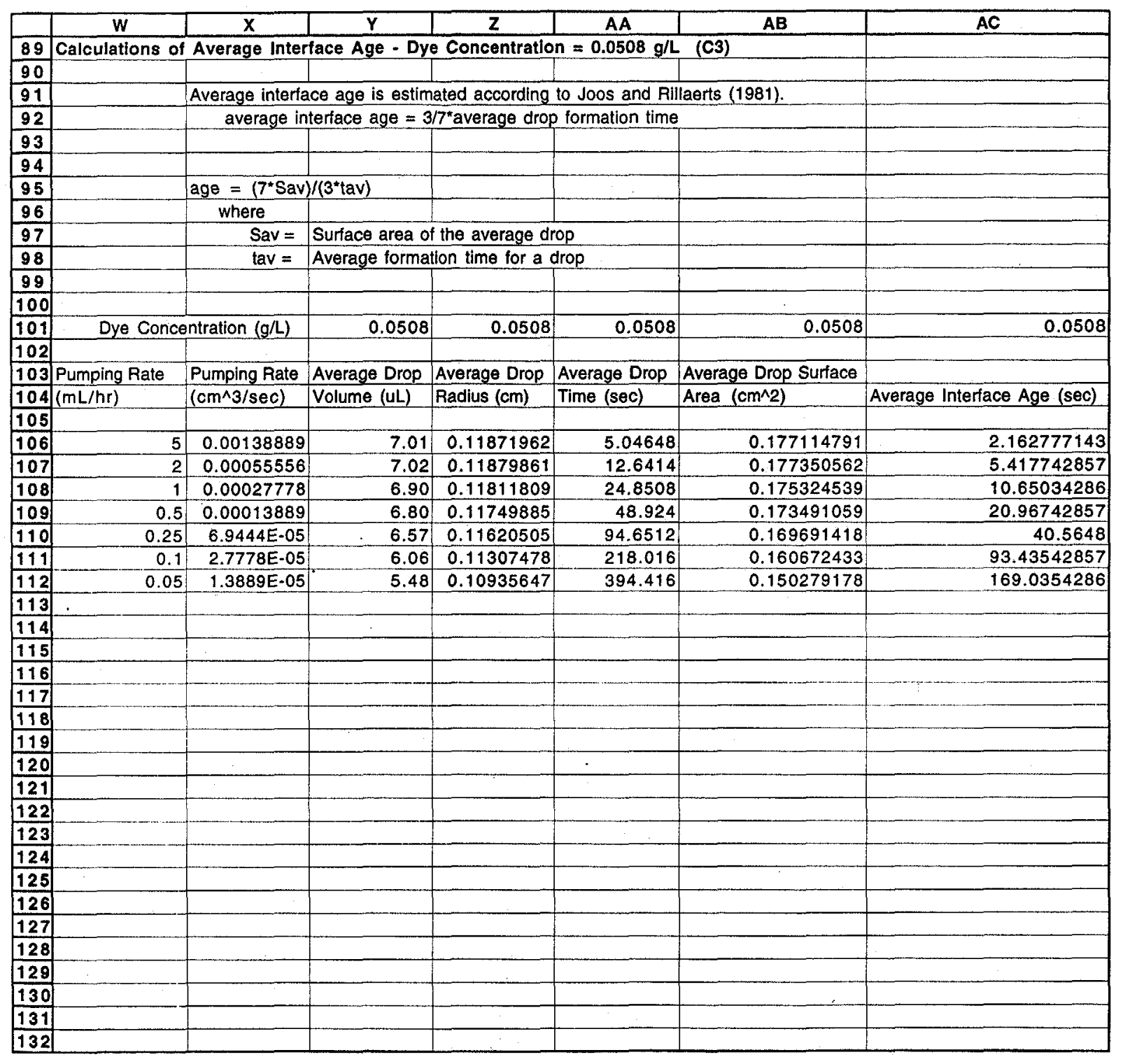




\begin{tabular}{|c|c|c|c|c|c|c|c|c|c|c|c|}
\hline & A & B & C & D & $\mathbf{E}$ & $\mathbf{F}$ & G & H & 1 & $\mathbf{J}$ & $\mathbf{K}$ \\
\hline \multirow{2}{*}{\multicolumn{12}{|c|}{\begin{tabular}{|l|l|l|l}
133 & Interfacial Tension by Drop Volume Method - Dye Concentration $=0.508 \mathrm{~g} / \mathrm{L} \quad$ (C2) \\
134 &
\end{tabular}}} \\
\hline & \multicolumn{11}{|c|}{134} \\
\hline 135 & Equation: & \multicolumn{10}{|c|}{$\mid F T=\left(V d^{*}\right.$ delrho* $\left.g\right) /\left(\left.P\right|^{*} d\right)=\mid F T=\left(V d^{*}(\text { rhoD }- \text { rhoL })^{*} g\right) /\left(P i^{*} d\right)$} \\
\hline 136 & & where & \multicolumn{4}{|c|}{ IFT = Interfacial Tension (dynes $/ \mathrm{cm}$ or $\mathrm{mN} / \mathrm{m}$ ) } & & & & & \\
\hline 137 & & & \multicolumn{4}{|c|}{\begin{tabular}{|l|l}
$V d=$ the volume of the drop $\left(\mathrm{cm}^{* *} 3\right)$ & \\
\end{tabular}} & & & & & \\
\hline 138 & & & \multicolumn{4}{|c|}{ delrho $=$ the difference in the fluid densities $\left(\mathrm{g} / \mathrm{cm}^{* *} 3\right)$} & & & & & \\
\hline 139 & & & \multicolumn{4}{|c|}{ rhoD $=$ density of the higher density fluid $\left(\mathrm{g} / \mathrm{cm}^{* *} 3\right)$} & & & & & \\
\hline 140 & & & \multicolumn{4}{|c|}{ rhot $=$ density of the lower density fluid $(\mathrm{g} / \mathrm{cm} * * 3)$} & & & & & \\
\hline 141 & & & \multicolumn{4}{|c|}{$\mathrm{g}=$ acceleration of gravity $\left(\mathrm{cm} / \mathrm{sec}^{* * 2}\right)$} & & & & & \\
\hline 142 & & & \multicolumn{4}{|c|}{$\mathrm{Pi}=$ standard mathemetical meaning } & & & & & \\
\hline 143 & & & \multicolumn{5}{|c|}{$\mathrm{d}=$ diameter of the tip from whlch the drop is suspended $(\mathrm{cm})$} & & & & \\
\hline \multicolumn{12}{|c|}{ (2) } \\
\hline 145 & & \multicolumn{2}{|c|}{ numerical value for $d(\mathrm{~cm})$ : } & 0.0254 & & & & & & & \\
\hline 146 & & & $\begin{array}{l}\text { value for d }(\mathrm{cm}) \text { : } \\
\text { hoD }\left(\mathrm{g} / \mathrm{cm}^{* *} 3\right) \text { : }\end{array}$ & 1.6147 & & & & & & & \\
\hline 147 & & \multicolumn{2}{|c|}{ rhoL $\left(\mathrm{g} / \mathrm{cm}^{* * 3}\right)$} & 0.9962 & & & & & & & \\
\hline 148 & & \multicolumn{2}{|c|}{ L delrho $\left(\mathrm{g} / \mathrm{cm}^{* *} 3\right)$ : } & 0.6185 & & & & & & & \\
\hline 149 & \multicolumn{3}{|c|}{ numerical value for (delrho* $\mathrm{g}) /\left(\mathrm{Pi}^{*} \mathrm{~d}\right)\left(1 / \mathrm{sec}^{* *} \mathrm{2}\right)$ : } & 7603.32038 & & & & & & & \\
\hline \multicolumn{12}{|c|}{ - } \\
\hline 151 & Dye Concentration $(g / L)$ & & 0.508 & & 0.508 & & 0.508 & & 0.508 & & 0.508 \\
\hline 152 & PCE Flow Rate (mL/hr.) & 5.00 & 5.00 & 2.00 & 2.00 & 1.00 & 1.00 & 0.50 & 0.50 & 0.25 & 0.25 \\
\hline \multicolumn{12}{|c|}{153} \\
\hline 154 & & & Interfacial & & Interfacial & & Interfacial & & Interfacial & & Interfacial \\
\hline 155 & & Drop & Tension & Drop & Tension & Drop & Tension & Drop & Tension & Drop & Tension \\
\hline 156 & & Volume (uL) & $(\mathrm{mN} / \mathrm{m})$ & Volume (UL) & $(\mathrm{mN} / \mathrm{m})$ & Volume (UL) & $(\mathrm{mN} / \mathrm{m})$ & Volume (UL) & $(\mathrm{mN} / \mathrm{m})$ & Volume (UL) & $(\mathrm{mN} / \mathrm{m})$ \\
\hline \multicolumn{12}{|l|}{157} \\
\hline 158 & drop \# 1 & 6.56 & 49.878 & 6.54 & 49.726 & 6.08 & 46.228 & 5.94 & 45.164 & 5.65 & 42.959 \\
\hline 159 & drop \# 2 & 6.77 & 51.474 & 6.41 & 48.737 & 6.08 & 46.228 & 6.14 & 46.684 & 5.73 & 43.567 \\
\hline 160 & drop \# 3 & 6.54 & 49.726 & 6.60 & 50.182 & 6.11 & 46.456 & 5.71 & 43.415 & 5.78 & 43.947 \\
\hline 161 & drop \# 4 & 6.72 & 51.094 & 6.37 & 48.433 & 6.09 & 46.304 & 5.97 & 45.392 & 5.62 & 42.731 \\
\hline 162 & drop \# 5 & 6.57 & 49.954 & 6.68 & 50.790 & 6.27 & 47.673 & 6.12 & 46.532 & 5.52 & 41.970 \\
\hline 163 & drop \# 6 & 6.72 & 51.094 & 6.33 & 48.129 & 5.99 & 45.544 & 5.85 & 44.479 & 5.71 & 43.415 \\
\hline 164 & drop \# 7 & 6.62 & 50.334 & 6.55 & 49.802 & 6.19 & 47.065 & 5.98 & 45.468 & 5.57 & 42.350 \\
\hline 165 & drop \# 8 & 6.75 & 51.322 & 6.34 & 48.205 & 6.18 & 46.989 & 6.02 & 45.772 & 5.59 & 42.503 \\
\hline 166 & drop \# 9 & 6.72 & 51.094 & 6.47 & 49.193 & 6.05 & 46.000 & 5.84 & 44.403 & 5.64 & 42.883 \\
\hline 167 & drop \#10 & 6.69 & 50.866 & 6.26 & 47.597 & 6.38 & 48.509 & 6.08 & 46.228 & 5.80 & 44.099 \\
\hline \multicolumn{12}{|c|}{168} \\
\hline 169 & Mean IFT $(\mathrm{mN} / \mathrm{m})$ : & & 50.684 & & 49.079 & & 46.700 & & 45.354 & & 43.042 \\
\hline 170 & Standard Deviation $(\mathrm{mN} / \mathrm{m})$ : & & 0.65 & & 1.03 & & 0.88 & & 1.03 & & 0.70 \\
\hline 171 & Coefficient of Variation (\%): & & 1.28 & & 2.09 & & 1.88 & & 2.27 & & 1.62 \\
\hline 172 & & & & & & & & & & & \\
\hline 173 & & & & & & & & & & & \\
\hline 174 & & & & & & & & & & & \\
\hline 175 & & & & & & & & & & & \\
\hline 176 & & & & & & & & & & & \\
\hline
\end{tabular}




\begin{tabular}{|c|c|c|c|c|c|c|c|c|c|c|c|}
\hline & $L$ & M & \begin{tabular}{l|l}
$\mathbf{N}$ & \\
\end{tabular} & 0 & $\mathbf{P}$ & a & $\mathbf{R}$ & 5 & $T$ & U & v \\
\hline \multicolumn{12}{|c|}{133 Interfacial Tension by Drop Volume Method - Dye Concentration $=0.508 \mathrm{~g} / \mathrm{L}$ (C2) } \\
\hline 134 & & & & & & & & & & & \\
\hline 135 & & & & & & & \multicolumn{3}{|c|}{ Summary Data: Dye Concentration $=0.508 \mathrm{~g} / \mathrm{L}$} & & \\
\hline \multicolumn{12}{|c|}{ 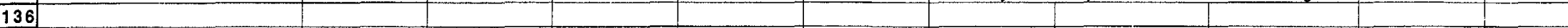 } \\
\hline 137 & & & & & & & & Mean & & & \\
\hline 138 & & & & & & & \begin{tabular}{|l|} 
PCE Flow \\
\end{tabular} & Interfacial & Standard & & \\
\hline 139 & & & & & & & Rate $(\mathrm{mL} / \mathrm{hr})$. & Tension $(\mathrm{mN} / \mathrm{m})$ & Deviation & & \\
\hline \multicolumn{12}{|l|}{140} \\
\hline 141 & & & 3 & & & & 5.00 & 50.68 & 0.65 & & \\
\hline 142 & & & & & & & 2.00 & 49.08 & 1.03 & & \\
\hline 143 & & & & & & & 1.00 & 46.70 & 0.88 & & \\
\hline 144 & & & & & & & 0.50 & 45.35 & 1.03 & & \\
\hline 145 & & & & & & & 0.25 & 43.04 & 0.70 & & \\
\hline 146 & & & & & & & 0.10 & 40.68 & 1.02 & & \\
\hline 147 & & & & & & & 0.05 & 39.52 & 1.79 & & \\
\hline \multicolumn{12}{|l|}{148} \\
\hline \multicolumn{12}{|l|}{149} \\
\hline \multicolumn{12}{|l|}{150} \\
\hline 151 & Dye Concnetration ( $g / L)$ & & 0.508 & & 0.508 & & & & & & \\
\hline 152 & PCE Flow Rate $(\mathrm{mL} / \mathrm{hr}$.) & 0.10 & 0.10 & 0.05 & 0.05 & & & & & & \\
\hline \multicolumn{12}{|c|}{153} \\
\hline 154 & & & Interfacial & & Interfacial & & & & & & \\
\hline 155 & & Drop & Tension. & Drop & Tension & & & & & & \\
\hline 156 & & Volume (uL) & $(\mathrm{mN} / \mathrm{m})$ & Volume (UL) & $(\mathrm{mN} / \mathrm{m})$ & & & & & & \\
\hline \multicolumn{12}{|l|}{157} \\
\hline 158 & drop \# 1 & 5.30 & 40.298 & 5.44 & 41.362 & & & $\therefore$ & & & \\
\hline 159 & drop \# 2 & 5.34 & 40.602 & 5.33 & 40.526 & & & & & & \\
\hline 160 & drop \# 3 & 5.19 & 39.461 & 5.08 & 38.625 & & & & & & \\
\hline 161 & drop \# 4 & 5.56 & 42.274 & 5.15 & 39.157 & & & & & & \\
\hline 162 & drop \# 5 & 5.36 & 40.754 & 4.81 & 36.572 & & & & & & \\
\hline 163 & drop \# 6 & & & 5.38 & 40.906 & & & & & & \\
\hline 164 & drop \# 7 & & & & & & & & & & \\
\hline 165 & drop \# 8 & & & & & & & & & & \\
\hline 166 & drop \# 9 & & & & & & & & & & \\
\hline 167 & drop $\# 10$ & & & & & & & & & & \\
\hline \multicolumn{12}{|l|}{168} \\
\hline 169 & Mean IFT $(\mathrm{mN} / \mathrm{m})$ : & & 40.678 & & 39.525 & & & & & & \\
\hline 170 & Standard Deviation $(\mathrm{mN} / \mathrm{m})$ : & & 1.02 & & 1.79 & & & & & & \\
\hline 171 & Coefficient of Variation (\%): & & 2.51 & & 4.52 & & & & & & \\
\hline \multicolumn{12}{|l|}{172} \\
\hline \multicolumn{12}{|l|}{173} \\
\hline \multicolumn{12}{|l|}{174} \\
\hline 175 & & & & & & & & & & & \\
\hline 176 & & & & & & & & & & & \\
\hline
\end{tabular}




\begin{tabular}{|c|c|c|c|c|c|c|c|}
\hline & $\mathbf{w}$ & $\mathbf{x}$ & $\bar{Y}$ & $\mathbf{Z}$ & $\overline{A A}$ & $\overline{A B}$ & AC \\
\hline \multicolumn{8}{|c|}{ 133 Calculations of Average Interface Age - Dye Concentration $=0.508 \mathrm{~g} / \mathrm{L}$ (C2) } \\
\hline \multicolumn{8}{|c|}{ 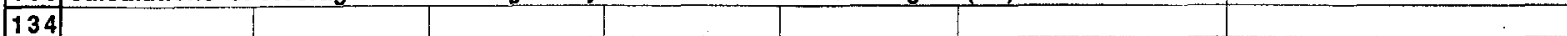 } \\
\hline 135 & & \multicolumn{5}{|c|}{ Average interface age is estimated according to Joos and Rillaerts (1981). } & \\
\hline 136 & & \multicolumn{5}{|c|}{ average interface age $=3 / 7^{*}$ average drop formation time } & \\
\hline \multicolumn{8}{|c|}{ 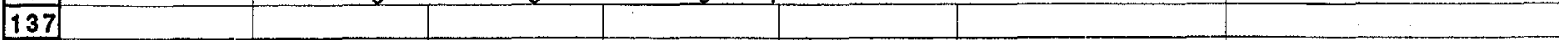 } \\
\hline \multicolumn{8}{|l|}{138} \\
\hline 139 & & \multicolumn{2}{|c|}{ age $=\left(7^{*} \mathrm{Sav}\right) /\left(3^{*}\right.$ tav $)$} & & & & \\
\hline 140 & & where & & & & & \\
\hline 141 & & Sav $=$ & \multicolumn{3}{|c|}{ Surface area of the average drop } & & \\
\hline 142 & & $\operatorname{tav}=$ & \multicolumn{3}{|c|}{ Average formation time for a drop } & & \\
\hline \multicolumn{8}{|l|}{143} \\
\hline \multicolumn{8}{|l|}{144} \\
\hline 145 & \multicolumn{2}{|c|}{ Dye Concentration $(g / L)$} & 0.508 & 0.508 & 0.508 & 0.508 & 0.508 \\
\hline \multicolumn{8}{|c|}{146} \\
\hline 147 & Pumping Rate & Pumping Rate & Average Drop & Average Drop & Average Drop & Average Drop Surface & \\
\hline 148 & $(\mathrm{~mL} / \mathrm{hr})$ & $\left(\mathrm{cm}^{\wedge} 3 / \mathrm{sec}\right)$ & Volume (uL) & Radius $(\mathrm{cm})$ & Time (sec) & Area $\left(\mathrm{cm}^{\wedge} 2\right)$ & Average Interface Age (sec) \\
\hline \multicolumn{8}{|c|}{149} \\
\hline 150 & 5 & 0.00138889 & 6.67 & 0.11675054 & 4.79952 & 0.171288286 & 2.056937143 \\
\hline 151 & 2 & 0.00055556 & 6.46 & 0.11550547 & 11.619 & 0.1676544 & 4.979571429 \\
\hline 152 & 1 & 0.00027778 & 6.14 & 0.11360752 & 22.1112 & 0.162189972 & 9.476228571 \\
\hline 153 & 0.5 & 0.00013889 & 5.97 & 0.11250555 & 42.948 & 0.15905882 & 18.40628571 \\
\hline 154 & 0.25 & $6.9444 \mathrm{E}-05$ & 5.66 & 0.11056089 & 81.5184 & 0.153607667 & 34.93645714 \\
\hline 155 & 0.1 & $2.7778 \mathrm{E}-05$ & 5.35 & 0.108498 & 192.6 & 0.147928997 & 82.54285714 \\
\hline 156 & 0.05 & $1.3889 \mathrm{E}-05$ & 5.20 & 0.10746289 & 374.28 & 0.145119868 & 160.4057143 \\
\hline \multicolumn{8}{|l|}{157} \\
\hline \multicolumn{8}{|l|}{158} \\
\hline \multicolumn{8}{|l|}{159} \\
\hline \multicolumn{8}{|l|}{160} \\
\hline \multicolumn{8}{|l|}{161} \\
\hline \multicolumn{8}{|l|}{162} \\
\hline \multirow{2}{*}{\multicolumn{8}{|c|}{$\frac{163}{164}$}} \\
\hline \multicolumn{5}{|l|}{164} & & & \\
\hline \multicolumn{8}{|l|}{165} \\
\hline 166 & & & & & & & \\
\hline \begin{tabular}{|l|}
67 \\
\end{tabular} & & & & & & & \\
\hline 168 & & & & & & & \\
\hline 169 & & & & & & & \\
\hline 170 & & & & & & & \\
\hline 171 & & & & & & & \\
\hline 172 & & & & & & & \\
\hline 173 & & & & & & & \\
\hline 174 & & & & & & . & \\
\hline 175 & & & & & & & \\
\hline 176 & & & & & & & \\
\hline
\end{tabular}




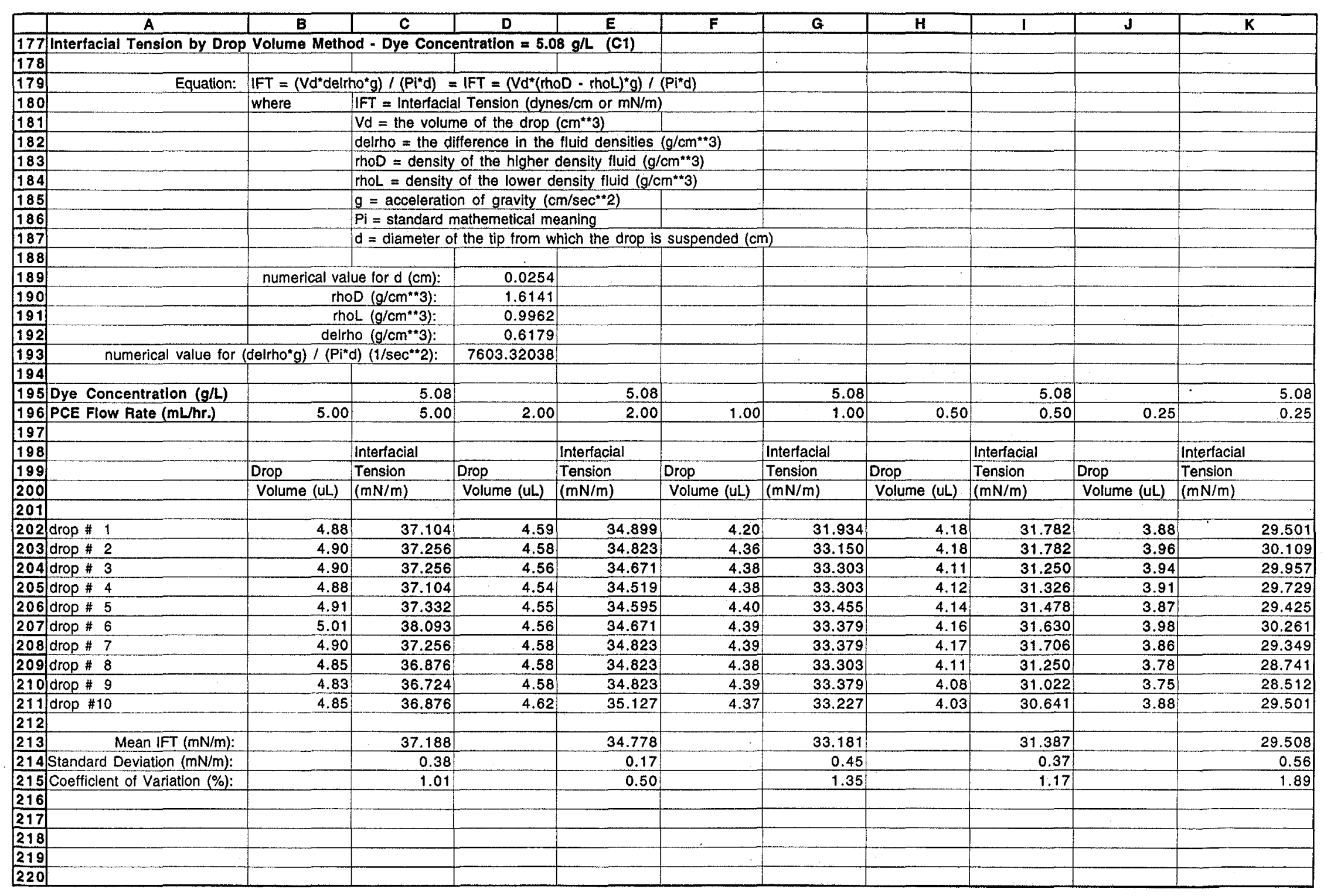




\begin{tabular}{|c|c|c|c|c|c|c|c|c|c|c|c|}
\hline & $L$ & M & $\mathbf{N}$ & 0 & $\mathbf{P}$ & $\mathbf{Q}$ & $\mathbf{R}$ & $\mathbf{s}$ & $\mathbf{T}$ & $\mathbf{u}$ & $\mathbf{v}$ \\
\hline \multirow{2}{*}{\multicolumn{12}{|c|}{\begin{tabular}{|l|l|l|l}
177 & Interfacial Tension by Drop Volume Method - Dye Concentration $=5.08 \mathrm{~g} / \mathrm{L}$ (C1) \\
178 &
\end{tabular}}} \\
\hline & & & & & & & & & & & \\
\hline 179 & & & & & & & \multicolumn{3}{|c|}{ Summary Data: Dye Concentration $=5.08 \mathrm{~g} / \mathrm{L}$} & & \\
\hline \multicolumn{12}{|l|}{180} \\
\hline \begin{tabular}{|c|}
181 \\
\end{tabular} & & & & & & & & Mean & & & \\
\hline 182 & & & & & & & PCE Flow & Interfacial & Standard & & \\
\hline 183 & & & & & & & Rate (mL/hr.) & Tension $(\mathrm{mN} / \mathrm{m})$ & Deviation & & \\
\hline \multicolumn{12}{|c|}{ (2) } \\
\hline 185 & & & & & & & 5.00 & 37.19 & 0.38 & & \\
\hline 186 & & & & & & & 2.00 & 34.78 & 0.17 & & \\
\hline 187 & & & & & & & 1.00 & 33.18 & 0.45 & & \\
\hline 188 & & & & & & & 0.50 & 31.39 & 0.37 & & \\
\hline 189 & & & & & & & 0.25 & 29.51 & 0.56 & & \\
\hline 190 & & & & & & & 0.10 & 27.89 & 0.65 & & \\
\hline 191 & & & & & & & 0.05 & 26.08 & 0.80 & & \\
\hline \multicolumn{12}{|l|}{192} \\
\hline \multicolumn{12}{|l|}{193} \\
\hline \multicolumn{12}{|c|}{194} \\
\hline 195 & Dye Concnetration $(g / L)$ & & 5.08 & & 5.08 & & & & & & \\
\hline 196 & PCE Flow Rate (mL/hr.) & 0.10 & 0.10 & 0.05 & 0.05 & & & & & & \\
\hline \multicolumn{12}{|c|}{197} \\
\hline 198 & & & Interfacial & & Intertacial & & & & . & & \\
\hline 199 & & Drop & Tension & Drop & Tension & & & & & & \\
\hline 200 & & Volume (uL) & $(\mathrm{mN} / \mathrm{m})$ & Volume (uL) & $(\mathrm{mN} / \mathrm{m})$ & & & & & & \\
\hline \multicolumn{12}{|l|}{201} \\
\hline 202 & drop \# 1 & 3.68 & 27.980 & 3.43 & 26.079 & & & & & & \\
\hline 203 & drop \# 2 & 3.51 & 26.688 & 3.53 & 26.840 & & & & & & \\
\hline 204 & drop \# 3 & 3.65 & 27.752 & 3.40 & 25.851 & & & & & & \\
\hline 205 & drop \# 4 & 3.76 & 28.588 & 3.52 & 26.764 & & & & & & \\
\hline 206 & drop \# 5 & 3.69 & 28.056 & 3.27 & 24.863 & & & & & & \\
\hline 207 & drop \# 6 & 3.72 & 28.284 & & & & & & & & \\
\hline 208 & drop \# 7 & & & & & & & & & & \\
\hline 209 & drop \# 8 & & & & & & & & & & \\
\hline 210 & drop \# 9 & & & & & & & & & & \\
\hline 211 & drop \#10 & & & & & & & & & & \\
\hline \multicolumn{12}{|l|}{212} \\
\hline 213 & Mean IFT $(\mathrm{mN} / \mathrm{m})$ : & & 27.892 & & 26.079 & & & & & & \\
\hline 214 & Standard Deviation $(\mathrm{mN} / \mathrm{m})$ : & & 0.65 & & 0.80 & & & & & & \\
\hline 215 & Coefficient of Variation (\%): & & 2.35 & & 3.08 & & & & & & \\
\hline \multicolumn{12}{|c|}{ - } \\
\hline \multicolumn{12}{|l|}{217} \\
\hline 218 & & & & & & 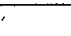 & & & & & \\
\hline 219 & & & & & & & & & & & \\
\hline 220 & & & & & & & & & & & \\
\hline
\end{tabular}




\begin{tabular}{|c|c|c|c|c|c|c|c|}
\hline & W & $\mathbf{x}$ & $\mathbf{Y}$ & $\mathbf{z}$ & AA & $A B$ & AC \\
\hline \multicolumn{8}{|c|}{177 Calculations of Average Interface Age - Dye Concentration $=5.08 \mathrm{~g} / \mathrm{L}$ (C1) } \\
\hline \multicolumn{8}{|c|}{\begin{tabular}{l|l|l|}
178 & & \\
\end{tabular}} \\
\hline 179 & & \multicolumn{5}{|c|}{ Average interface age is estimated according to Joos and Rillaerts (1981). } & \\
\hline 180 & & \multicolumn{5}{|c|}{ average interface age $=3 / 7^{*}$ average drop formation time } & \\
\hline \multicolumn{8}{|c|}{ 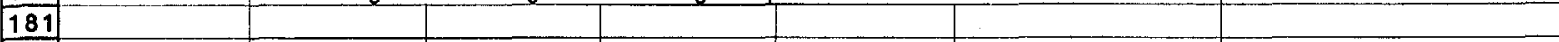 } \\
\hline \multicolumn{8}{|l|}{182} \\
\hline 183 & & \multicolumn{2}{|c|}{ age $=\left(7^{*} \mathrm{Sav}\right) /\left(3^{*} \mathrm{tav}\right)$} & & & & \\
\hline 184 & & where & & & & & \\
\hline 185 & & Sav $=$ & \multicolumn{3}{|c|}{ Surface area of the average drop } & & \\
\hline 186 & & $\operatorname{tav}=$ & \multicolumn{3}{|c|}{ Average formation time for a drop } & & \\
\hline \multicolumn{8}{|c|}{ 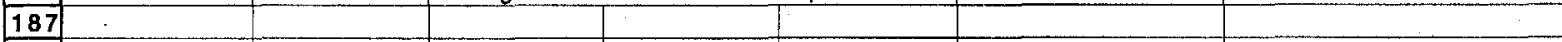 } \\
\hline \multicolumn{8}{|l|}{188} \\
\hline 189 & \multirow{2}{*}{\multicolumn{2}{|c|}{ Dye Concentration $(g / L)$}} & 5.08 & 5.08 & 5.08 & 5.08 & 5.08 \\
\hline \multicolumn{6}{|l|}{190} & & \\
\hline 191 & Pumping Rate & Pumping Rate & Average Drop & Average Drop & Average Drop & Average Drop Surface & \\
\hline 192 & $(\mathrm{~mL} / \mathrm{hr})$ & $\left(\mathrm{cm}^{\wedge} 3 / \mathrm{sec}\right)$ & Volume (uL) & Radius (cm) & Time (sec) & Area $\left(\mathrm{cm}^{\wedge} 2\right)$ & Average Interface Age (sec) \\
\hline \multicolumn{8}{|c|}{193} \\
\hline 194 & 5 & 0.00138889 & 4.89 & 0.10530193 & 3.52152 & 0.139342169 & 1.509222857 \\
\hline 195 & 2 & 0.00055556 & 4.57 & 0.10297596 & 8.2332 & 0.133254402 & 3.528514286 \\
\hline 196 & 1 & 0.00027778 & 4.36 & 0.10137527 & 15.7 .104 & 0.129143916 & 6.733028571 \\
\hline 197 & 0.5 & 0.00013889 & 4.13 & 0.09951389 & 29.7216 & 0.124444942 & 12.73782857 \\
\hline 198 & 0.25 & $6.9444 \mathrm{E}-05$ & 3.88 & 0.09748812 & 55.8864 & 0.119429942 & 23.95131429 \\
\hline 199 & 0.1 & $2.7778 \mathrm{E}-05$ & 3.67 & 0.09567388 & 132.06 & 0.115026168 & 56.59714286 \\
\hline 200 & 0.05 & $1.3889 \mathrm{E}-05$ & 3.43 & 0.09355532 & 246.96 & 0.109988397 & 105.84 \\
\hline \multicolumn{8}{|l|}{201} \\
\hline \multirow{2}{*}{\multicolumn{8}{|c|}{$\frac{202}{203}$}} \\
\hline & & & & & & & \\
\hline \multicolumn{8}{|l|}{$\frac{203}{204}$} \\
\hline \multicolumn{8}{|l|}{205.} \\
\hline \multicolumn{8}{|l|}{206} \\
\hline 207 & & & & & & & $\therefore$ \\
\hline \multicolumn{8}{|l|}{208} \\
\hline \multicolumn{8}{|l|}{209.} \\
\hline \multicolumn{8}{|l|}{210} \\
\hline \multirow{2}{*}{\multicolumn{8}{|c|}{$\frac{211}{212}$}} \\
\hline & & & & & & & \\
\hline 213 & & & & & & & \\
\hline 214 & & & & & & & \\
\hline 215 & & & & & & & \\
\hline 216 & & & & & & & \\
\hline 217 & & & & & & & \\
\hline 218 & & & & & & & \\
\hline 219 & & & & & & & \\
\hline 220 & & & & & & & \\
\hline
\end{tabular}

